
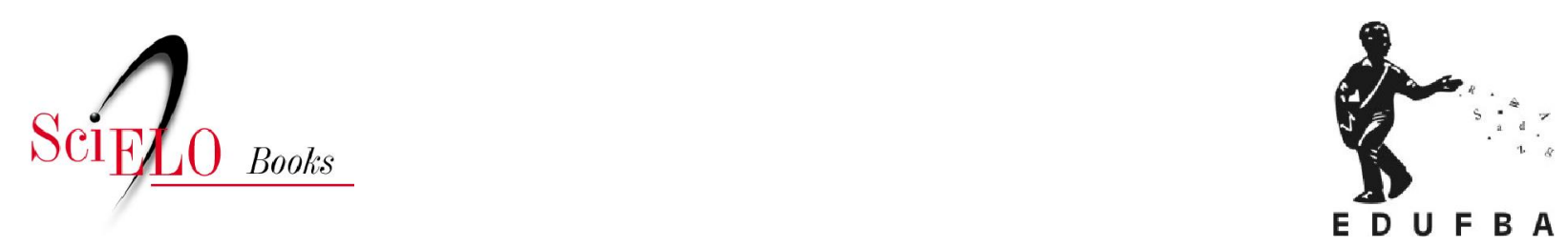

\title{
Risco, radiodiagnóstico e vigilância sanitária
}

\author{
Marcus Vinícius Teixeira Navarro
}

SciELO Books / SciELO Livros / SciELO Libros

NAVARRO, MVT. Risco, radiodiagnóstico e vigilância sanitária. Salvador: EDUFBA, 2009, 166 p. ISBN 978-85-232-0924-7. Available from SciELO Books $<$ http://books.scielo.org $>$.

\section{(c) (1)(2)(2)}

All the contents of this chapter, except where otherwise noted, is licensed under a Creative Commons Attribution-Non Commercial-ShareAlike 3.0 Unported.

Todo o conteúdo deste capítulo, exceto quando houver ressalva, é publicado sob a licença Creative Commons Atribuição - Uso Não Comercial - Partilha nos Mesmos Termos 3.0 Não adaptada.

Todo el contenido de este capítulo, excepto donde se indique lo contrario, está bajo licencia de la licencia Creative Commons Reconocimento-NoComercial-CompartirIgual 3.0 Unported. 


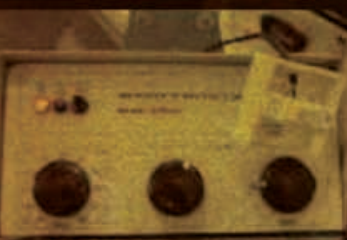

Marcus Vinícius Teixeira Navarro

$$
\begin{gathered}
\text { Risco, Radiodiagnóstico } \\
\text { e Vigilância Sanitária }
\end{gathered}
$$
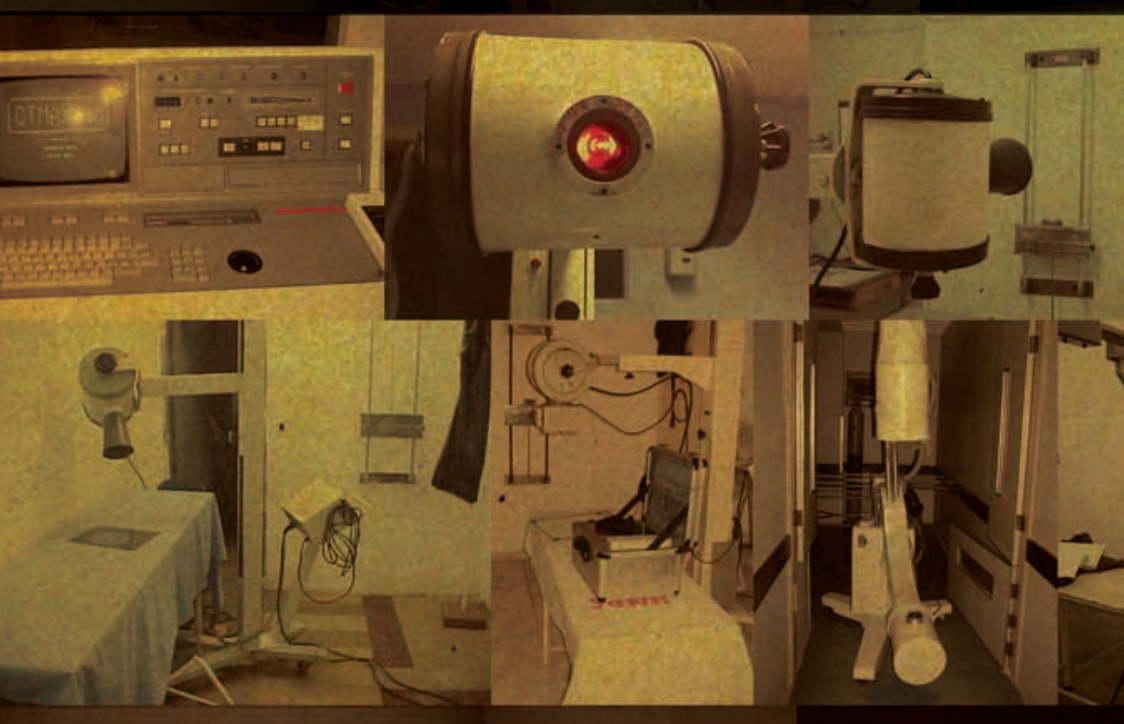
Risco, Radiodiagnóstico e Vigilância Sanitária 


\section{Universidade Federal da Bahia}

Reitor

Naomar Monteiro de Almeida Filho

Vice-Reitor

Francisco Mesquita

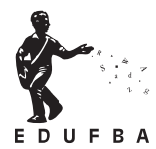

Editora da Universidade Federal da Bahia

Diretora

Flávia Goullart Mota Garcia Rosa

Conselho Editorial

Titulares

Angelo Szaniecki Perret Serpa

Caiuby Álves da Costa

Charbel Niño El Hani

Dante Eustachio Lucchesi Ramacciotti

José Teixeira Cavalcante Filho

Maria do Carmo Soares Freitas

Suplentes

Alberto Brum Novaes

Antônio Fernando Guerreiro de Freitas

Armindo Jorge Carvalho Sá Hoisel

Cleise Furtado Mendes

Maria Vidal de Negreiros Camargo

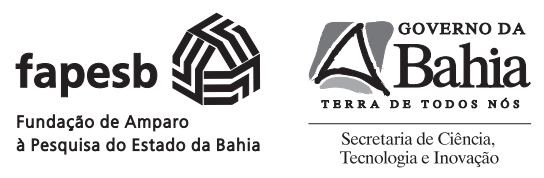




\title{
Risco, Radiodiagnóstico e Vigilância Sanitária
}

Marcus Vinícius Teixeira Navarro

\author{
EDUFBA
}

Salvador, 2009 
Direitos para esta edição cedidos à Edufba.

Feito o Depósito Legal.

Capa e Projeto Gráfico

Gabriela Nascimento

Revisão

Tania Aragão

Normalização

Normaci Correia

Sistema de Bibliotecas - UFBA

Navarro, Marcus Vinícius Teixeira.

Risco, radiodiagnóstico e vigilância sanitária / Marcus Vinícius Teixeira Navarro. Salvador : EDUFBA, 2009.

$166 \mathrm{p}$.

ISBN 978-85-232-0620-8

1. Radiologia médica. 2. Vigilância sanitária. 3. Saúde pública. I. Título.

CDD - 616.0757

Editora afiliada à

exde

ASOCIACION DE EDITOAIALES

WIVEASTAAIAS DEAMEATCA
LATINA YEL CARIBE

Editora da UFBA

Rua Barão de Jeremoabo

$\mathrm{s} / \mathrm{n}$ - Campus de Ondina

40170-115 - Salvador - Bahia

Tel.: +55 71 3283-6164

Fax: +55 71 3283-6160

www.edufba.ufba.br

edufba@ufba.br

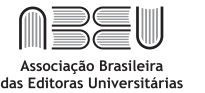

$\mathrm{CBaL}$ 


\begin{abstract}
A minha Mãe, Josélia Teixeira Navarro, que muito me amou e militou intensamente na saúde pública. Provavelmente, estou realizando um sonho que ela mesma gostaria de realizar. Ao meu Pai, Hermenegildo Navarro Pinto Filho, que com muito amor me apresentou a diversos mundos.
\end{abstract}




\section{Agradecimentos}

Este trabalho foi realizado com a contribuição, direta e indireta, de diversas pessoas e instituições. Assim, agradeço imensamente:

À minha esposa Valéria Navarro e aos meus filhos Camila, Laís, Juan e Marcus, pelo carinho em todos os momentos.

Aos meus tios Maria Célia, Terezinha, Tereza, João e José, pelo apoio constante.

Ao Prof. Drexler e Anamélia, que muito me ajudaram neste trabalho e na compreensão da importância da radiologia para a Saúde Coletiva.

A Ediná Costa, uma companheira de jornada que contribuiu de forma substancial para a realização deste livro e para a consolidaçáo da vigilância sanitária, como um campo de produçáo de conhecimento.

À Conceição Riccio, uma gestora de vigilância sanitária com visão de futuro, que, com a equipe da Diretoria de Vigilância e Controle Sanitário do Estado da Bahia (DIVISA), foram determinantes na estruturação do Núcleo de Tecnologia em Saúde do Instituto Federal da Bahia (IFBA) e no desenvolvimento deste estudo.

À comunidade da Universidade Estadual do Sudoeste da Bahia (UESB), que me apoiou no momento mais difícil da minha vida, contribuindo para que pudesse, doze anos depois, realizar este sonho. 
Aos Professores da Technische Fachhochschule (TFH) de Berlin e do Hospital Charité, que muito contribuíram nas primeiras idéias deste trabalho. Em especial, Cora Koch, Jürgen Eichler, Kay-Uwe, Martin Roll, Ralf Juran, Wolfgang Deeg and Wolfgang Vollmann.

Agradeço também à Universidade Federal da Bahia e ao Instituto Federal da Bahia. Espero que essas instituições continuem lutando contra as constantes e novas investidas dos diversos governos, permanecendo públicas, gratuitas, de qualidade e produzindo ciência e tecnologia.

À Agência Nacional de Vigilância Sanitária (ANVISA), pelo apoio e financiamento. Que as deficiências dos serviços de saúde, apontadas neste e em outros estudos, sejam suficientes para estimular os serviços de vigilância sanitária a atuar, efetivamente, nos serviços de saúde. 
Sentir profundamente qualquer injustiça cometida contra qualquer pessoa em qualquer parte do mundo é a qualidade mais bonita de um revolucionário.

(Guevara, carta aos filhos) 


\title{
Lista de Siglas e Abreviaturas
}

\author{
ANVISA Agência Nacional de Vigilância Sanitária \\ CEFETBA Centro Federal de Educação Tecnológica da Bahia \\ CNEN Comissão Nacional de Energia Nuclear \\ DIVISA Diretoria de Vigilância e Controle Sanitário do Estado da Bahia \\ FDA Food and Drug Administration - Administração de Alimentos e Drogas \\ IAEA International Atomic Energy Agency - Agência Internacional de Energia \\ Atômica \\ ICRP International Commission on Radiological Protection - \\ Comissão Internacional de Proteção Radiológica \\ ICRU International Commission on Radiation Units and Measurements - \\ Comissão Internacional de Unidades e Medidas em Radiação \\ IEC International Electrotechnical Commission - Comissão Internacional de \\ Eletrotécnica \\ IFBA Instituto Federal da Bahia \\ IOMP International Organisation for Medical Physics - Organização Internacional \\ de Física Médica \\ ISO International Standards Organization - Organização Internacional para \\ Padronização \\ ISR \\ International Society of Radiology - Sociedade Internacional de Radiologia
}


ISRRT International Society of Radiographers and Radiological Technologists Sociedade Internacional de Técnicos e Tecnólogos em Radiologia

LAFIR Laboratório de Física Radiológica do CEFETBA

NRC National Research Council - Conselho Nacional de Pesquisa

NTS Núcleo de Tecnologia em Saúde do CEFETBA

OECD Organisation for Economic Co-operation and Development Organização para o Desenvolvimento Econômico e Cooperativo

OIT Organização Internacional do Trabalho

PAHO/OPAS The Pan American Health Organization - Organização Pan-americana de Saúde

PGQ Programa de Garantia de Qualidade

RBE Relative Biological Effectiveness - Eficiência Biológica Relativa

RDC Resolução da Diretoria Colegiada

REBLAS Rede Brasileira de Laboratórios Analíticos em Saúde

SESAB Secretaria de Saúde do Estado da Bahia

SNVS Sistema Nacional de Vigilância Sanitária

UNSCEAR United Nations Scientific Committee on the Effects of Atomic Radiation Comitê Científico das Nações Unidas sobre os Efeitos da Radiação Atômica

UTI Unidade de Terapia Intensiva

VISA Vigilância Sanitária

WHO/OMS World Health Organization - Organização Mundial de Saúde 


\section{Sumário}

15 | Prefácio

19 | Introdução

25 0 radiodiagnótico na Saúde Pública

31 | Evolução tecnológica do radiodiagnóstico

37 | Conceito e controle de riscos à saúde

Um conceito de risco para a Vigilância Sanitária 42

Identificação e controle de riscos em radiodiagnóstico 49

77 | Sistemas de proteção radilológica

85 | Avaliando o risco potencial

Modelo de Avaliação de Risco Potencial (MARP) 86

MARP para serviços de radiodiagnóstico 99

Aplicando o MARP em serviços de radiodiagnóstico 114

Avaliação de riscos potenciais em serviços de

radiodiagnóstico no Estado da Bahia 117

Fluoroscopia 119

Mamografia 122

Radiografia convencional 126

Tomografia 130

135 | Análise da situação de risco potencial

147 | Perspectivas e considerações

153 | Referências 


\section{Prefácio}

É com imenso prazer que assumo o privilégio que o autor me concedeu de apresentar esta obra. Tive a satisfaçáo de acompanhar de perto o trabalho de Marcus Vinícius Teixeira Navarro e seu esforço para contribuir no desenvolvimento de referenciais para abordagem de temáticas da área de vigilância sanitária. Sei que apenas alguém com sua formação, qualificação e experiência, somadas ao seu peculiar espírito crítico poderia ter conseguido os resultados alcançados. Tais resultados, relevantes para a Saúde Coletiva, aliam uma construção teórico-conceitual e metodológica para o estudo de serviços de saúde na perspectiva da regulaçáo e vigilância sanitária à investigação de uma dada situação concreta.

A originalidade da abordagem do tema é sustentada numa discussão a respeito do risco e formulaçáo de um modelo tecnológico para avaliar o radiodiagnóstico. Além de descrever a situação do radiodiagnóstico no Estado da Bahia, o autor dedica um esforço para identificar os condicionantes da situação encontrada e os diversos atores que detêm parcelas de responsabilidades com a problemática em estudo; responsabilidades sanitárias, técnicas e éticas por estarem envolvidos com açôes e serviços de saúde, que são de relevância pública, conforme instituído na Constituiçáo que estabeleceu a saúde como um direito de cidadania e dever do Estado.

A linguagem adotada transforma o texto em leitura agradável e acessível; provoca seguido interesse ao diluir, ao longo dos capítulos, a história da tecnologia, seus sucessos e desastres, assim como o esforço internacional para a construção dos conceitos que fundamentam as estratégias para a proteção da saúde. 
Além dos aportes para a área de regulação e vigilância sanitária, sugerido pelo título, o leitor seguramente perceberá três contribuiçôes dessa obra: a primeira decorre do modelo formulado e sua abrangência, pois a aplicação do MARP não se restringe à avaliação do radiodiagnóstico. A segunda corresponde à avaliação em si, isto é, os resultados do estudo permitem traçar um diagnóstico da situação dos serviços de radiodiagnóstico no Estado da Bahia, que se mostraram preocupantes, requerendo intervenção imediata; ademais, fornecem indicaçóes preciosas para gestores, técnicos e pesquisadores acerca dos condicionantes da situação encontrada e que certamente confirmam os achados de outros estudos. A compreensáo dos diversos fatores de natureza técnica, ética, política e organizacional relacionados às condiçóes de prestação de serviços de saúde e que interferem em sua qualidade revelam-se relevantes para a formulação de diretrizes e estratégias mais amplas que a elaboração de normas e a respectiva fiscalização, de modo a que possam impactar efetivamente nos padróes de qualidade dos serviços de saúde ofertados à população.

Abordar temáticas de vigilância sanitária é tratar de riscos, de proteção da saúde, de responsabilidades repartidas entre distintos atores vinculados ao Estado, ao mercado e à sociedade. Tais atores têm responsabilidades específicas e interligadas; do cumprimento delas depende a população para que receba o máximo de benefícios com o mínimo possível de efeitos nocivos das tecnologias utilizadas em saúde. Se o risco zero não pode ser alcançado nas práticas em saúde, deve, entretanto, ser buscado, mediante a responsabilizaçáo dos diversos atores e de um conjunto organizado de práticas - a serem realizadas pelo Estado, através dos serviços de vigilância sanitária - que devem acompanhar a produção, a comercializaçáo, o uso e descarte das tecnologias em saúde.

Em contextos de intensas mutaçóes sociais, tecnológicas e culturais, a saúde - que também é um setor de acumulação de capital - revela-se um permanente desafio à capacidade das naçóes, no sentido de sua organizaçáo como parte de sistemas globais de proteção e promoção da saúde, capazes de reduzir o risco de doenças e agravos nas populaçóes e de promover o 
acesso a serviços de saúde e suas tecnologias, com o mínimo possível de riscos, e a custos compatíveis com a realidade social concreta e o princípio da equidade.

Diversas iniciativas vêm sendo desenvolvidas mais recentemente para promover o desenvolvimento da área de vigilância sanitária, provavelmente o componente menos explorado nos estudos sobre a saúde no Brasil. Atualmente, pode-se verificar que o interesse acadêmico e institucional pela temática vem se tornando mais visível, também por uma crescente consciência social a respeito da importância dessas práticas para a efetivação da integralidade na atenção à saúde.

Trata-se de um contexto muito favorável para o lançamento do livro. Diante das redefiniçóes do Sistema Único de Saúde, a chamada à responsabilidade sanitária por parte dos gestores, profissionais e usuários dos serviços de saúde, configura um momento importante para a reflexão que a obra propóe. A área de regulação e vigilância sanitária, em particular, seguramente ganhou uma contribuição relevante na estruturação de bases teórico-metodológicas para investigação e avaliação dos serviços de saúde que se apresentam como espaços singulares de esforços para a proteção da saúde contra riscos inerentes às tecnologias médicas e outros evitáveis, resultantes da má qualidade dos serviços prestados à população.

Salvador, abril de 2009

\section{Ediná Alves Costa}

Doutora em Saúde Pública, Profa ${ }^{a}$ do Instituto de Saúde Coletiva da Universidade Federal da Bahia. 


\section{Introdução}

As descobertas científicas do final do século XIX e início do século XX desencadearam transformações nos paradigmas das ciências naturais e nas bases teóricas e práticas da medicina.

Entre essas, a dos raios-X talvez tenha sido aquela cujas aplicaçóes foram mais importantes e que mais rapidamente foram incorporadas às práticas médicas. A descoberta de Röntgen possibilitou a visualização do interior do corpo humano, de forma não invasiva, proporcionando grandes mudanças na medicina, principalmente no campo da anatomia e fisiologia humana. Em 1896, a realização de radiografias e fluoroscopias, com fins de diagnóstico, já eram realizadas na Alemanha, Áustria, nos Estados Unidos, Inglaterra, França, Rússia, Escócia, Espanha e Itália. (ABRAMS, 1996, CALDER, 2001, MARTIN; SUTTON, 2002, MARTINS, 1997, 1998, MARTÍNEZ-NOGUERA et al., 1996, OUDKERK; ROSENBUSCH, 1995, AMMANN, 1997, PERIAGO, 2006, STEINER; KRAMER, 1996).

O princípio básico de formação da imagem em radiodiagnóstico consiste na utilização de raios-X para induzir mudanças em detectores químicos e elétricos, após passar pelo corpo humano. A quantidade de raios-X que atravessa o corpo humano ${ }^{1}$ depende da constituição da região ou do órgão radiografado.

1 O corpo humano pode ser descrito de uma forma simplificada, como constituído de tecido mole (predomínio de átomos leves), ossos, que contêm átomos pesados (minerais) e ar (átomos muito leves). Um filme exposto aos raios-X que penetraram o corpo humano terá uma imagem formada por áreas claras (pequena exposição), áreas acinzentadas (média exposição) e áreas escuras (grande exposição), dependendo da quantidade de raios-X que passou por cada parte do corpo. As estruturas ósseas, por exemplo, têm imagens mais claras que as regióes de tecido mole. São essas diferenças em tons de cinza, às vezes muito tênues, que permitem visualizar informaçóes que conduzem ao diagnóstico. (ORGANIZAÇÃO MUNDIAL DE SAÚDE, 2001) 
No final da década de 1960 e início da década de 1970, a introdução de mais duas tecnologias contribuiu para consolidar o radiodiagnóstico como uma das ferramentas de suporte à diagnose mais poderosa à disposição da medicina. Em 1966, foi desenvolvido o primeiro equipamento de raios-X dedicado à mamografia e em 1971, foi instalado, na Inglaterra, o primeiro equipamento de tomografia computadorizada. Essa nova técnica revolucionou a radiologia convencional e completou o radiodiagnóstico, com suas quatro técnicas (radiografia, fluoroscopia, mamografia e tomografia) que produzem informaçôes morfológicas ou fisiológicas de pacientes, de forma não invasiva. (FELDMAN, 1989, NATIONAL RESEARCH COUNCIL, 2001, ORGANIZAÇÃO PANAMERICANA DE SAÚDE, 1997, PERIAGO, 2006, THOMAS; BANERJEE; BUSCH, 2005)

A medicina transformou-se após ter acesso a uma das ferramentas mais poderosas do diagnóstico médico e de estudos sobre o interior do corpo humano. Poucas descobertas causaram tamanho impacto na medicina, de forma que continua por mais de um século, sendo uma das principais fontes de informação para os diagnósticos médicos e, consequentemente, de fundamental importância para a atenção à saúde humana. Contudo, essa nova tecnologia não trouxe consigo apenas benefícios. Tão rápidos quanto a sua utilização foram os danos causados em pesquisadores, médicos, pacientes e outros indivíduos expostos a esse tipo de radiação. (ARIAS, 2006; MOULD, 1995A; PERIAGO, 2006)

Por outro lado, os possíveis danos causados por essas tecnologias não estão relacionados, apenas, aos efeitos nocivos das radiaçôes ionizantes. Entre esses possíveis danos, os mais importantes são aqueles relacionados aos erros em diagnóstico. Em 2000, o Instituto Britânico de Radiologia organizou um seminário com o tema "Quanto erro é aceitável em radiologia?" que, segundo Goddard e outros (2001), refletiu a preocupação dos profissionais da área com o tema.

Conforme Graber (2005), os erros em radiodiagnóstico, nos EUA, contribuem com 10 a $15 \%$ dos erros em medicina, quando comparados com os resultados de necropsias. Os trabalhos de Robinson (1997), Williams, Con- 
nely e Wadsworth (2000) e Rencoret (2003) chamam a atençáo para outra dimensão dos erros em radiodiagnóstico: os custos para o sistema de saúde e para os profissionais ou instituiçóes envolvidas em processos indenizatórios. Rencoret (2003) estima que o custo nacional por eventos médicos adversos, lucro cessante e outros, nos EUA em 2001, foi de U\$40.000.000,00, ou seja, os diversos atores implicados no processo de realização dos exames diagnósticos estão sendo responsabilizados legalmente por eventuais falhas. Por outro lado, os aspectos econômicos relacionados a esse tema não podem ser negligenciados. Nesse sentido, alguns estudos foram desenvolvidos para quantificar os efeitos da implantação de programas de garantia de qualidade (PGQ) em radiodiagnóstico, como o trabalho desenvolvido por Noyes (1980) que estimou entre U\$33,000 a U\$51,000 a economia anual de um departamento com 12 salas de diagnóstico, após a implantação de um PGQ.

Como forma de minimizar esses riscos, os países desenvolvidos iniciaram, no final da década de 70 , um processo de implantação e fiscalização de programas de garantia de qualidade em radiodiagnóstico, que está sendo iniciado recentemente nos países em desenvolvimento, de forma muito incipiente. Países do Leste Europeu, Ásia, África e América Latina ainda discutem as primeiras avaliaçóes ou experiências na implantação de normas ou protocolos de controle de qualidade em radiologia convencional.

O trabalho de Sniureviciute e Adlience (2005) avaliou o processamento de filmes na Lituânia e mostrou que $40 \%$ das instituiçôes se encontravam em péssimas condiçôes de funcionamento, utilizando o sistema de revelação manual, tecnologia ainda presente nos países em desenvolvimento. Já nos países desenvolvidos, a referida tecnologia foi substituída, na década de 60, por sistemas de processamento automático, substituídos nos anos 80, por sistemas de processamento a seco e, atualmente, pelos sistemas digitais.

A Agência Internacional de Energia Atômica (IAEA) iniciou, em 1995, um projeto de proteção radiológica em radiodiagnóstico, em dezesseis países do Leste Europeu, África e Ásia, tendo como um dos seus objetivos avaliar o potencial para redução de dose em paciente no processo de otimização da proteção radiológica. $\mathrm{O}$ estudo concluiu que reduçôes consideráveis de 
doses em pacientes poderiam ser alcançadas, em radiografia convencional, implementando ações simples e baratas como filtração, uso de técnicas de tensão de pico - $\mathrm{kVp}$ altas, baixo produto corrente $\mathrm{x}$ tempo - $\mathrm{mAs}$ e uso de combinação de tela-filme apropriada. (INTERNATIONAL ATOMIC ENERGY AGENCY, 2004)

$\mathrm{Na}$ América Latina, tanto o estudo desenvolvido pela Organização Panamericana de Saúde (2001), avaliando os serviços de radiodiagnóstico de cinco países (Argentina, Bolívia, Colômbia, Cuba e México), quanto o trabalho de Brandan e outros (2004), que avaliou cinco serviços de mamografia no México, mostraram que a qualificação técnica da equipe influencia mais a qualidade dos diagnósticos do que os equipamentos; e entre os equipamentos, os negatoscópios são os que apresentaram mais problemas.

No Brasil, os estudos sobre os serviços de radiodiagnóstico passaram a ter maior repercussão após a publicação da Portaria MS 453/98 (BRASIL. Ministério da Saúde. Secretaria de Vigilância Sanitária, 1998), que regulamentou o papel da vigilância sanitária como autoridade reguladora dessa área e estabeleceu a obrigatoriedade da implantação de PGQ'S, bem como as diretrizes regulatórias do radiodiagnóstico no País.

Os estudos sobre doses em pacientes retratam realidades semelhantes em diferentes serviços de radiodiagnóstico no Brasil. A utilização de técnicas e equipamentos inadequados resultam na administração de doses elevadas nos pacientes, inclusive em crianças, chegando-se a encontrar valores 43 vezes maiores do que os níveis de referência para diagnóstico. (AZEVEDO et al., 2005, D'IPPOLITO; MEDEIROS, 2005, KOTSUBO; MARCHIORI; AZEVEDO, 2003, LIMA; CARVALHO; AZEVEDO, 2004, OLIVEIRA; KHOURY, 2003)

O interesse de Medeiros, Alves e Ruberty (2003) sobre a influência do negatoscópio nas leituras mamográficas concluiu que a detectabilidade é superior quando esses são específicos para mamografia. Este estudo é importante, pois chama a atenção para um equipamento fundamental nos serviços de radiodiagnóstico. 
O sistema de processamento dos filmes, incluindo os resíduos químicos, foi estudado por Magalhães, Azevedo e Carvalho (2002, 2004) e Fernandes, Carvalho e Azevedo (2005a, 2005b), que verificaram a importância do reprocessamento dos químicos utilizados na revelação dos filmes e a necessidade da realização de testes de desempenho nas processadoras automáticas.

Com relação aos diagnósticos, Benveniste, Ferreira e Aguilar (2006) avaliaram a eficácia da dupla leitura em mamografias de rotina, estudou 22.024 mamografias, durante um ano, verificando que essa prática aumentou em $8,5 \%$ o índice de detecção de câncer.

Os estudos realizados no Brasil têm refletido a perspectiva de avaliar desempenho de equipamentos, sem abordar as questóes relativas aos condicionantes da situação encontrada, bem como as responsabilidades dos diversos setores e atores envolvidos no processo de controle, como a vigilância sanitária, o responsável legal, o responsável técnico, a indústria, os conselhos profissionais e as universidades.

A vigilância sanitária, entendida como um campo do conhecimento científico e de práticas organizadas, visando à proteção da saúde (COSTA, 2004), ainda está em processo de consolidação, demandando que os estudos nesta área, além da descrição situacional, aporte contribuições teóricas e metodológicas. Assim, visando contribuir para o desenvolvimento da área de controle de riscos em radiodiagnóstico, nos campos de conhecimento da Saúde Coletiva e vigilância sanitária, tão importantes para a saúde individual e coletiva, publica-se, neste livro, a análise do controle de riscos em radiodiagnóstico e seus condicionantes, considerando o marco regulatório vigente e a identificação dos diversos atores implicados nessas práticas.

Esse estudo foi desenvolvido na Tese Conceito e Controle de Riscos à Saúde: uma Abordagem de Vigilância Sanitária, apresentada por Marcus Navarro no Instituto de Saúde Coletiva da Universidade Federal da Bahia, no final de 2007. 



\section{O Radiodiagnóstico na Saúde Pública}

Até o final do século XIX, a única forma de visualizar o interior do corpo humano era através de incisóes, geralmente em cadáveres. Já o funcionamento dos órgãos e sistemas do corpo ficava por conta da imaginação. A descoberta de Röntgen, em 1895, possibilitou a realização destes estudos (anatômicosradiografia e fisiológicos-fluoroscopia).

A importância do radiodiagnóstico ${ }^{2}$ para a saúde foi percebida imediatamente após sua descoberta. Em 1896, diversos países da Europa, América e Ásia, já realizavam exames com e sem contraste, de cabeça, pescoço, tórax, pulmão, mediastino, coração, pâncreas, baço, rim e intestino. O governo belga, por exemplo, sugeriu em 1897, que todos os hospitais deveriam ter um equipamento de raios-X. Naquele mesmo ano, os governos da Alemanha, Inglaterra e Rússia incentivaram e disponibilizaram recursos para estudos sobre a utilização dos raios-X com fins médicos. Dois anos mais tarde, Hermann Gocht, um ortopedista e estudioso da Roentgnologia publicou Das Lehrbuch der Roentgen-Untersuchung zum Gebrauche fuer Mediziner (livro de Ensino de exames radiológicos e suas aplicaçóes na medicina), considerado o primeiro livro de radiologia diagnóstica. No final de 1897, foi nomeado o primeiro professor de radiologia numa escola de medicina, em Amsterdá. (GLASSER, 1993, ROSENBUSCH; OUDKERK; AMMANN, 1995)

A rápida evolução tecnológica dos equipamentos e suas aplicaçóes na medicina levaram também à necessidade de que os temas relativos às radiaçóes ionizantes fizessem parte da formação de médicos, físicos, técnicos,

2 Qualquer procedimento que utiliza um equipamento de raios-X para irradiar qualquer parte do corpo humano, com o propósito de diagnóstico. (ORGANIZAÇÃO MUNDIAL DE SAÚDE, 1982; ORGANIZAÇÃO PANAMERICANA DE SAÚDE, 1997) 
engenheiros, enfermeiros, profissionais da Saúde Pública e técnicos das autoridades reguladoras. Nesse sentido, a Organização Mundial de Saúde (OMS) elaborou uma publicação, em 1958, propondo um currículo mínimo sobre radiaçóes ionizantes, a ser incluído nos cursos de pós-graduação de profissionais da área médica, bem como para os que trabalhavam com saúde pública (ORGANIZAÇÃO MUNDIAL DE SAÚDE, 1958b). Logo, em seguida, publicou o TRS 155, ressaltando a relevância da inclusão do tema de radiaçóes ionizantes nos cursos de graduação em medicina (ORGANIZAÇÃO MUNDIAL DE SAÚDE, 1958a), devido à importância e riscos das radiaçóes ionizantes para a saúde. Nesse mesmo sentido, foi publicada, em 1968, a base de referência para a formação dos profissionais de física médica (ORGANIZAÇÃO MUNDIAL DE SAÚDE, 1968). Nessas três publicaçóes, os currículos propostos abrangem: conteúdos de física aplicada, efeitos biológicos das radiações, quantidades e medidas radiológicas, radioproteção e aplicaçôes médicas das radiações ionizantes.

Em 1965, o TRS 306 (ORGANIZAÇÃO MUNDIAL DE SAÚDE, 1965) Public Health and the Medical use of Ionizing Radiation colocou em cena temas bastante relevantes à época e nos dias atuais, como as escolhas de exames pelos médicos, a atenção com a radioproteção e com o funcionamento adequado dos equipamentos ${ }^{3}$.

A importância do radiodiagnóstico para a saúde pública, como foi alertado no TRS 306, tanto no que se refere aos riscos quanto aos benefícios,

\footnotetext{
3 "[...] o aumento do uso médico das radiaçôes ionizantes e o fato que este aumento é, do ponto de vista de saúde pública, duplamente significativo: por um lado, a radiologia é essencial à medicina moderna; por outro, a radiologia diagnóstica se constituiu na principal fonte de exposição da população às radiaçóes artificiais. Conseqüentemente, para obter o máximo benefício associado ao menor perigo da radiologia médica, é necessário objetivar a qualidade mais alta dos procedimentos radiológicos ao mesmo tempo em que reduzir tanto quanto possível as exposiçóes indesejadas. Isto, contudo, não é só questão de usar procedimentos radiológicos corretos e aparatos satisfatórios: questôes de julgamento clínico e de indicaçóes para uso de outras ferramentas clínicas estão envolvidas." (ORGANIZAÇÃO MUNDIAL DE SAÚDE, 1965, p. 1)
} 
foi o tema da publicação seguinte, o TRS $492^{4}$ The Medical Uses of Ionizing Radiation and Radioisotopes. (ORGANIZAÇÃO MUNDIAL DE SAÚDE, 1972)

Assim, a questáo da acessibilidade começou a ser discutida. Enquanto os países desenvolvidos estavam praticando o radiodiagnóstico em larga escala, inclusive, iniciando os programas de monitoração, screening, as populaçóes dos países em desenvolvimento ainda não tinham acesso às tecnologias mais simples da radiologia diagnóstica. Contudo, os dois mundos precisavam ampliar o acesso aos serviços de radiodiagnóstico, garantir a qualidade dos exames e a proteçáo dos pacientes, trabalhadores e indivíduos do público ${ }^{5}$, pois as principais causas de mortalidade nesses mundos, doenças crônicodegenerativas, infecto-contagiosas e causas externas, em grande parte têm como base de diagnóstico a radiologia.

A realidade das Américas, também presente no Brasil, se reflete nos dados do Banco de dados do Sistema Único de Saúde (DATASUS), referentes a 2004. Entre as dez primeiras causas de mortalidade, sete têm no radiodiagnóstico uma das principais fontes de informação para a diagnose (doenças cerebrovasculares, agressóes, pneumonia, acidentes de transporte, neoplasias malignas de traquéia, brônquios e pulmóes, neoplasia maligna do estômago e neoplasia maligna da mama). Outro importante papel do radio-

4 “Os países desenvolvidos têm alcançado um nível onde, em média, metade da população provavelmente realiza um radiodiagnóstico a cada ano. Originalmente, os procedimentos radiológicos eram usados principalmente como uma ajuda para diagnose clínica. Hoje em dia, eles também são amplamente usados na vigilância, gerenciamento e acompanhamento das doenças, durante e depois do tratamento. Isto enfatiza a importância do papel que a radiologia diagnóstica está representando na administração de quase todas as doenças e nas atividades de todos os ramos da medicina. Muitas especialidades médicas e cirúrgicas quase não poderiam existir sem o auxílio da radiologia diagnóstica necessária para cada paciente. Um fator adicional de grande importância no atual crescimento da radiologia diagnóstica é seu uso na identificação de doenças antes dos sintomas se desenvolverem." (ORGANIZAÇÃO MUNDIAL DE SAÚDE, 1972, p. 9)

$5 \mathrm{Na}$ proteção radiológica a população exposta às radiaçóes ionizantes é dividida em três grupos: trabalhadores, pacientes e indivíduos do público. (INTERNATIONAL COMMISSION ON RADIOLOGICAL PROTECTION, 1991) 
diagnóstico na saúde pública refere-se ao programa de "screening" mediante mamografia. A implantação de programa de "screening" com mamografia nos países escandinavos reduziu em 63\% a mortalidade de câncer de mama entre as mulheres que participaram do programa. Outra informação importante refere-se à modificação nos padrões de estadiamento. Nos EUA, por exemplo, após a implantação do programa, os estadiamentos II, III e IV, que representavam 59\%, passaram a representar 32\% dos tumores detectados. Isso significa possibilidade de cura ou aumento da expectativa de vida, pois enquanto $26 \%$ das mulheres com estadiamento III e IV sobrevivem durante cinco anos, 98\% das mulheres com estadiamento I sobrevivem o mesmo período. (FEIG, 2006)

Contudo, para que os radiodiagnósticos possam contribuir para salvar vidas e/ou aumentar a expectativa de vida, é necessário que sejam realizados de forma adequada. Se as condiçóes não forem satisfeitas, essa potente ferramenta de diagnóstico e prevenção deixa de ser uma solução para o sistema de saúde pública e passa a ser um problema. (ORGANIZAÇÃO MUNDIAL DE SAÚDE, 1982, 2001; ORGANIZAÇÃO PANAMERICANA DE SAÚDE, 1997)

Um diagrama simplificado do processo de atendimento médico pode ser observado na Figura 1, que mostra a demanda dos pacientes por atendimento médico (causas externas, avaliaçóes periódicas ou sinais e sintomas de doenças), o processo de tomada de decisão inicial do médico (com base na história e exame clínico do paciente decide se existe necessidade e quais exames complementares serão solicitados) e a continuidade do processo de atendimento (ORGANIZAÇÃO MUNDIAL DE SAÚDE, 2001). Este diagrama pode estar representando o atendimento médico de uma clínica ortopédica, pediátrica, de urgência/emergência ou hospitais, ficando evidente que os profissionais envolvidos nesses procedimentos quase nunca são radiologistas. Isto significa que os profissionais de saúde, principalmente os médicos, necessitam de formação básica em radiologia, pois a tomada de decisão inicial será de fundamental importância para os procedimentos que serão adotados com reflexos na atenção à saúde dos pacientes. 
FIGURA 1. FLUXOGRAMA DOS PROCEDIMENTOS MÉDICOS

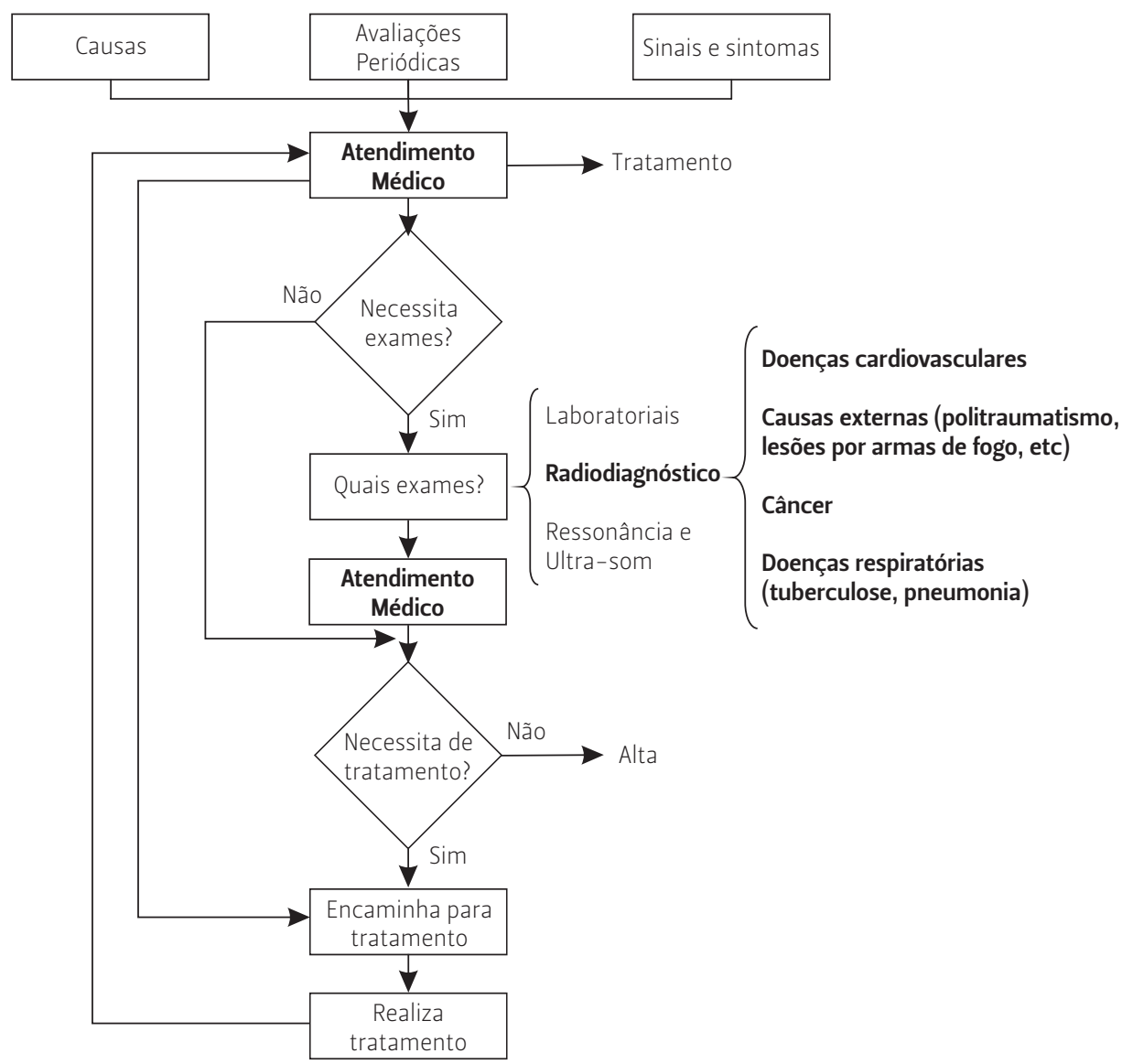


O radiodiagnóstico não deve ser tratado como uma caixa de ferramentas em que todas as ferramentas são retiradas, aleatoriamente, e utilizadas por tentativa e erro. $\mathrm{O}$ exame de radiodiagnóstico serve para confirmar uma suspeita clínica, exceto nos programas de screening, e assim, geralmente, mostram o que se suspeitava existir (INTERNATIONAL ATOMIC ENERGY AGENCY, 2004, 2006; ORGANIZAÇÃO MUNDIAL DE SAÚDE, 1958a, 1958b, 1965, 1972, 1982, 2001; ORGANIZAÇÃO PANAMERICANA DE SAÚDE, 1997). Assim, o nível de qualidade dos serviços de radiodiagnóstico e seu conseqüente papel para o sistema de saúde de um país estão associados basicamente ao nível de formação técnica, científica e ética dos profissionais e da sociedade. 


\section{Evolução tecnológica do radiodiagnóstico}

Os primeiros equipamentos empregados para a realização de radiografia e fluoroscopia eram semelhantes aos utilizados por Röntgen: produziam raios-X através de um tubo de raios catódicos que não tinha sido projetado para este fim. Por isso, não tinham estabilidade nem reprodutibilidade, muito menos qualquer tipo de proteção ou direcionamento dos raios-X que eram produzidos. (GLASSER, 1993, ROSENBUSCH; OUDKERK; AMMANN, 1995) Assim, para a consolidação do radiodiagnóstico na medicina, era necessário o desenvolvimento de equipamentos e técnicas que possibilitassem a padronização e reprodução dos exames, conhecendo e controlando parâmetros como tensão do tubo ${ }^{6}$, corrente aplicada, tempo de exposição e distância tubo-paciente.

Em 1907, Kienböck publicou o primeiro estudo propondo uma classificação qualitativa dos raios-X, com relação à sua penetrabilidade no tecido humano, ou seja, com relaçáo à qualidade do feixe de raios-X (AMMANN; KUTSCHERA, 1997). A qualidade do feixe de raios-X é de fundamental importância para o contraste radiográfico, principal item da visualização da imagem. Quanto mais denso ou mais espesso é o local a ser radiografado, maior deverá ser a qualidade do feixe a ser utilizado. Em 1912, o físico e médico Suíço Th. Christén elaborou o conceito de Camada Semi Redutora $(\mathrm{CSR})^{7}$ camada semi-redutora (MOULD, 1995a), que possibilitou especificar, de forma quantitativa, a qualidade de um feixe e,

${ }^{6}$ A tensão aplicada no tubo para produzir os raios-X é um dos principais fatores que influenciam a qualidade do feixe. Quanto maior a tensão aplicada, maior será a energia dos raios-X produzidos e, consequentemente, maior será sua penetrabilidade ou qualidade.

7 CSR é a quantidade de material necessário para reduzir a intensidade de um feixe de raios-X à metade. Em radiodiagnóstico é dado em milímetros de alumínio ( $\mathrm{mmAl})$. 
consequentemente, relacionar à qualidade do feixe adequada para cada tipo de exame.

Em 1904, a Siemens-Reiniger produziu o primeiro aparelho de raios-X com um gerador monofásico e retificação de onda completa. (ROSENBUSCH; OUDKERK; AMMANN, 1995) Esse tipo de gerador possibilitou a produção de maior quantidade de raios-X e a consequente redução dos tempos de exames. Quanto menor o tempo do exame, melhor a qualidade da radiografia, pois diminui a possibilidade de movimentos voluntários ou involuntários, do paciente, que provocam manchas nas imagens. Contudo, foram necessários mais sete anos para que o engenheiro W. D. Coolidge idealizasse o tubo de alto vácuo com focalização de feixe, semelhante aos tubos modernos, possibilitando um grande avanço na qualidade e reprodutibilidade dos feixes de raios-X. (AMMANN; KUTSHERA, 1997, ROSENBUSCH; OUDKERK; AMMANN, 1995)

Outros dois importantes componentes no processo de formação da imagem são os colimadores e a grade antidifusora. A colimação do feixe de raios-X possibilita a identificação e limitação da radiação na área de interesse radiográfico, reduzindo a área irradiada e a radiação espalhada, enquanto a grade antidifusora reduz a radiação espalhada que chega ao receptor de imagem. Quanto menor for a radiação espalhada, melhor será a qualidade da imagem. Entre 1903 e 1908, foram desenvolvidos os colimadores (cônicos, cilíndricos e reguláveis) e a luz de campo, respectivamente. O colimador regulável com a luz de campo possibilita a visualização e limitação da área que será irradiada, em quaisquer distâncias. O sistema de colimação regulável passou a ter a luz de campo acoplada em 1938. A grade antidifusora, desenvolvida pelo radiologista Gustav Bucky, em 1912, passou a ser comercializada em 1921, pela General Eletric - GE. (AMMANN; KUTSHERA, 1997, ROSENBUSCH; OUDKERK; AMMANN, 1995) Também voltados para a qualidade da imagem, em 1904, foram desenvolvidos os primeiros phantoms, que são simuladores de partes do corpo humano utilizados para testar a qualidade da imagem, evitando as exposições humanas. Para melhor visualizar as imagens radiográficas, foram produzidos comercialmente, em 1907, 
os primeiros negatoscópios com persianas que ajustavam a área luminosa do negatoscópio ao tamanho do filme radiográfico a ser avaliado. Sem o sistema, caso o filme avaliado seja menor que o tamanho do negatoscópio, a área não coberta pelo filme emite luz diretamente nos olhos do observador e dificulta a visualização de baixo contraste nos filmes. (MOULD, 1995a; ROSENBUSCH; OUDKERK; AMMANN, 1995)

Todas essas tecnologias foram desenvolvidas, principalmente, visando à melhoria da qualidade da imagem e a realização de novos exames. $\mathrm{O}$ uso de colimadores e grade antidifusora é um bom exemplo, pois eram utilizados visando à redução da radiação espalhada no paciente e a melhoria da qualidade da imagem, em equipamentos sem nenhuma proteção da ampola, que emitia radiação em todas as direçóes.

Em continuidade aos avanços nos equipamentos de raios- $\mathrm{X}$ (componentes e acessórios) e utilizando a tecnologia do tubo de alto vácuo, proposta por Coolidge, em 1915, a GE desenvolveu o primeiro tubo de anodo rotatório e a Siemens-Reiniger, o primeiro gerador de raios-X trifásico. No ano seguinte, a Siemens-Reiniger desenvolveu o primeiro circuito que possibilitou o controle de tensão do tubo $(\mathrm{kV})$, tempo de exposição, corrente do tubo $(\mathrm{mA})$ e inseriu um novo conceito nas técnicas radiográficas, que foi o produto dose $\mathrm{x}$ tempo (mAs). Assim, a técnica radiográfica passou a ser especificada pelo $\mathrm{kV}$ e mAs, devendo-se buscar o maior $\mathrm{mA}$ e o menor tempo possível de exposição. (AMMANN; KUTSHERA, 1997, ROSENBUSCH; OUDKERK; AMMANN, 1995)

$\mathrm{Na}$ primeira metade da década de 30, a Siemens-Reiniger introduziu uma grande inovação no tocante aos equipamentos móveis, ao produzir um equipamento em que a ampola e o gerador estavam juntos, dentro de uma esfera metálica de $22 \mathrm{~cm}$ de diâmetro, cheia de óleo. Este equipamento, chamado de esfera de Röntgen Röntgenkugel, tinha potência de até $4 \mathrm{~kW}$ e era facilmente transportado. Foi uma inovaçáo tão relevante que o equipamento, com pequenas modificaçóes, foi produzido durante 40 anos. (ROSENBUSCH; OUDKERK; AMMANN, 1995) 
No início da década de 1940, os serviços de radiodiagnóstico dispunham, comercialmente, de praticamente todos os componentes presentes num serviço convencional atual, exceto o sistema automático de exposição e de informatização. Em 1942, já era possível encontrar equipamentos de raios-X trifásico, de $100 \mathrm{~kW}$, com tempo de feixe em torno de $30 \mathrm{~ms}$, ampolas de anodo rotatório, imersas em óleo e revestidas de chumbo, com colimadores reguláveis e luz de campo; mesa radiográfica com grade antidifusora; chassis com écrans ${ }^{8}$; filmes radiográficos apropriados para esses écrans; processadoras automáticas com secagem de filmes e negatoscópios com persianas para limitar o campo luminoso. (AMMANN; KUTSHERA, 1997, ROSENBUSCH; OUDKERK; AMMANN, 1995)

$\mathrm{Na}$ década de 50, os radiologistas já tinham percebido que as diferenças entre crianças e adultos eram de fundamental importância, tanto nas questóes relacionadas à radioproteção, quanto nas referentes à qualidade da imagem. As crianças necessitam de equipamentos com proteçóes, filtraçóes e tempos de exposiçóes especiais. Esses dispositivos começaram a ser comercializados em 1950 e no início dos anos 1970, foi produzido o primeiro equipamento de radiografia e fluoroscopia dedicado à pediatria, o INFANTOSKOP. (AMMANN et al., 1995)

A fluoroscopia, exame que provocava maior exposição de trabalhadores e pacientes devido aos longos tempos dos feixes, com a observação realizada diretamente numa tela próxima ao paciente, passou por uma verdadeira revolução quanto à radioproteção. No final da década de 1950, surgiram os primeiros sistemas óticos de visualização da imagem, evitando a exposição direta dos feixes de raios-X. Vinte anos depois, os equipamentos de fluoroscopia já dispunham de sistemas comandados à distância, com monitores, que também foram incorporados aos equipamentos portáteis utilizados em cirurgias, conhecidos como Arco-C. (AMMANN et al., 1995)

8 Écrans são telas que, ao receberem os raios-X, emitem luz visível, possibilitando a formação da imagem no filme com menos radiação. Nessa época, os écrans já possibilitavam a redução da dose em 5 vezes. 
Apesar dos exames de radiodiagnóstico de mama serem realizados desde 1913, é no final da década de 60 que passam a ter o formato que se conhece hoje. Em 1966, o físico francês Charles Gros desenvolveu o primeiro equipamento dedicado à mamografia, o SENOGRAPH (imagem da mama, em francês). Nos anos 70, o radiologista Robert Egan foi o primeiro a usar o termo mamografia e a propor a realização de exames mamográficos de monitoraçáo, screening, para detecção precoce do câncer de mama. No final daquela década, os mamógrafos produzidos comercialmente já possuíam sistema automático de exposição (Automatic Exposure Control - AEC), de compressão da mama e grade antidifusora. (THOMAS; BANERJEE; BUSCH, 2005) Esse sistema mede a quantidade de radiação que chega ao receptor de imagem, possibilitando sua formaçáo com a quantidade de radiação necessária e suficiente para produzir as informaçôes diagnósticas de interesse, reduzindo a repetiçáo de exames, as doses nos pacientes e melhorando a qualidade da imagem.

O equipamento de tomografia computadorizada (CT), desenvolvido por Godfrey Hounsfield e Alan Cormack, no início dos anos 70, foi tão importante para a medicina que lhes proporcionou o Prêmio Nobel de Medicina e Fisiologia de 1979. A realização de cortes transversais do corpo possibilitou melhor visualização de órgáos e tecidos, ampliando o conhecimento e as possibilidades diagnósticas. (THOMAS; BANERJEE; BUSCH, 2005)

No final dos anos 70, já eram produzidos equipamentos fixos e portáteis, com geradores de alta freqüência ou trifásicos de 12 pulsos. Os fixos, com potência superior a $100 \mathrm{~kW}$, possibilitavam corrente de tubo de até 2.000 $\mathrm{mA}$ e tempo de exposição de $1 \mathrm{~ms}$. Nesse período, foram incorporados aos equipamentos colimadores que limitavam, automaticamente, o tamanho do campo ao tamanho do filme radiográfico utilizado e uma das mais importantes tecnologias do radiodiagnóstico: o controle automático de exposição - AEC. (AMMANN et al., 1995)

As mesas radiográficas e porta-chassis verticais, além de utilizarem materiais de baixa absorção, passaram a ter acoplado porta-chassis com 
grade antidifusora móvel, possibilitando a redução da radiação espalhada e consequente melhoria da qualidade da imagem. Os chassis de plástico e os écrans de terras-raras possibilitaram uma redução, entre 1897 e 1970, de 100 vezes na radiação necessária para formar uma boa imagem. As processadoras automáticas de filmes ficaram acessíveis, possibilitando realizar o processo de revelação e secagem de forma mais rápida e controlada (AMMANN et al., 1995). Na década de 1980, os equipamentos de raios-X, mamografia, tomografia, fluoroscopia, negatoscópios e processadoras alcançaram níveis elevados de qualidade e segurança, possibilitando exames cada vez mais rápidos e melhor qualidade da imagem, com conforto e segurança para pacientes e equipe técnica.

O final do século XX foi marcado por uma revolução tecnológica, ainda em andamento, que teve início com a introdução dos equipamentos digitais e foi fortalecida com o advento dos tomógrafos multicortes "Multislice", levando o radiodiagnóstico ao desconhecido mundo dos exames virtuais e da comunicação e integração entre as tecnologias, com os "Picture Archiving and Communication Systems - PACS" (THOMAS; BANERJEE; BUSCH, 2005). Maravilhas modernas que não são objeto deste estudo, por representarem uma realidade bem distante da imensa maioria dos serviços de radiodiagnóstico do Brasil e da Bahia. 


\section{Conceito e controle de riscos à saúde}

Com as transformaçôes vividas pela humanidade, produzindo e incorporando ao seu modo de vida as mais diversas tecnologias, cada vez mais as fontes de perigo foram associadas às práticas humanas. $\mathrm{Na}$ sociedade atual, é difícil separar os perigos produzidos pelo homem dos perigos "naturais" (BECK, 2003). Uma enchente, por exemplo, que acontecia como um fenômeno completamente espontâneo, hoje pode ocorrer como consequência da ação do homem sobre a natureza. Por outro lado, os danos causados por uma possível enchente não estão associados, necessariamente, apenas à saúde humana. Podem estar relacionados a diversos eventos indesejados, como danos materiais (plantaçôes e moradias) e imateriais (psicológicos e culturais).

Covello e Munpower (1985) lembram que, por volta de 3.200 a.C., no vale entre os rios Tigre e Eufrates, vivia um grupo chamado $A$ sipu. Uma das principais funçóes dos membros do grupo era auxiliar pessoas que precisavam tomar decisóes difíceis. $\mathrm{O}$ Asipu, quando procurado, identificava a dimensão do problema, as alternativas e as conseqüências de cada alternativa. Assim, elaborava uma tabela, marcando os pontos positivos e negativos de cada uma delas, para indicar a melhor decisão. Com as grandes navegaçóes, no século $\mathrm{XV}$, emergiu a necessidade de avaliar os prejuízos causados pelas possíveis perdas dos navios. Surge então o termo "risco", que desde a sua origem está associado à possibilidade de ocorrência de um evento indesejado. $\mathrm{O}$ desenvolvimento da probabilidade, em meados do século XVII, possibilitou quantificar estas possibilidades. (COVELLO; MUNPOWER, 1995, FREITAS; GOMEZ, 1997)

9 O termo risco tem sua origem na palavra italiana riscare (FREITAS; GÓMEZ, 1997) ou na palavra grega rhiza (COVELLO; MUNPOWER, 1985). Para os dois autores, essas palavras foram introduzidas, com o objetivo de avaliar as possibilidades de perdas nas viagens marítimas e tinham o significado original de navegar entre rochedos. 
Vale ressaltar que probabilidade e risco são conceitos distintos para a maioria das disciplinas. Enquanto a probabilidade é definida, matematicamente, como a possibilidade ou chance de um determinado evento ocorrer, sendo representada por um número entre 0 e 1 (GELMAN; NOLAN, 2004; TRIOLA, 2005), o risco está associado à possibilidade de ocorrência de um evento indesejado e sua severidade, não podendo ser representado apenas por um número. Caso dois eventos $\mathrm{A}$ e $\mathrm{B}$ tenham, respectivamente, as probabilidades de 0,10 e 0,90 de ocorrerem o evento $B$ é classificado como nove vezes mais provável do que o evento A. Contudo, não se pode dizer que o evento $\mathrm{B}$ tem maior risco que o evento A. Para o conceito de risco, é fundamental conhecer quáo danoso será o evento. Por outro lado, a avaliação das probabilidades de ocorrência dos eventos A e B é realizada, puramente, com análise matemática, enquanto a avaliação dos riscos requer juízo de valor. Assim, todos os observadores concordarão que o evento B é mais provável que o evento $\mathrm{A}$, mas nem todos os observadores devem concordar sobre qual evento representa maior risco, conhecendo-se, ou não, os danos.

O risco deve ser entendido como uma elaboração teórica, que é construída, historicamente, com o objetivo de mediar à relação do homem com os perigos, visando minimizar os prejuízos e maximizar os benefícios. Assim, não é uma grandeza que está na natureza para ser medida, não é independente do observador e de seus interesses. É formulado e avaliado dentro de um contexto político-econômico-social, tendo um caráter multifatorial e multidimensional. (BECK, 2003, COVELLO; MUNPOWER, 1985, FISCHHOFF et al., 1983, FISCHHOFF; BOSTRUM; QUADREL, 2005, GLYN, 2004, HAMPEL, 2006, INTERNATIONAL COMMISSION ON RADIOLOGICAL PROTECTION, 1991, KAHNEMAN; SLOVIC; TVERSKY, 1982, KOH; JEYARATNAM, 2005, LINDELL, 1996a, 1996b; OMENN; FAUSTMAN, 2005)

$\mathrm{O}$ primeiro relato de uma avaliação de risco quantitativa aplicada à saúde remete a Laplace, no final do século Xvinı, que calculou a probabilidade de morte entre pessoas com e sem vacinação de varíola. Com os estudos 
de Pasteur, no final do século XIX, foi possível utilizar as ferramentas da estatística para avaliar os fatores relacionados às doenças transmissíveis, dando origem ao conceito de risco epidemiológico. (COVELLO; MUNPOWER, 1985, CZERESNIA, 2004)

Os estudos epidemiológicos sobre as doenças contagiosas possuem duas características muito específicas. A primeira refere-se ao objeto, que é apenas fonte de danos. A segunda diz respeito aos objetivos, que visam determinar a relação entre a causa e o efeito, ou seja, entre a exposição e a doença. Então, mesmo tendo determinantes multifatoriais, é uma avaliação unidimensional. Assim, numa avaliaçáo entre expostos e náo expostos, o conceito de risco aproxima-se da definiçáo de probabilidade. Contudo, quando o objetivo inclui o julgamento sobre a severidade do agravo ou a comparaçáo entre diferentes agravos de diferentes exposiçóes, a probabilidade passa a ser uma das informações que compõem o conceito de risco.

O início do século XX foi marcado por grandes avanços científicos, cujas aplicaçóes, principalmente após a Segunda Guerra, produziram novas tecnologias ${ }^{10}$ e trouxeram consigo também novos riscos à saúde (LUCCHESE, 2001). Se por um lado, algumas tecnologias produziam riscos desconhecidos, por outro lado, trouxeram benefícios que propiciaram sua incorporação, produção e consumo. Assim, a rápida utilização das novas tecnologias (como raios-X, energia nuclear, asbesto e formaldeídos) como se fossem fontes apenas de benefícios trouxeram consequências à saúde da população e ao meio ambiente, que só vieram a ser percebidas e compreendidas pela sociedade, na década de 70. A divulgação destes riscos induziu pressóes sobre os governos, para controlar os riscos ocupacionais, ambientais, de agentes químicos e radioativos. Neste contexto de grandes mobilizaçóes sociais, foi fortalecida a necessidade de intervenção do Estado, com o objetivo de regular a utilização de produtos potencialmente danosos à saúde e ao ambiente. (FREITAS, 2000, LIPPMANN; COHEN;

${ }_{10}$ Tecnologia entendida no sentido mais amplo, como produtos ou processos. (FIGUEIREDO, 1989) 
SCHLESINGER, 2003, NATIONAL RESEARCH COUNCIL, 1983, OMENN; FAUSTMAN, 2005, SAMET, 2005)

A regulação de riscos à saúde é entendida como uma interferência governamental no mercado ou em processos sociais, com o propósito de controlar consequências potencialmente danosas à saúde (HOOD; ROTHSTEIN; BALDWIN, 2004). O modelo do sistema regulador, implantado em cada país, depende de conjunturas políticas, econômicas e sociais. Assim, na década de 1970, enquanto os países europeus exerceram, inicialmente, seu poder regulatório, por meio dos órgãos da administração direta do Estado, os Estados Unidos exerceram o poder, principalmente, através de agências independentes e especializadas. Atualmente, a maioria dos países da União Européia utiliza o modelo de agências reguladoras (LUCCHESE, 2001) que chegou ao Brasil no final da década de 1990.

Os reflexos econômicos e sociais relacionados às primeiras ações regulamentadoras mostraram que o processo de definição e regulação de riscos é um exercício de poder, carregado de interesses e concepçóes político-econômicosociais, podendo influenciar fortemente na alocação de recursos públicos e privados de uma nação. (FISCHHOFF; BOSTRUM; QUADREL, 2005, SLOVIC, 2000)

Um exemplo disso é a luta dos trabalhadores de minas de carvão, em meados do século passado, tentando conseguir incentivos e melhores condiçóes de trabalho, mostrando que sua atividade era uma das mais arriscadas, pois o número de mortes/1000 trabalhadores estava entre os mais altos da mineração. Contudo, os proprietários das mineradoras preferiam utilizar o indicador de número de mortes/tonelada produzida, pois quando comparado a outros tipos de mineração, mostrava-se entre os mais baixos. (SLOVIC, 2000) Um simples coeficiente de mortalidade, que parecia ser uma medida objetiva e única, mostrava-se subjetivo e de tantas possibilidades de definição quantas fossem as intençóes de seu uso.

Logo, o risco que era concebido como a probabilidade de ocorrência de um evento indesejado, calculado pelos especialistas e apresentado à sociedade como uma verdade absoluta e neutra, passa a ser questionado. 
Os conflitos de interesse sobre a divisão dos riscos, mostraram que não era possível separar as análises técnicas sobre os riscos das decisóes de quem deveria ser protegido, dos custos e das alternativas disponíveis, pois os estudos ou avaliaçóes de riscos ocorrem, necessariamente, para subsidiar tomadas de decisão. (BECK, 2003, FISCHHOFF; BOSTRUM; QUADREL, 2005, FREITAS; GOMEZ, 1997, INTERNATIONAL COMMISSION ON RADIOLOGICAL PROTECTION, 1991, KOH; JEYARATNAM, 2005, OMENN; FAUSTMAN, 2005, SLOVIC, 2000)

As novas tecnologias, por produzirem benefícios e possíveis danos, necessitam de um conceito de risco que aborde essa complexidade. Nessas situaçóes, os riscos não podem simplesmente ser eliminados, pois com eles eliminam-se também os benefícios. Assim, entram em cena outras dimensôes dos riscos como sua aceitabilidade que é dependente dos benefícios, sua percepção e a confiança no sistema regulador.

No início dos anos 1980, o Congresso Americano percebeu a necessidade de estruturar um modelo de avaliação de riscos que tivesse ampla aceitaçáo, bem como uniformizasse a realização dos estudos nas diversas áreas, estabeleceu uma Diretiva que designou a FDA (Food and Drug Administration) como responsável em coordenar um estudo para a harmonização. Esse estudo, conhecido internacionalmente como Red Book, estabelece um processo com sete estágios: (1) Identificação dos perigos; (2) Avaliação dose x resposta; (3) Avaliação de exposições; (4) Caracterização dos riscos; (5) Estabelecimento das opçôes regulatórias; (6) Decisão e implementação da opção de regulação; (7) Avaliação da regulação. Todas as etapas acontecem com a participação dos diversos atores, especialistas ou não. Os estágios 1 a 4 são classificados como avaliação de riscos e são de base técnico-científica. Os outros estágios (5 a 7) fazem parte do gerenciamento de riscos, que, levando em consideraçáo as informaçóes obtidas no primeiro estágio, avaliam e implementam as melhores opçóes regulatórias, considerando questôes econômicas, políticas e sociais. (FISCHHOFF; BOSTRUM; QUADREL, 2005, KOH; JEYARATNAM, 2005; LINDELL, 1996a, MARTIN; SUTTON, 2002, 
NATIONAL RESEARCH COUNCIL, 1983, OMENN; FAUSTMAN, 2005, THOMPSON; DEISLER; SCHWING, 2005)

$\mathrm{Na}$ sociedade atual, os riscos têm um papel de tamanha importância que a sociedade industrial evoluiu para a "Sociedade do Risco", em que as lutas sócio-politico-econômicas passam a ter como objeto os bens e os males produzidos pela sociedade, organizados e distribuídos pelo Estado (BECK, 1992, 2003). Assim, o risco ganha mais força política de mobilização do que as desigualdades associadas às classes, raças e gêneros. Por outro lado, conforme Hood, Rothstein e Baldwin (2004), em conseqüência das privatizaçôes e da redução, cada vez maior, do estado, enquanto agente empregador produtivo, a contemporaneidade tem se caracterizado como uma "Sociedade de Risco" e um "Estado Regulador", responsável apenas pelo controle, circulação e distribuição dos riscos na sociedade.

\section{Um conceito de risco para a vigilância sanitária}

Um diagrama do paradigma dos riscos aplicado à área da vigilância sanitária está representado na Figura 2.

No centro do mapa, está a informação que caracteriza a particularização do modelo para a vigilância sanitária (VISA): o objeto de estudo. Objetos de atuação da VISA, aqui referidos como tecnologias para saúde ${ }^{11}$, têm três características básicas: são de interesse da saúde humana, produzem benefícios e possuem riscos intrínsecos. São essas características que justificam a ação da vigilância sanitária sobre as tecnologias para saúde.

Esta tríade saúde-benefício-risco está presente nas mais distintas tecnologias, objeto de regulação pela vigilância sanitária, como um elo de identidade entre elas. Assim, caso uma tecnologia não possua um dos três atributos, não deve estar sob controle da vigilância sanitária, a não ser que

${ }^{11}$ Essa denominação tem apenas o objetivo de tentar sintetizar, em uma palavra, os produtos, serviços e processos que estáo sob ação da vigilância sanitária. 
FIGURA 2. DIAGRAMA DO PARADIGMA DO RISCO

Fonte: Adaptado de Omenn e Faustman (2005, p.1084).

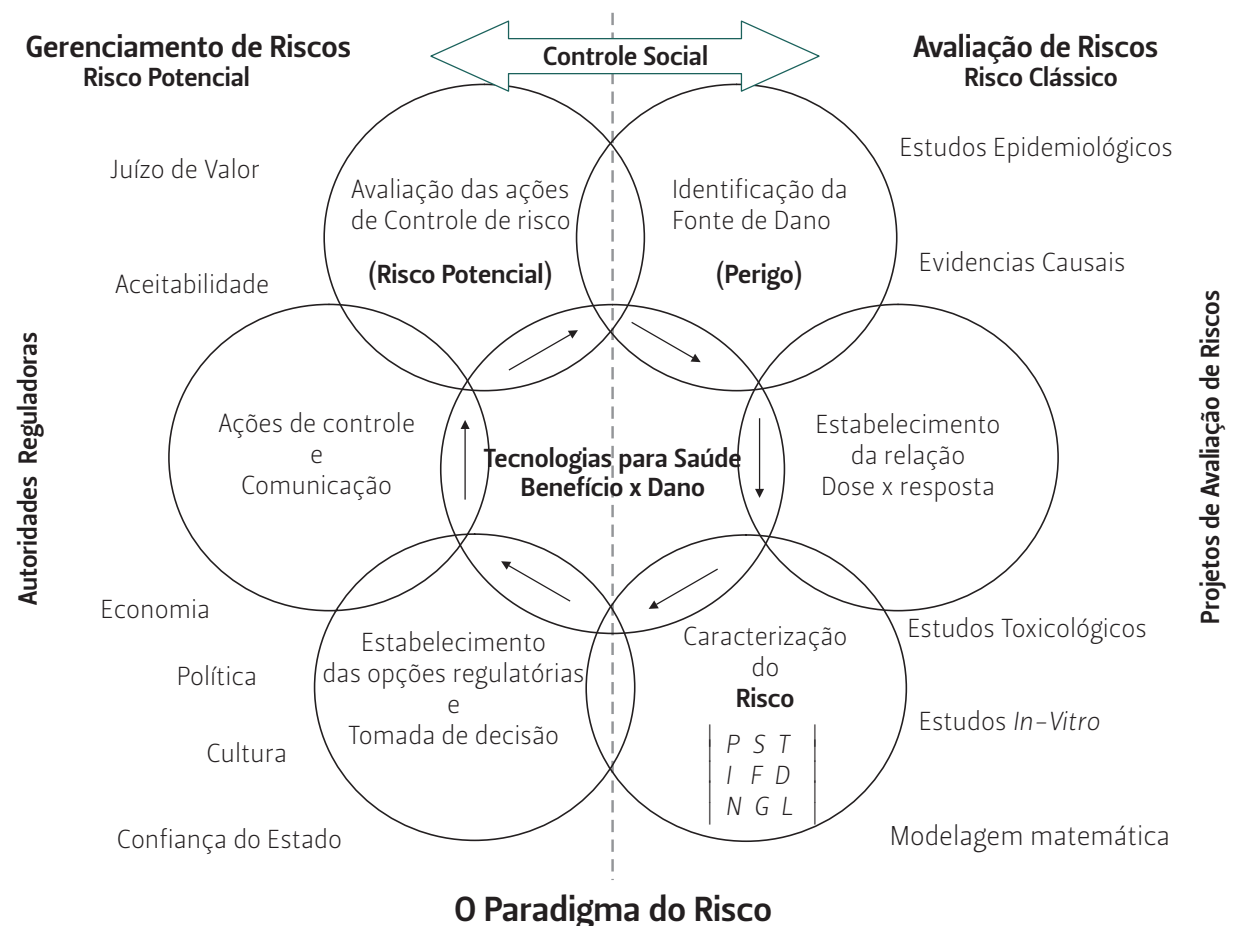


esteja em processo de estudos para identificar a pertinência à área. Contudo, cabe salientar que a VISA é uma área cujas práticas têm por base informaçóes técnico-científicas, sociais, políticas e de juízo de valor (COSTA, 2004). A tríade é um dos elementos que devem subsidiar a tomada de decisão sobre a pertinência, ou náo, de uma tecnologia para saúde ao campo da VISA.

Uma importante característica dessa tríade refere-se ao risco. Como o risco é intrínseco ao objeto, não se pode eliminá-lo sem eliminar o uso do objeto, podendo apenas ser minimizado. Assim, todas as tecnologias para saúde representam, essencialmente, algum tipo de risco e, caso exista alguma que não contenha riscos, provavelmente não será objeto da vigilância sanitária. Por possuírem riscos inerentes à sua natureza, as tecnologias devem ser utilizadas na observância do princípio bioético do benefício. (COSTA, 2003, 2004)

O diagrama, representado na Figura 2, está dividido ao meio, transpassado pelo controle social e pelo objeto de estudo. O lado direito representa o campo da avaliaçáo de riscos e o lado esquerdo, o campo do gerenciamento de riscos. Avaliação de risco é o uso de evidências objetivas para definir os efeitos à saúde devidos à exposição de indivíduos ou populaçóes a materiais ou situaçôes perigosas. $\mathrm{O}$ gerenciamento de riscos refere-se ao processo de integrar os resultados da avaliaçáo de riscos com questóes sociais, econômicas e políticas, ponderando as alternativas e selecionando a mais apropriada à ação reguladora. (NATIONAL RESEARCH COUNCIL, 1983) Tendo em vista que os processos de avaliação e gerenciamento de riscos afetam diretamente a vida das pessoas e os recursos públicos e privados, a participação de todos os atores envolvidos direta ou indiretamente, leigos ou especialistas, com controle social, é de fundamental importância para a credibilidade, legitimidade e aceitabilidade das decisóes e das açóes regulatórias que serão implantadas.

A avaliação de riscos é composta de três passos: identificação da fonte de dano, estabelecimento da dose x resposta e caracterização do risco. No primeiro momento, a identificação dos riscos é basicamente a resposta para a pergunta: qual componente dessa tecnologia para saúde causa um evento 
adverso? É uma questão que pode ser respondida com base em evidências causais, toxicológicas, epidemiológicas ou testes in vitro. (NATIONAL RESEARCH COUNCIL, 1983, OMENN; FAUSTMAN, 2005)

No segundo momento, duas questôes precisam ser respondidas: como ocorrem as exposiçôes? E como é a relação entre exposição x efeitos (dose $\mathrm{x}$ resposta)? Para responder a primeira questão, devem ser avaliadas as condiçôes (intensidade, freqüência, duração, susceptibilidade e período da exposição), em que os indivíduos ou as populaçóes são expostos e, a segunda pergunta deve ser respondida com estudos epidemiológicos, toxicológicos, experimentais, in vitro e utilizando extrapolaçóes ou modelagem matemática, para estabelecer a probabilidade de ocorrência. (NATIONAL RESEARCH COUNCIL, 1983, OMENN; FAUSTMAN, 2005) A última etapa da avaliação é a caracterização do risco, no sentido clássico. É um momento de síntese, quando se estabelecem os danos possíveis de ocorrer e sua probabilidade (P), a severidade dos danos (S), o tempo de vida perdido (T) e as vulnerabilidades de exposição, como a intensidade de exposição (I), a freqüência de exposição $(\mathrm{F})$, a duração da exposição $(\mathrm{D})$, a população exposta $(\mathrm{N})$, os grupos populacionais $(\mathrm{G})$ e a acessibilidade à localização geográfica da população $(\mathrm{L})$.

A avaliação de riscos é um momento eminentemente técnico-científico, em que os modelos teóricos, os procedimentos experimentais e a validação dos resultados são os elementos dos estudos realizados (epidemiológicos, toxicológicos, in vitro e modelagem matemática, entre outros), para que possam ter rigor e legitimidade científica. Contudo, os modelos de avaliação não são independentes dos observadores e seus objetivos, conforme ressalta Czeresnia (2004, p. 448):

Construir um modelo para medir o efeito de uma causa, ou um conjunto de causas, exige um processo de 'purificação'. É necessário assumir algumas premissas que viabilizam o modelo, isolando os elementos que se deseja observar. Este processo constrói uma abstração do fenômeno estudado. $\mathrm{Na}$ medida em que o modelo é construído, o fenômeno passa a ser apreendido 
mediante uma representação, que reduz sua complexidade. A construção da representação é inerente à lógica do modelo, e é justamente a simplificação que viabiliza sua operacionalização.

A avaliação de riscos nem sempre é possível de ser realizada quantitativamente. No caso das radiaçóes ionizantes, por exemplo, as populaçóes estudadas (Hiroshima e Nagasaki, Chernobyl e pacientes de radioterapia) foram expostas a altas doses, com altas taxas de dose. Assim, foi necessária a utilização do princípio da precaução para postular que, por extrapolação dos resultados de exposição em altas doses, deve-se considerar a relação dose $\mathrm{x}$ resposta linear, sem limiar threshold. (INTERNATIONAL COMMISSION ON RADIOLOGICAL PROTECTION, 1991) Situaçôes semelhantes também ocorrem nas exposiçóes a outros elementos físicos e químicos (KOH; JEYARATNAM, 2005, LIPPMANN; COHEN; SCHLESINGER, 2003), refletindo a complexidade dos processos de avaliação de riscos. Com base nas informaçôes da avaliação de riscos, inicia-se o processo de gerenciamento de riscos, realizado pela autoridade reguladora também composta de três etapas: estabelecimento das opçóes regulatórias e tomada de decisão, implantação das açóes de controle e comunicação dos riscos e avaliação das açôes de controle.

$\mathrm{Na}$ primeira etapa, são levantadas todas as possibilidades de açóes que podem minimizar os riscos, quando a viabilidade político-econômicocultural de cada uma das açóes deve ser avaliada. Geralmente, existem várias possibilidades de regulação, quando a melhor deve ser escolhida. $\mathrm{A}$ melhor opção não é necessariamente a de menor risco ou a que se deseja, é a opção possível no contexto avaliado. O resultado do juízo de valor será o estabelecimento dos limites de aceitabilidade e das açóes de controle necessárias para manter os riscos dentro destes limites. (LINDELL, 1996b, NATIONAL RESEARCH COUNCIL, 1983, OMENN; FAUSTMAN, 2005) No caso da vigilância sanitária, este é o momento de elaboração e publicação das normas de regulação sanitária.

A etapa seguinte é o momento de informar à sociedade sobre os riscos que estão sendo regulados e as açóes de controle que estão sendo imple- 
mentadas. Paralelo ao processo de comunicação, a autoridade reguladora deve adotar as medidas necessárias para que as açóes de controle sejam efetivamente cumpridas pelo segmento regulado. Uma autoridade reguladora autônoma, com recursos financeiros e técnicos capacitados, é condição sine qua non para a implementação das ações regulatórias. Contudo, a tradição das instituiçôes, do segmento regulado e da sociedade é fundamental para que as açôes de controle de riscos deixem de ser apenas normas para serem praticadas. (INTERNATIONAL ATOMIC ENERGY AGENCY, 1996, NATIONAL RESEARCH COUNCIL, 1983, OMENN; FAUSTMAN, 2005)

A última etapa é a avaliação de todo o processo. É o fim do primeiro ciclo e, talvez, demande o início de um novo ciclo de avaliação e gerenciamento de riscos. Para realizar a avaliação, entendida como um julgamento sobre uma prática social ou sobre qualquer dos seus componentes, com o objetivo de auxiliar na tomada de decisões, é necessário formular estratégias, selecionar abordagens, critérios, indicadores e padrôes. (SILVA, 2005)

No processo de gerenciamento de riscos, as açôes de vigilância sanitária estáo voltadas, em geral, para o controle de riscos e náo para a fonte de riscos. $\mathrm{Na}$ avaliaçáo de riscos, a fonte de perigo é identificada, relacionada aos danos e suas conseqüências, assim o risco é caracterizado. No gerenciamento de riscos, as formas de controle são identificadas, implantadas e avaliadas; assim é caracterizado o controle.

As normas sanitárias geralmente não regulamentam a ação das substâncias químicas, físicas ou biológicas; regulamentam ações, procedimentos, produtos e equipamentos que devem ser utilizados de modo que as tecnologias para a saúde produzam o máximo de benefício com o mínimo de riscos, considerando as questóes científicas, éticas, econômicas, políticas e sociais. As açôes de controle não estão relacionadas, necessariamente, às fontes de riscos. Podem estar relacionadas às condiçóes ambientais, de procedimentos, de recursos humanos ou gerenciais do próprio sistema de controle de riscos. Como as açôes da VISA estão voltadas, geralmente, para o controle de riscos 
e não para os riscos em si, torna-se difícil o estabelecimento da relação causaefeito.

A licença sanitária, por exemplo, é um conceito operativo que instrumenta a vigilância sanitária para controlar riscos, mas que não está relacionada diretamente a nenhuma fonte de risco. Um serviço de saúde funcionando sem licença sanitária representa um "risco" para o controle do sistema, mas pode não representar um risco no sentido clássico. Não é possível se afirmar quais são os danos que podem ocorrer e em que probabilidade. Até porque o serviço pode estar cumprindo todas as exigências técnicas e de segurança. Contudo, a ausência da licença representa uma situaçáo de risco potencial inaceitável para o controle do sistema, dado que este é um dos instrumentos estabelecidos para tal controle. Raciocínio semelhante pode ser utilizado para avaliar o registro de equipamentos e certificação profissional, entre outros.

A luminosidade dos negatoscópios, utilizados para visualizar as imagens radiográficas, é outro bom exemplo. A luminosidade inadequada do negatoscópio, apesar de não causar nenhum dano direto ao paciente, pode ocultar informaçóes radiológicas e provocar um erro de diagnóstico. Para a visualização dos diferentes tons de cinza, numa radiografia com densidade ótica entre 0.5 e 2.2, é necessário um negatoscópio com luminância entre 2.000 e 4.000 nit $^{12}$. (ABDULLAH, 2001) Então, qual é o risco da utilização de um negatoscópio com luminância de 500 nit? São tantas as variáveis envolvidas que a pergunta torna-se de difícil resposta. A possibilidade de erro ou perda de informação diagnóstica, por exemplo, não pode ser entendida como um dano ao paciente. $\mathrm{O}$ dano poderá ser causado quando a tomada de decisão do procedimento médico, baseado nas informaçóes diagnósticas incorretas ou incompletas, for efetivada. Assim, não é possível se determinar os danos que serão causados e quais as probabilidades de ocorrência. Não se pode afirmar, sequer, que ocorrerão danos. Contudo, é uma situação de risco potencial inaceitável, pois se sabe da luminosidade mínima necessária num negatoscópio para produzir uma condição confiável de diagnóstico.

${ }^{12}$ A unidade de luminância no Sistema Internacional é o $\mathrm{cd} / \mathrm{m}^{2}$, conhecido como nit. 
O risco potencial diz respeito à possibilidade de ocorrência de um agravo à saúde, sem necessariamente descrever o agravo e sua probabilidade de ocorrência. É um conceito que expressa o juízo de valor sobre exposição em potencial a um possível risco. É como se representasse o risco do risco.

Um importante aspecto do conceito de risco potencial refere-se à dimensão temporal das relações causais. Enquanto o risco clássico tem suas bases de avaliação em eventos ocorridos, o risco potencial tem suas bases causais de avaliaçáo nos acontecimentos que ocorrem no presente e os efeitos poderáo, ou náo, ocorrer no futuro. Assim, permite trabalhar com a dimensão temporal do risco voltado para o futuro ou para uma meta-realidade e náo para o passado. No caso das tecnologias para saúde, o elemento central no gerenciamento de riscos é o risco potencial que, apesar de não representar, necessariamente, uma relaçáo de causa e efeito definida, pode ser quantificado e classificado em níveis de aceitabilidade, conforme será discutido no Modelo de Avaliação de Risco Potencial (MARP), constituindo-se num importante conceito operacional da vigilância sanitária. Contudo, o risco potencial, como o risco clássico, não pode ser representado na maioria dos campos científicos apenas por um número. Deve ser entendido e avaliado dentro de um contexto e com limites de aceitabilidade estabelecidos pelos determinantes técnicos e sociais. Assim, as avaliaçóes realizadas pelas autoridades reguladoras no processo de gerenciamento de risco têm como indicadores, na maioria dos casos, os instrumentos de controle de riscos e, como consequência, uma medida de risco potencial, que vai indicar se as condiçóes de controle são aceitáveis ou não.

\section{Identificação e controle de riscos em radiodiagnóstico}

Os raios-X possuem energia suficiente para ionizar os átomos, similar às radiaçôes provenientes dos elementos radioativos; por isto são chamadas de radiaçóes ionizantes $(\mathrm{RI})$. As radiaçóes ionizantes podem ter procedência nuclear (radiaçóes $\alpha, \beta$ e $\gamma$ ) ou atômica (raios-X). Os raios-X e os raios $\gamma$ 
são ondas eletromagnéticas assim como a luz, as ondas de rádio (AM, FM e outras) e as ondas de telefone celular. O que as diferencia é a freqüência e, consequentemente, sua energia. Logo, os raios-X são ondas eletromagnéticas com energia suficiente para ionizar os átomos.

Inicialmente, não foi observado que a utilização das radiaçôes ionizantes, tal como todas as tecnologias, também traziam consigo perigos, intrínsecos e desconhecidos, no momento de sua incorporação às práticas sociais (BECK, 2003). O conhecimento dos possíveis danos associados à utilização das radiaçóes ionizantes pode ser melhor compreendido quando descritos em quatro períodos, representados pela identificação das exposiçóes (ocupacionais, médicas e públicas) e suas conseqüências.

O primeiro período (1895-1915) abrange os vinte anos iniciais da utilização dos raios-X: é caracterizado pelos primeiros relatos de danos; pela ausência quase completa de açóes de proteção contra os efeitos nocivos das RI; ausência de normas de proteção; rápida expansão das aplicaçóes dos raios-X e pelo surgimento das primeiras associaçóes e publicaçóes de radiologia, bem como pelo desenvolvimento tecnológico dos equipamentos e das práticas. Durante esse período, todas as lesóes identificadas eram observáveis clinicamente, pouco tempo após a irradiaçáo, ou seja, os efeitos eram imediatos. Provavelmente, como a nova descoberta não teve nenhuma expectativa de produzir qualquer efeito fisiológico, os pioneiros não conheciam motivos para se proteger dos raios-X. Talvez, o grande entusiasmo da descoberta e das aplicaçóes tenha contribuído para a falta de atenção quanto aos relatos de lesôes causadas pelos raios-X. (GLASSER, 1993; LINDELL, 1996b, MARTIN; SUTTON, 2002, MOULD, 1995a, 1995b, ROSENBUSCH; OUDKERK; AMMANN, 1995)

Os primeiros equipamentos utilizados para a realização de radiografia e fluoroscopia não tinham qualquer tipo de proteção ou direcionamento do feixe. Assim, produziam e emitiam raios-X praticamente em todas as direçôes, expondo não só o local de interesse radiográfico como também tudo e todos que estivessem ao redor da ampola. Uma radiografia, que hoje pode ser realizada com centésimos ou milésimos de segundo, era realizada com ex- 
posiçóes entre 20 a 40 minutos. Os exames de fluoroscopia chegavam a durar até uma hora e meia. (GLASSER, 1993; LINDELL, 1996b, MOULD, 1995a, 1995b, ROSENBUSCH; OUDKERK; AMMANN, 1995)

Além das aplicações médicas propriamente ditas, esse foi um período de exibiçôes e demonstraçôes da "nova fotografia”. Médicos, físicos, engenheiros, inventores e curiosos faziam testes e demonstraçóes públicas da nova maravilha, expondo-se às radiaçóes. Thomas Edison, por exemplo, organizou em 1896, em Nova York, uma demonstração pública da fluoroscopia, mostrando a imagem da mão dos visitantes. Nas demonstraçóes, tanto o público quanto a equipe ficavam ao lado do equipamento durante todo o tempo, expostos aos raios-X.

Como resultado dessas exposiçóes, em março de 1896, foi relatado o primeiro caso de lesão de pele devido à exposição aos raios-X e, até o final daquele ano, houve mais de 30 publicaçóes em revistas científicas e congressos, relatando lesóes de pele, queda de pelos/cabelos e problemas nos olhos. (GLASSER, 1993)

Mr. Dally, um dos assistentes de Thomas Edison em seus experimentos, teve uma grave lesão de pele que evoluiu continuamente até causar sua morte em 1904. Esta talvez tenha sido a primeira morte, de muitas, entre os pioneiros da utilização dos raios-X. Após a morte de Mr. Dally, Thomas Edison parou os trabalhos com raios-X. (GLASSER, 1993, LINDELL, 1996a, 1996b, MOULD, 1995a, ROSENBUSCH; OUDKERK; AMMANN, 1995) Nesses primeiros anos, mais de 300 mortes foram relacionadas, posteriormente, aos raios-X (NITSKE, 1971) e diversos foram os relatos de amputação de mãos e dedos (MOULD, 1995a, 1999b), cujos efeitos da exposição aos raios-X também estimulavam o interesse pela sua utilização das formas mais diversas. Glasser (1993) relata o caso de um francês que, em 1896, após tomar conhecimento de que a exposição aos raios-X poderia causar a queda dos cabelos, resolveu aplicar a técnica para retirar pêlos indesejados da face de mulheres. Em 1907, Kassabian publicou um livro sobre as aplicaçóes terapêuticas dos raios-X, utilizadas na Europa e 
nos Estados Unidos, listando mais de 30 indicaçóes, como a acne, queda de cabelo, lepra, tuberculose e epilepsia. (MOULD, 1995a)

Devido aos relatos dos efeitos nocivos dos raios-X, a Roentgen Society constituiu, em 1898, um comitê para avaliar os possíveis efeitos danosos dos raios-X. (MARTIN; SUTTON, 2002) Na época, as principais suspeitas sobre as causas dos danos eram associadas aos raios ultravioleta, aos efeitos provenientes de fenômenos elétricos da alta tensão e à possibilidade de contaminação por materiais provenientes da ampola. Contudo, mesmo sem recomendaçóes ou normas regulamentadoras, a experiência levou os radiologistas a iniciarem, por volta de 1905, o uso de aventais, luvas e máscaras de chumbo, bem como a blindagem da ampola de raios-X, alojando-a num invólucro de chumbo com uma abertura para a saída do feixe. (GLASSER, 1993; MOULD, 1995a, 1995b; ROSENBUSCH; OUDKERK; AMMANN, 1995)

Nesse período, as radiaçóes ionizantes não haviam sido identificadas, de forma direta, como uma fonte de perigo. Mesmo nos relatos que descreviam a clara associação entre a realização de um exame e lesóes de pele ou queda de cabelos, ainda restava a dúvida se o que causava o dano eram os raios-X ou outros possíveis elementos físicos e químicos presentes no processo.

O segundo período (1915-1945) caracteriza-se pelo início da identificação das radiações ionizantes como uma fonte de perigo e a consequente intervenção das associaçôes profissionais e dos governos, no sentido de recomendar e regulamentar normas de proteção radiológica (radioproteção). Importantes avanços aconteceram, com relação à implantação de novas tecnologias, visando à qualidade da imagem e a proteção dos trabalhadores. Tal período também foi marcado pela grande difusão da utilização das radiaçóes ionizantes, de forma banalizada, abusiva e até fraudulenta. Não eram conhecidos os efeitos tardios das radiaçóes ionizantes e não havia preocupação com doses em pacientes e indivíduos do público. Durante este período, todas as lesóes identificadas só ocorriam após determinada quantidade de exposição, 
ou seja, supunha-se existir um limiar threshold de exposição, a partir do qual os danos aconteciam e abaixo dele o uso das $\mathrm{RI}^{13}$ era considerado seguro.

Como conseqüência dos estudos realizados pelo Commitee of $X$-ray Injuries, constituído em 1898, a Röntgen Society publicou, em 1915, as primeiras recomendaçóes de proteção contra os efeitos prejudiciais dos raios-X. Esse primeiro comunicado, alertando sobre a necessidade de cautela no uso dos raios-X, foi voltado para os operadores, dando início formal à radioproteção. (LINDELL, 1996a, MARTIN; SUTTON, 2002)

No início dos anos 20 do século passado, diretrizes de radioproteção estavam sendo preparadas em vários países. Na Noruega, foi formado um grupo de trabalho, em 1922, para elaborar uma proposta de normas de radioproteção. Na Itália e na URSS, normas de radioproteção foram emitidas em 1925. Na Alemanha e EUA, vários grupos estavam trabalhando em recomendaçóes de radioproteção. Na Dinamarca, desde 1907, o uso de raios-X requeria licença e, em 1930, foi estabelecida uma lei regulando as aplicaçóes médicas. (LINDELL, 1996a) Em Londres, o British X-ray and Radium Committee publicou as primeiras recomendaçôes formais de radioproteção para radiodiagnóstico, aconselhando a utilização de blindagem no tubo de raios-X com $2 \mathrm{~mm}$ de chumbo, o uso de luvas de chumbo com proteção equivalente a $0,5 \mathrm{~mm}$ de chumbo e barreira para o operador. (MARTIN; SUTTON, 2002)

Em 1926, o Dutch Board of Health regulamentou o primeiro limite de exposição em 1 SED (Skin Erythema Dose - Dose de Eritema de Pele) por 90.000 horas trabalhadas. É o marco inicial da intervenção regulatória do Estado, estabelecendo legalmente limites para o uso dos raios-X.

Nos primeiros vinte anos do século XX, diversas foram as propostas de quantificar os raios-X. Como o eritema de pele era bem conhecido, foi proposto como uma referência de dose. Um eritema de pele (1 SED) correspondia à

${ }^{13}$ Nesse momento, o uso dos elementos radioativos já tinha se difundido tanto quanto o dos raios-X, revelando também seus efeitos danosos. Logo, em alguns momentos, não é possível se referir apenas aos efeitos ou estudos em radiodiagnóstico. 
quantidade de raios-X necessária para causar um eritema de pele. Alguns autores sugerem que 1 SED deveria corresponder a $6 \mathrm{~Gy}^{14}$. (LINDELL, 1996a) Como o estabelecimento da unidade de medida dos raios-X era de fundamental importância para as açóes de radioproteção, terapias e diagnósticos, o Primeiro Congresso Internacional de Radiologia (Londres), em 1925, teve como tema unidades e medidas e, como conseqüência, a criação do que hoje é conhecido como International Commission on Radiation Units and Measurements - ICRU (Comissão Internacional de Unidades e Medidas de Radiação).

Dado que o SED era uma medida que dependia de diversos fatores e de difícil comparação, o ICRU recomendou, no Segundo Congresso Internacional de Radiologia (Estocolmo), em 1928, o röntgen (R) como a unidade de medida, baseando-se na ionização do ar. Durante o evento, também foi criada a comissão conhecida hoje como International Commission on Radiological Protection - ICRP (Comissão Internacional de Proteção Radiológica). Desde então, a ICRU e a ICRP têm desenvolvido um importante papel na radioproteção, sendo duas das mais importantes e respeitadas instituições da área. Ao final do referido congresso, a ICRP recomendou a proteção contra os efeitos potencialmente danosos da radiaçáo, informando que eram conhecidos os efeitos de danos aos tecidos superficiais, órgáos internos e ao sangue. Apesar de não incluir recomendaçóes de limites de dose, recomendou a restrição de horas trabalhadas e prolongamento das férias dos trabalhadores expostos às radiaçóes. (LOCHARD; SCHIEBER, 2000) Embora um estudo experimental com drosófilas, publicado na Revista Science, em 1927, com o título Artificial Transmutation of the Gene, tenha mostrado que mutação genética após irradiação era possível, todas as ações de radioproteção, até a década de 1940, foram direcionadas para evitar os efeitos diretos da radiação. (KELLERER, 2002)

${ }^{14} \mathrm{O}$ gray (Gy) é a unidade de dose absorvida, no Sistema Internacional e para se ter uma idéia, a Portaria MS 453/98 estabelece como dose de referência para um raio-X do tórax (AP) 0,0004 Gy. 
Enquanto os governos de diversos países e instituiçóes da área da radiologia se voltavam para os estudos dos efeitos nocivos das RI e adoção de recomendaçôes e regulamentaçóes necessárias para evitar tais efeitos, o uso abusivo e até fraudulento das RI chegava a níveis alarmantes. Mesmo os raios-X, tendo certa dificuldade de serem utilizados por leigos, pois necessitavam de instalação e alguns conhecimentos para operação, não foram impedimento para que fossem disponibilizados equipamentos nas sapatarias, para visualização da acomodação dos pés nos novos sapatos (inclusive por crianças) ou em salas particulares, para pessoas que desejavam pagar por uma fotografia do próprio esqueleto. Contudo, os fatos mais graves se deram com a utilização de materiais radioativos. Até a década de 30, diversos foram os cremes faciais à base de materiais radioativos que ofereciam rejuvenescimento da pele; tinta luminosa contendo radium era utilizada para pintar mostradores de instrumentos e miras de rifles; a bebida Zoé. Le soda atomique era anunciada como uma fonte de energia e um tônico chamado Radithor era vendido para solucionar mais de 150 problemas, que iam desde pressão alta até impotência. (FELDMAN, 1989; LINDELL, 1996a, 1996b; MARTINS, 1997, 1998; MOULD, 1995a, 1995b, 1998) Um dos casos que mais contribuiu para o fim dos abusos e a adoção de medidas restritivas ao uso das RI, foi a morte de Eben Byers, um conhecido milionário e esportista, com severos danos causados pelo consumo de vários frascos do Radithor. (LINDELL, 1996a)

Como forma de lembrar os primeiros trabalhadores no campo das radiaçóes ionizantes a Germany Röntgen Society em Hamburgo, na Alemanha, ergueu, em 1936, um memorial aos mártires dos raios- $X$ e do radium. Inicialmente, este memorial tinha 169 nomes de 15 diferentes naçóes, chegando a 360 nomes em 1959. (MOULD, 1995a)

No início da década de 30, os limites de dose (ou dose tolerável) passaram a ser estabelecidos em röntgen (R) e, em 1934, a ICRP publicou 
sua primeira sugestấo quantitativa de limite de dose, que foi de $0,2 \mathrm{R} /$ dia $(-500 \mathrm{mSv} / \mathrm{ano})^{15}$.

Uma importante e pioneira ação de proteção radiológica para trabalhadores foi introduzida pelo britânico National Physical Laboratory NPL (Laboratório Nacional de Física). O NPL, em 1937, implantou um sistema de monitoração de dose dos seus trabalhadores, utilizando filmes de raios-X odontológicos. Este serviço foi estendido aos hospitais em 1942. (MARTIN; SUTTON, 2002)

O terceiro período (1945-1980) da identificação dos riscos associados às radiaçóes ionizantes caracterizou-se pela constatação dos efeitos estocásticos, cujos estudos tiveram de incorporar o campo da avaliaçáo/gerenciamento de riscos e conduziram ao consenso internacional para adoção de um modelo de radioproteção, para baixas doses, baseado na relação LNT linear no-threshold entre exposição e efeito. Ou seja, não existe exposição à radiação que não tenha possibilidade de causar danos. Assim, os organismos internacionais passaram a reconhecer a importância da proteção dos pacientes e indivíduos do público, incluindo-os em suas publicaçôes (normas e recomendaçóes). Esse fato se refletiu na Publicação da ICRP 26, em 1977, que introduziu os princípios básicos da radioproteção (justificação, limitação de dose e otimização).

As conseqüências das bombas de Hiroshima e Nagasaki, em agosto de 1945, foram fundamentais para mostrar ao mundo a possibilidade dos efeitos nocivos das radiaçóes ionizantes, que ainda não tinham despertado a atenção da comunidade política e científica, mesmo depois que diversos estudos experimentais com drosófilas mostraram a possibilidade de efeitos genéticos (BAUER; DEMEREC; KAUFMANN, 1938; SCHULTZ, 1933; SMITH, 1935). Os novos efeitos, conhecidos como efeitos estocásticos das RI, mostraram-se complexos e demandaram novos estudos, conceitos e tecnologias para seu controle. Inauguraram uma nova Era, que não se podia

${ }^{15}$ Como será abordado posteriormente, a recomendação atual da ICRP é de $20 \mathrm{mSv} / \mathrm{ano}$. O sievert (Sv) é a unidade de medida de dose efetiva, no Sistema Internacional. 
mais estabelecer um limite de dose que separava o seguro do perigoso e as açóes de radioproteção não podiam eliminá-los e sim reduzi-los. Findava-se uma Era, em que a utilização pacífica e voltada, principalmente, para as aplicaçóes médicas construiu uma percepção positiva das radiaçóes ionizantes. Após a bomba atômica mostrar seu poder de destruição, as radiaçóes ionizantes passaram a ser associadas a medo, guerra e horror. Contudo, se, por um lado, os efeitos imediatos e devastadores das bombas causaram perplexidade na humanidade que nunca tinha visto tamanho poder de destruição, por outro lado, os efeitos observados nos anos seguintes conduziram à percepção dos efeitos tardios relacionados à exposição a baixas doses e que têm um caráter probabilístico. (KELLERER, 2002, LINDELL, 1996b, LOCHARD; SCHEIBER, 2000)

Alguns anos após as bombas atômicas explodirem, os médicos observaram um inesperado número de casos de leucemia entre a populaçáo de Hiroshima. Foi então percebido que a radiação poderia transformar a célula e iniciar um processo que conduziria à leucemia. Foi o reconhecimento de que a radioproteção não poderia propiciar a segurança perfeita, podendo apenas reduzir os riscos. (KELLERER, 2002)

Os estudos epidemiológicos foram fundamentais para estabelecer as primeiras relaçóes entre exposição às radiaçóes e modificaçóes celulares. No entanto, não conseguiram responder a muitas questôes, levando o campo da radioproteção a utilizar extrapolações matemáticas e adotar o princípio da precaução. (LOCHARD; SCHEIBER, 2000, ROMERIO, 2002) Os efeitos das radiaçóes ionizantes, em baixas doses e baixas taxas de doses, continuam sendo estudados e ainda não houve consenso na comunidade científica sobre seus efeitos. Como consequência das primeiras informaçóes sobre os sobreviventes das bombas, o governo inglês publicou, em 1948, a primeira recomendação de monitoração de trabalhadores com filmes ou condensadores para avaliação de dose, em conjunto com exames médicos periódicos, incluindo contagens de células do sangue. Logo em seguida, em 1950, a ICRP voltou a funcionar, recomendando uma redução de dose para trabalhadores e alertando sobre os potenciais riscos de leucemia, doenças 
malignas, efeitos genéticos, danos superficiais e catarata. (MARTIN; SUTTON, 2002)

Com a corrida armamentista, no período da chamada Guerra Fria, a realização de testes nucleares se intensificou e as doses de radiação, medidas em diversas partes do mundo, alertaram a opiniáo pública e despertaram a preocupação de cientistas com relação aos possíveis efeitos genéticos. (LOCHARD; SCHEIBER, 2000) Para tentar responder as dúvidas sobre os efeitos de baixas doses de radiação, ainda na década de 50, foram criados alguns Comitês, que continuam funcionando. A Organização das Naçóes Unidas (ONU) estabeleceu o United Nations Scientific Committee on the Effects of Atomic Radiation - UNSCEAR; nos EUA, a Academia Nacional de Ciências criou o comitê Biological Effects of Ionizing Radiation e, em Londres, foi instalado o Medical Research Council.

A primeira publicação sobre o tema foi elaborada pela UNSCEAR, em 1958 e algumas questôes importantes devem ser ressaltadas. A primeira refere-se à questão da classificação das radiaçôes, com relação às fontes de produção, ou seja, as radiaçóes provenientes de fontes produzidas pelo homem (equipamentos ou elementos radioativos) e as radiaçóes provenientes de fontes naturais (radiação cósmica, radiação da terra, do próprio corpo e radiação do ar). Em seguida, foi dado o primeiro passo na avaliação dos efeitos da radiação com a definiçáo de dose como "a dose de radiação em qualquer material é a energia absorvida por massa de unidade do material. Às vezes, é útil descrever exposição à radiação sem referência para qualquer material presente" (UNSCEAR, 1958, \$21), sendo a unidade de dose de exposição o roentgen $(\mathrm{R})$ e o rad radiation absorbed dose, a unidade de dose absorvida. Contudo, a dose absorvida em rad náo informava sobre as características especificas de cada tipo de radiação nem sobre seus efeitos biológicos. Assim, foi introduzido o conceito de Relative Biological Effectiveness - RBE (Efetividade Biológica Relativa) ${ }^{16}$, para que fosse possível estabelecer uma

${ }^{16}$ A RBE da energia depositada no tecido depende do tipo de radiação, do processo biológico, nível e taxa de exposiçáo. Se, por exemplo, a RBE dos raios alfa tem o valor 10 , 
unidade de dose biologicamente equivalente ao rad, ou seja, uma grandeza que relacionasse a quantidade de radiação com os efeitos biológicos ${ }^{17}$, sendo proposto que:

É conveniente ter uma unidade de dose biologicamente equivalente ao rad, isto é, levar em conta o RBE. Esta unidade é o rem, definido pela relaçáo Dose em rem $=$ Dose em rad $\times$ RBE. Neste relatório, doses de tecido são expressas geralmente em rem. Nos cálculos, valores convencionais de RBE que têm sido usados são: 1 para raios-X, radiação gama e beta, e 10 para a radiação alfa. (UNSCEAR, 1958, \$25)

O rem foi a unidade de medida de dose utilizada para estimar o risco. Enquanto o rad é uma unidade de medida física, quantitativamente determinada, que deve ter o mesmo valor, independente do método ou do equipamento utilizado, o RBE foi estabelecido com base em estudos sobre os efeitos biológicos das radiaçóes ionizantes, que dependem dos modelos e dos avaliadores. Assim, o rem teve por base uma medida física, mas era determinada teoricamente. Foi utilizada na radioproteção para comparar os possíveis efeitos das radiaçóes e propor níveis de aceitabilidade de dose. Esse conceito foi desenvolvido para dar conta das demandas da radioproteção, sendo utilizado para avaliar baixas doses e suas conseqüências, não devendo ser usado em altas doses, quando os efeitos são determinísticos e a medida utilizada era a dose absorvida em rad.

Estabelecida a forma de medir as radiaçóes, tratou-se então dos seus efeitos, classificando-os segundo a forma de dano celular ${ }^{18}$ (direto ou

uma dose de raios alfa de 1 rad vai produzir o mesmo grau de efeito biológico de uma dose de 10 rad de raios-X.

${ }^{17}$ Os efeitos biológicos da radiação podem ser, entre outros: leucemia, tumores sólidos e catarata.

${ }^{18}$ A radiaçáo pode causar um dano direto em importantes estruturas moleculares ou pode interagir com as moléculas de água, produzir radicais livres, e danificar as células indiretamente. 
indireto) e com relação ao tipo de célula e efeito produzido ${ }^{19}$ (somático ou genético). Com essa publicação da UNSCEAR (1958), mostrando os primeiros resultados dos estudos com baixas doses de radiação, a comunidade científica internacional reconheceu a possibilidade de ocorrência de efeitos rádio-induzidos do tipo estocástico, para níveis de exposição bem abaixo dos relatados em efeitos determinísticos. (LOCHARD; SCHEIBER, 2000) Como esses últimos eram relativamente simples de serem evitados, pois só ocorrem após um limite de exposição, os efeitos estocásticos passaram a ser a principal preocupação, levando à necessidade de utilização do conceito de risco. (LINDELL, 1996a)

Contudo, não existiam informaçóes de como seria a relação dose versus resposta. A solução para o problema, por falta de informaçóes científicas, teve que ser postulada. Assim, utilizando o princípio da precaução, a ICRP propôs o modelo Linear No-Threshold - LNT, linear sem limite de exposiçáo e devido à preocupação com os impactos econômicos do modelo, adotou o seguinte posicionamento:

[...] como qualquer exposição pode envolver algum grau de risco, a Comissão recomenda que qualquer exposição desnecessária seja evitada, e que todas as doses sejam mantidas tão baixo quanto razoavelmente exeqüíveis, levando em consideração as questóes econômicas e sociais. (INTERNATIONAL COMMISSION ON RADIOLOGICAL PROTECTION, 1966)

Desse modo, bem antes de ser aplicado na proteção contra outros tipos de riscos, a ICRP utilizou o Princípio da Precaução, um valioso instrumento protetor como uma primeira resposta para o novo. $\mathrm{O}$ reconhecimento pela ICRP , em 1959, que não havia nenhum limiar, em que baixas doses pudessem induzir leucemia e que a incidência era proporcional à dose,

${ }^{19}$ Os efeitos somáticos estão relacionados aos efeitos, apenas, no indivíduo que sofreu a ação da radiação, enquanto o efeito genético refere-se aos efeitos apenas nos descendentes de quem sofreu ação da radiação. 
representou um marco importante da formulaçáo teórica dos riscos em radiaçóes ionizantes, pois estabeleceu a impossibilidade de recomendação de um limite de dose, abaixo do qual não haveria riscos. (INTERNATIONAL COMMISSION ON RADIOLOGICAL PROTECTION, 1959, LOCHARD; SCHEIBER, 2000, STARR, 2003)

Após um período de intensas pesquisas teóricas e experimentais, em 1977, a ICRP , com a Publicação 26, estruturou as bases do formalismo da radioproteção, que continua sendo utilizado, com as devidas atualizações, até os dias atuais. Assim, introduziram-se novos conceitos e propostas. A medida de dose para fins de radioproteção passou a ser a dose equivalente efetiva, e a unidade sievert (Sv) substituiu o rem. A expressão limite de dose foi substituída por dose máxima permitida Maximum Permissible Dose-MPD e as MPD's para trabalhadores e indivíduos do público foram propostas em $50 \mathrm{mSv} /$ ano e $5 \mathrm{mSv} / \mathrm{ano}$, respectivamente. Foi introduzido também o conceito de detrimento ${ }^{20}$, que levava em consideração questôes de saúde, econômicas e sociais. Outra importante inovação foi o estabelecimento dos três princípios da radioproteção ${ }^{21}$ : o princípio da justificação, o princípio da limitação de dose e o princípio da otimização. (INTERNATIONAL COMMISSION ON RADIOLOGICAL PROTECTION, 1977; LINDEL, 1996a)

As preocupaçóes relacionadas à possibilidade dos raios-X causarem leucemia e efeitos genéticos induziram a realização de estudos sobre as exposiçóes em radiodiagnóstico. Um dos primeiros e mais completo estudo foi realizado pelo Comitê Adrian, na Inglaterra, cujos primeiros resultados foram publicados em 1960 e mostraram que as doses entre diferentes serviços tinham grandes variaçóes, chegando a diferir por um fator de $10.000 \mathrm{em}$ exames de coluna lombar. (WALL; SHRIMPTON, 1998) Os resultados

${ }^{20}$ Detrimento é um conceito que combina probabilidade, severidade e tempo de manifestação de um dano. (INTERNATIONAL COMMISSION ON RADIOLOGICAL PROTECTION, 1991)

${ }^{21}$ A explicitação e discussão dos princípios da radioproteção serão realizadas, logo em seguida, com os conceitos específicos das aplicaçóes médicas das radiações ionizantes estabelecidos na ICRP 73. 
despertaram a atenção para a necessidade de harmonização das técnicas utilizadas nos exames de radiodiagnóstico, cujas primeiras recomendaçóes foram publicadas pela ICRP, em 1954, evoluindo posteriormente para o conceito de nível de referência de radiodiagnóstico diagnostic reference levels com a ICRP 73, de 1996. (DREXLER, 1998) A partir do final do século $\mathrm{XX}$, o nível de referência de radiodiagnóstico e a qualidade da imagem tornaram-se os fundamentos da regulação de risco em radiodiagnóstico.

A última década foi marcada pelo crescente conhecimento da sociedade em relação aos efeitos das novas tecnologias sobre o homem e o ambiente. As evidências científicas de que as radiações ionizantes e diversas substâncias químicas, que eram comercializadas e consumidas, provocavam malefícios indicaram que o setor produtivo não tinha condiçóes de controlar os riscos à saúde, relativos à sua produção. Surgiram então, fortes pressôes sociais para que houvesse uma intervenção governamental no processo de controle de riscos. Assim, devido à comprovada incapacidade do setor produtivo praticar a auto-regulação, os estados passaram a desempenhar o papel exclusivo da regulação de riscos à saúde, em maior ou menor intensidade, dependendo do grau de pressão e consciência de cada sociedade. (LUCCHESE, 2001; NATIONAL RESEARCH COUNCIL, 1983; SLOVIC, 2000) Segundo Beck (2003), esse é o momento em que a sociedade evoluiu de simples produtora de riscos para produtora e conhecedora dos riscos.

Essas novas tecnologias e suas regulaçóes demandaram conhecimento especializado dos profissionais que atuavam na área e o desenvolvimento de estudos sobre o desempenho, efetividade e formas de controle. Como resultado, surgiram, na década de 1970, as primeiras recomendaçóes e protocolos de controle de qualidade, bem como as primeiras regulamentaçôes da área. (BUNGER et al., 1976, BURKHART, 1980, GOLDMAN, 1979, HENDEEW; ROSSI, 1980a, 1980b, NORWEGIAN SOCIETY OF MEDICAL RADIATION PHYSICS, 1980, ORGANIZAÇÃO MUNDIAL DE SAÚDE, 1982)

No final da década de 1970, nos EUA e na Europa, estudos mostraram uma diferença de dose de até 30 vezes, para os mesmos exames realizados em 
diferentes serviços. (WALL; SHRIMPTON, 1998) Neste mesmo período, três estudos desenvolvidos de forma independente e simultânea, nos EUA, indicaram que as baixas performances dos equipamentos eram a principal causa da rejeição de radiografias, devido à qualidade da imagem, inadequada para os fins diagnósticos que se propunham. A redução de 50\% nos índices de rejeição das radiografias representaria uma economia de U\$235 milhôes/ ano para os serviços de radiodiagnóstico americanos. (ORGANIZAÇÃO MUNDIAL DE SAÚDE, 1982)

Foi nesse contexto que, em 1979, aconteceu em Neuherberg, Alemanha, um seminário com especialistas da área de radiologia. Nesse evento, concluiuse que um importante passo no desenvolvimento de estudos sobre eficiência/ eficácia seria a adoção, por todos os países, de programas de garantia de qualidade em radiodiagnóstico, com o objetivo de melhorar a qualidade da imagem, reduzir as doses e os custos de funcionamento, sendo consenso que a Organização Mundial de Saúde (OMS) e a Agência Internacional de Energia Atômica (IAEA) deveriam ter um papel catalisador, no sentido de difundir a implantação dos programas. Foi ressaltado, ainda, que apenas um limitado número de países tinha iniciado programas nacionais de garantia de qualidade em radiodiagnóstico. Entretanto, um grande número deles tinha iniciativas locais que dependiam do interesse particular dos especialistas (radiologistas, físicos médicos, técnicos). (ORGANIZAÇÃO MUNDIAL DE SAÚDE, 1982)

O quarto período (1980-2006) na identificação e controle dos riscos em radiaçóes ionizantes teve como principal característica a ampliação do conceito de risco, no campo da saúde, em especial na radioproteção, com a consequente consolidação do conceito de qualidade, como fundamental no processo de controle dos riscos. Esse importante aspecto se refletiu em diversas normas e recomendaçóes, que passaram a ter como foco central a implantação e fiscalização de Programas de Garantia de Qualidade (PGQ) ${ }^{22}$

${ }^{22} \mathrm{O}$ PGQ consta de um conjunto de atividades, cujo objetivo é garantir que todos os trabalhos de controle de qualidade sejam efetivos. O objetivo do controle de qualidade é 
nos serviços de radiodiagnóstico, inclusive no Brasil. Também nesse período, deu-se a constituição da avaliação de riscos como uma área de conhecimento, com um formalismo teórico e metodológico próprio, de fundamental importância para a avaliação e regulação dos riscos em radiodiagnóstico, bem como dos diversos riscos à saúde e ao ambiente. (BRASIL. Ministério da Saúde. Secretaria de Vigilância Sanitária, 1998, INTERNATIONAL ATOMIC ENERGY AGENCY, 1996, 2006, INTERNATIONAL COMMISSION ON RADIOLOGICAL PROTECTION, 1996, ORGANIZAÇÃO MUNDIAL DE SAÚDE, 1982, THOMPSON; DEISLER; SCHWING, 2005)

O marco inicial desse período foi o "Workshop" realizado em Neuherberg, em 1980, organizado pelo governo alemão e a OMS, com a perspectiva de estabelecer recomendaçóes, visando incentivar e orientar açóes das autoridades reguladoras, das comissóes internacionais e dos serviços, no sentido de melhorar a efetividade dos radiodiagnósticos. As recomendaçóes do evento foram publicadas em 1982, pela OMS, num guia intitulado Quality Assurance in Diagnostic Radiology (ORGANIZAÇÃO MUNDIAL DE SAÚ$\mathrm{DE}, 1982)$, que representa um referencial histórico no conceito de controle de riscos em radiodiagnóstico, estabelecendo as bases teóricas e operacionais para a regulação na área.

O foco dos riscos em radiodiagnóstico, que estava basicamente direcionado para os possíveis danos causados em pacientes, trabalhadores e indivíduos do público, devido às exposiçôes aos raios-X, sofreu grande mudança de concepção. Foi a primeira recomendação internacional estabelecendo que os principais objetivos de controle, em serviços de radiodiagnóstico, deveriam visar o diagnóstico correto, a redução das doses e dos custos dos serviços, ou seja, o principal risco associado ao radiodiagnóstico passa a ser entendido como a informação diagnóstica incorreta e não os possíveis efeitos biológicos causados pelos raios-X.

proporcionar uma qualidade que seja satisfatória, adequada e econômica. Os programas de controle de qualidade são os segmentos do PGQ responsáveis pelas medidas, qualidade da imagem e integridade dos equipamentos. (THOMAS, 1973) 
A tríade, que ficou conhecida como o princípio dos 3 D's (Diagnostic, Doses and Dólares), representa a necessidade de garantir as melhores informaçóes diagnósticas, para que se possa ter a melhor decisão sobre o tratamento, ou seja, em primeiro lugar, está a preocupação com o risco do erro de diagnóstico ou com informaçôes diagnósticas não completas. Em segundo lugar, está a preocupação com as doses (nos pacientes, trabalhadores e indivíduos do público) e, em terceiro lugar, os custos de funcionamento dos serviços que, sendo otimizados, possibilitam a ampliação do atendimento à população. (AICHINGER, 2004; BRITISH INSTITUTE OF RADIOLOGY, 2001; GRAY, 1983; ORGANIZAÇÃO MUNDIAL DE SAÚDE, 1982; ORGANIZAÇÃO PANAMERICANA DE SAÚDE, 1997; STEVENS, 2001)

Além do princípio dos $3 \mathrm{D}$ 's, dois aspectos se destacaram: o primeiro refere-se ao entendimento do radiodiagnóstico como um processo em que o equipamento de raios-X é, apenas, um dos componentes, tão importante para os fins diagnósticos quanto os chassis, écrans, mesas radiográficas, grade antidifusora, filmes, produtos químicos radiográficos, processadora de filmes, negatoscópio e equipe técnica especializada. $\mathrm{O}$ segundo aspecto refere-se às responsabilidades, pois, quando o tema é risco, não se pode deixar de abordar essa questão. (BECK, 2003) Dessa forma, é recomendada a implantação de sistemas nacionais, coordenados por uma autoridade reguladora e com responsabilidade compartilhada entre o Estado, os proprietários dos serviços, os fabricantes, os profissionais que atuam na área e suas associações, com o apoio das instituiçóes acadêmicas e de pesquisas, tanto nacionais quanto internacionais. Tais aspectos passaram a balizar todas as recomendaçôes internacionais em radiodiagnóstico. (INTERNATIONAL ATOMIC ENERGY AGENCY, 2006; ORGANIZAÇÃO MUNDIAL DE SAÚDE, 1982; ORGANIZAÇÃO PANAMERICANA DE SAÚDE, 1997)

O processo de implantação das regulamentaçóes nacionais, estabelecendo a obrigatoriedade de PGQ's em radiodiagnóstico, teve início ainda na década de 80 (EURATOM 4666/84; ALEMANHA, 1987; NCRP 99, 1988; NRPB, 1988); mas, foi na década de 90, que as regulamentaçóes 
foram difundidas por todo o mundo (MQSA, 1992; ARGENTINA. Ministerio de la Salud, 1993; MÉXICO. SSa Salud Ambiental, 1996; BRASIL. Ministério da Saúde. Secretaria de Vigilância Sanitária, 1998; ESPANHA, 1999). Devido à consolidação da Comunidade Européia e a consequente necessidade de harmonização normativa, na segunda metade da década de 90, foram editadas as diretivas básicas de radioproteção geral para a Comunidade Européia (EURATOM 29, 1996) e de radioproteção em exposições médicas (EURATOM 43, 1997), bem como publicaçôes técnicas específicas de qualidade em radiodiagnóstico da Comissão Européia. (EUROPEAN COMISSION, 1996a, 1996b, 1996c, 1996d)

Uma questáo importante do processo de regulamentação e implantação de PGQ's em radiodiagnóstico refere-se ao período de publicação, implantação e avaliação das normas. Nos países denominados desenvolvidos, o processo aconteceu nos últimos vinte anos do século passado, conforme mostram diversos estudos que concluem pela importância dos PGQ's e a relação positiva entre a qualidade da imagem, a redução das doses e dos custos. (BERG et al., 1998, BURKHART, 1980, CHEVALIER et al., 1998, HENDEEW; ROSSI, 1980a, 1980b, KARILA, 1988, LEWELLEN; GRAHAM, 1981, MACCIA; CASTELLANO, 1994, MILLER; STOLTZFUS; LATSHAW, 1981, NORWEGIAN SOCIETY OF MEDICAL RADIATION PHYSICS, 1980, POMBAR, 1998, REGULLA; EDER, 2005, ROSSI et al., 1981, WACH; RIEDE, 1993, YOUNG; RAMSDALE; BIGNELL, 1998) No bloco dos chamados países em desenvolvimento, os estudos sobre os serviços de radiodiagnóstico passam a ser mais frequentes a partir do início deste século e mostram a situação de baixa qualidade dos exames realizados, indicando a necessidade de implantação de PGQ's, mesmo após quase dez anos de publicação de normas nacionais. (INTERNATIONAL ATOMIC ENERGY AGENCY, 2004; ORGANIZAÇÃO PANAMERICANA DE SAÚDE, 2001)

Em 1985, a ICRP formalizou um grupo de trabalho, com o objetivo de revisar e atualizar a Publicação 26, de 1977. Em novembro de 1990, a versão final foi aprovada e publicada (INTERNATIONAL COMMISSION ON 
RADIOLOGICAL PROTECTION, 1991), ressaltando que não irá mais considerar a palavra "risco" como sinônimo de probabilidade ${ }^{23}$.

Considerando a grande abrangência da ICRP 60 e a necessidade de uma publicação específica para as aplicaçôes médicas das radiaçôes ionizantes, foi publicada, em 1996, a ICRP 73. (DREXLER, 1998) Consolidando os conceitos da ICRP 26, os efeitos das radiaçóes ionizantes foram agrupados em determinísticos e estocásticos. Os efeitos determinísticos acontecem quando a irradiação, geral ou localizada, em um órgão ou tecido, provoca mais morte celular do que pode ser compensado pelo organismo (limiar de efeitos clínicos). Acima desse limiar, a severidade do dano aumenta com a dose. Apesar de possuírem o caráter determinístico, podem ser reversíveis ou náo. Também podem ser entendidos como efeitos para os quais existe um limiar de dose necessário para sua ocorrência e cuja gravidade aumenta com o aumento da dose. (INTERNATIONAL COMMISSION ON RADIOLOGICAL PROTECTION, 1991, 1996) Por seu lado, os efeitos estocásticos acontecem quando a irradiação geral ou localizada, num órgão ou tecido, provoca menos morte celular do que pode ser compensado pelo organismo. A morte de algumas células pode não significar nenhum dano e a modificação de uma única célula pode provocar um câncer. Este tipo de efeito possui um caráter probabilístico. Assim, o aumento da dose provoca o aumento de probabilidade de ocorrência do dano e não da severidade, não existindo um limiar de dose para sua ocorrência. A probabilidade total dos efeitos estocásticos (câncer fatal, não fatal e efeitos hereditários) é de

23 “Nas publicaçóes prévias, por motivo de simplicidade, a Comissão tinha usado o termo 'risco' como um sinônimo para probabilidade de um efeito nocivo. Contudo, fora do campo da radioproteção, 'risco' tem muitos outros significados. [...]. Os diferentes significados têm causado confusôes nas comunicaçóes transdisciplinares [...] Com um extenso significado de palavras, 'risco' é mais um conceito do que uma quantidade, embora também possa ser considerada uma quantidade multi-dimensional" [...] "O termo 'risco' é melhor utilizado em expressóes como 'risco aceitável', 'riscos das radiaçóes' ou 'avaliação de riscos', que nesta publicação não é sinônimo de 'avaliação de probabilidade”". (INTERNATIONAL COMMISSION ON RADIOLOGICAL PROTECTION, 1991, p. 165) 


\section{7,3\%/Sv. (INTERNATIONAL COMMISSION ON RADIOLOGICAL}

PROTECTION, 1991, 1996)

Os desenvolvimentos científicos e tecnológicos, entre o final do século passado e início deste século, contribuíram para importantes avanços nos estudos sobre os efeitos das radiaçóes ionizantes a baixas taxas de dose e baixas doses. A publicação da Academia Francesa de Ciências (TUBIANA et al., 2005) e a publicação do primeiro draft revisado, que deverá substituir a International Commission on Radiological Protection (1991), colocam mais uma vez em cena dúvidas sobre o modelo sem limiar de exposição, o LNT. A publicação francesa aponta para a possibilidade de existência de limiar de exposição, paraefeitosestocásticos, além detrazerevidências, com experimentos in-vitro, de possíveis efeitos benéficos das RI (hormesis) abaixo de $100 \mathrm{mSv}$. Embora tenha havido evidências de threshold e hormesis em baixas doses, continua sendo consenso, para propósitos regulatórios e de radioproteção, a utilização do princípio da precaução e a manutenção do modelo com LNT, conforme mostra o texto do draft da ICRP (INTERNATIONAL COMMISSION ON RADIOLOGICAL PROTECTION, 2005):

(56) Então, o sistema prático de proteção radiológica recomendado pela Comissão continuará sendo fundamentado na suposição que em doses abaixo de $100 \mathrm{mSv}$, um determinado incremento em dose produzirá um incremento diretamente proporcional na probabilidade de incorrer câncer ou efeitos hereditários atribuíveis à radiação, uma hipótese que é conhecida como "linear sem limiar" ou LNT. Essa visão concorda com a publicação UNSCEAR (2000) e a NAS/NRC (2006). Por outro lado, um recente relatório da Academia Francesa (2005) discute em defesa de um limiar prático para risco de câncer de radiação.

Esse 'draft' também propóe uma redução da probabilidade total dos efeitos estocásticos de $7,3 \times 10^{-2} / \mathrm{Sv}$ para $6,0 \times 10^{-2} / \mathrm{Sv}$, que representa uma redução de quase $18 \%$. Isto contribuiu no sentido de quantificar a radiação, a ICRP 60 consolidou a dose absorvida (D), como a quantidade 
dosimétrica fundamental, introduzindo novas grandezas dosimétricas. No Sistema Internacional de Medidas, a unidade de dose absorvida é o gray (Gy), que representa a quantidade de energia de 1 joule (J) depositada em uma massa de $1 \mathrm{~kg}$. A dose absorvida é mais apropriada para a avaliação dos efeitos determinísticos, sendo a grandeza medida com detectores de radiação, servindo de base para a definição de dose efetiva (E), cuja unidade é denominada sievert (Sv) e está associada aos efeitos estocásticos. Vale ressaltar que a dose efetiva leva em consideração não apenas a quantidade de radiação que chega em um meio, medida pela dose absorvida, mas também os diferentes efeitos biológicos causados pelos diferentes tipos de radiaçóes ionizantes e a sensibilidade dos diversos órgãos ou tecidos.

Dado que estão relacionados à proteção da saúde humana contra os efeitos nocivos das radiaçóes ionizantes, os estudos da área da radioproteçáo não podem ser conduzidos apenas por consideraçóes científicas. Suas bases teóricas, necessariamente, incluem os julgamentos sociais e científicos, pois o principal objetivo é estabelecer as razóes que justifiquem o uso benéfico das radiaçóes, prevenindo a ocorrência dos efeitos determinísticos e reduzindo os efeitos estocásticos. Assim, foram consolidados os princípios básicos da radioproteçáo. O Princípio da Justificação estabelece que nenhuma prática deve ser realizada, a não ser que produza benefícios para os indivíduos expostos ou para a sociedade, suficientes para compensar o detrimento correspondente. (INTERNATIONAL COMMISSION ON RADIOLOGICAL PROTECTION, 1991) No entanto, as especificidades das aplicaçôes médicas das RI levou a International Commission on Radiological Protection (1996) a acrescentar que:

(41) Em princípio, a decisão para adotar ou continuar alguma atividade humana envolve uma revisão dos benefícios e desvantagens das possíveis opçóes. Esta revisão normalmente provê um número de procedimentos alternativos que serão mais benéficos que danosos. O processo mais elaborado de julgamento que define qual é o 'melhor', por exemplo, escolher entre o uso de raios-X ou ultra-som, é necessário e ainda mais complexo. O dano, mais 
estritamente o detrimento, a ser considerado não é limitado aos associados com a radiação - deve incluir outros detrimentos e os custos econômicos e sociais da prática. Freqüentemente, o detrimento de radiação será só uma parte pequena do total.

$[\ldots]$

(43) Existem três níveis de justificação de uma prática em medicina.

a) $\mathrm{O}$ primeiro e mais geral é o uso de radiação em medicina, que é aceito como fazendo mais benefício que prejuízo. Sua justificação é tomada como condição.

b) No segundo, um procedimento específico com um objetivo específico é definido e justificado, ou seja, radiografia de tórax para pacientes que mostram sintomas pertinentes. $\mathrm{O}$ objetivo desta justificação genérica é julgar se, na maioria dos casos, o procedimento radiológico aprimora o diagnóstico ou tratamento ou promove informação necessária sobre os indivíduos expostos. c) No terceiro nível, a aplicação do procedimento para um paciente deve ser justificada, isto é, a aplicação particular deve ser julgada se produz mais benefício que dano.

O Princípio da Otimização diz que a proteção radiológica deve ser otimizada de forma que a magnitude das doses individuais, o número de pessoas expostas e a probabilidade de ocorrência de exposiçóes mantenhamse táo baixos quanto possa ser razoavelmente exequível, tendo em conta os fatores econômicos e sociais. (INTERNATIONAL COMMISSION ON RADIOLOGICAL PROTECTION, 1991) Devido às especificidades das aplicaçôes médicas, deve-se considerar que:

(49) A otimização da proteção é o mais poderoso dos componentes do sistema de proteção radiológica. Ele pode penetrar todas as fases do uso das radiaçóes na medicina, desde o projeto dos locais e equipamentos até os procedimentos cotidianos. Seu uso começa no incentivo de uma forma de pensar em que qualquer tarefa pertinente é aprimorada. [...] 
(50) A otimização da proteção é normalmente aplicada em dois níveis: (1) o projeto e construção de equipamentos e instalaçôes e (2) os métodos cotidianos de trabalhar, chamados aqui de procedimentos de trabalho. Nas aplicaçôes não médicas, a fase de projeto é normalmente a mais importante, porque reduz a dependência dos fatores humanos nos procedimentos. Em medicina, ênfase deve também ser colocada na otimização de proteção dos procedimentos de funcionamento, porque estes têm uma influência direta no cuidado dos pacientes.

$[\ldots]$

(64) A otimização da proteção em exposiçôes médicas não necessariamente significa a redução das doses para o paciente. Por exemplo, o equipamento de radiografia diagnóstica usa freqüentemente grades anti-espalhamento para melhorar o contraste e resolução da imagem, ainda que a remoção da grade permita uma redução das doses entre 2 a 4 vezes.

O Princípio do Limite de Dose estabelece que a exposição normal dos indivíduos deve ser restringida de tal modo que não exceda o limite de dose especificado para trabalhadoreseindivíduosdo público.(INTERNATIONAL COMMISSION ON RADIOLOGICAL PROTECTION, 1991) Também nesse princípio, a International Commission on Radiological Protection (1996) traz algumas consideraçôes:

(71) Os limites de dose individuais foram fixados pela Comissão para exposiçôes ocupacionais e públicas [...].

(72) Contanto que as doses para pacientes estejam corretamente justificadas, não é apropriado aplicar limites de dose às exposiçôes médicas, porque tais limites frequentemente causariam mais prejuízo que benefício. Eles, às vezes, impediriam a obtenção de informação diagnóstica e impediriam toda a radioterapia.

$[\ldots]$.

(74) [...] Em resumo, o limite para dose efetiva em exposição profissional é $20 \mathrm{mSv}$ por um ano, com a flexibilidade de ser $50 \mathrm{mSv}$ em um único 
ano, contanto que a dose efetiva total em 5 anos sucessivos não exceda 100 $\mathrm{mSv}$, portanto com uma dose anual média de $20 \mathrm{mSv}$. [...]. Para exposições públicas, o limite de dose é expresso com um limite anual de $1 \mathrm{mSv}$, com cálculo da média em cinco anos.

Para se ter uma idéia do que os limites representam, na última publicação da UNSCEAR (2000), foi estimado que a dose de radiação média mundial, proveniente de todas as fontes naturais, é de 2,4 mSv/ano, podendo variar entre 1 e $10 \mathrm{mSv} /$ ano. Os limites de dose, discutidos acima, referem-se às exposiçóes públicas e ocupacionais, estando explicitamente excluídas as exposiçóes médicas, causando uma lacuna no sistema de radioproteção. Enquanto em radioterapia os protocolos de tratamento ${ }^{24}$ estabeleciam as doses de terapia dos pacientes, em radiodiagnóstico, não existiam valores de dose em paciente, nos diversos exames diagnósticos, que servissem como referência de comparação, planejamento ou otimização. A International Commission on Radiological Protection (1996), então, introduzindo um importante avanço para o sistema de radioproteção, propôs o conceito de nível de referência de radiodiagnóstico diagnostic reference level, com a seguinte formulação:

(100) A Comissão recomenda agora o uso de nivel de referência de diagnóstico para pacientes. Estes níveis que são uma forma de nível de investigação ${ }^{25}$, utilizando medidas de simples quantificação, normalmente a dose absorvida em ar [...] o nível de referência diagnóstico deverá ser usado como um teste simples para identificar situaçóes onde os níveis de dose paciente ou a atividade administrada, são extraordinariamente altas. [...]

${ }^{24}$ Os protocolos de radioterapia são estabelecidos, em geral, por organismos internacionais de reconhecida competência, como o ICRU.

${ }^{25}$ Nível de investigação é um limite de dose de radiação que, caso seja ultrapassado, demanda uma investigação para verificar as razóes pelas quais o limite foi excedido. Para os trabalhadores e indivíduos do público, aplicam-se os limites de dose. Para os pacientes, nível de referência de radiodiagnóstico. 
(101) Os níveis de referência em diagnóstico são suplementos ao julgamento profissional e não representam uma linha dividindo a medicina boa e ruim. É inapropriada quando usada com propósitos regulatórios ou comerciais.

(102) Níveis de referência em diagnóstico são aplicados às exposiçóes médicas, não às exposições profissionais e públicas. (INTERNATIONAL COMMISSION ON RADIOLOGICAL PROTECTION, 1996, grifo nosso)

Essa publicação também ressaltou o importante papel que deve ser exercido pela autoridade reguladora, as responsabilidades compartilhadas pelos diversos atores que participam da radiologia e a necessidade de treinamento específico para os membros das equipes técnicas das diversas instituiçôes, incluindo a autoridade reguladora. A International Commission on Radiological Protection (1996) fortaleceu as diretrizes estabelecidas pela publicação da Organização Mundial de Saúde (1982), consolidando a atenção à qualidade da imagem radiográfica e a implantação de PGQ's.

Com a finalidade de contribuir para a harmonização internacional dos sistemas de radioproteção, em 1990 foi constituído o Comitê Interinstitucional de Segurança Radiológica (IACRS), formado, inicialmente, pela IAEA, FAO, ILO, NEA/OECD, OPAS, OMS, OIT, UNSCEAR, ICRP, ICRU, IRPA, IEC e ISSO. Em seguida, foi criada uma secretaria do IACRS, responsável pela elaboração das Normas Básicas Internacionais de Segurança para a Proteção contra a Radiação Ionizante e para a Segurança das Fontes de Radiaçáo. O documento final do estudo foi publicado pela IAEA, na Série Segurança, em 1996, ficando conhecido como os padróes básicos de segurança Basic Safety Standards - BSS, da Agência. (INTERNATIONAL ATOMIC ENERGY AGENCY, 1996)

Baseada, principalmente, nas recomendaçôes da ICRP, a publicação conjunta da Agência tentou fornecer subsídio para a estruturação de sistemas de radioproteção em todas as áreas de aplicação das radiaçóes ionizantes. Contudo, da mesma forma que ocorreu com a ICRP, a IAEA percebeu a necessidade de uma recomendação específica para as aplicações médicas, 
que só foi publicada em 2006. (INTERNATIONAL ATOMIC ENERGY AGENCY, 2006)

Os principais aspectos definidos pela Organização Mundial de Saúde (1982) e a International Commission on Radiological Protection (1996), tais como o foco da qualidade da imagem, a importância da qualificação, a responsabilização dos diversos atores, os princípios da radioproteção e o nível de referência diagnóstico foram reforçados pela International Atomic Energy Agency (1996, 2006), inclusive com a proposição de valores de referência em diagnóstico para diversos exames. A importância do conceito de nível de referência de radiodiagnóstico foi fundamental na concepção dos novos modelos de proteção radiológica, como aconteceu na Comunidade Européia, com a publicação da Diretiva EURATOM 43/97. A Comissão Européia, em conjunto com o Instituto de Higiene das Radiaçóes para Radioproteção, da Alemanha, organizaram um workshop, em 1998, em Luxemburgo, com o tema References Doses and Quality in Medical Imaging - What the Referring Practioner and Directing Medical Staff Should Know, tendo como objetivo acelerar o processo de informação sobre as consequências da adoção do conceito de Diagnostic Reference Level. Esse evento pode ser considerado como sendo, aproximadamente, uma versão moderna do workshop de Neuherberg, em 1980.

Três aspectos relevantes do encontro devem ser ressaltados: o primeiro diz respeito à importância do princípio da otimização, que pode ser aplicado inclusive no sistema de regulação. O trabalho de Wall e Shrimptom (1998) resgatou que, nas primeiras avaliaçôes em pacientes de radiodiagnóstico, nos anos 50 , as doses para a realização de um mesmo exame variavam até 10.000 vezes entre serviços. Até meados da década de 90, variaçóes de até 30 vezes entre diferentes serviços, realizando o mesmo exame, foram relatadas em radiografia convencional, mamografia, fluoroscopia e tomografia. (OESTMANN, 1998, SAXEBOL et al., 1998, WALL; SHRIMPTOM, 1998) Como ressalta Oestmann (1998), as variaçóes não podem ser explicadas apenas pela variação do tamanho e composição do corpo do paciente. Assim, se no primeiro momento o objetivo era harmonizar as doses, num 
segundo momento, o objetivo passa a ser a harmonização em torno de uma referência.

O segundo aspecto relevante do encontro de $1988 \mathrm{diz}$ respeito ao uso dos raios-X em pediatria. Mesmo tendo evoluído bastante, desde a década de 70, este é um campo da radiologia que necessita ampliar a utilização de equipamentos e programas de garantia de qualidade específicos para a prática, estabelecer doses de referência para todas as faixas etárias e consolidar a radiologia pediátrica como uma especialidade. (CHAPPLE; BROADHEAD; FAULKNER, 1998, PERLMUTTER et al., 1998)

O terceiro e último aspecto refere-se à evolução do sistema de avaliação dos serviços de radiodiagnóstico e à incorporação do conceito de diagnostic reference level nas práticas da autoridade reguladora. Sua utilização com fins regulatórios era, inclusive, desaconselhada pela International Commission on Radiological Protection (1996); No entanto, o conceito ganhou tamanha força e importância que passou a ser utilizado por autoridades reguladoras. Segundo Moores, Cannolly e Cole (1998), os critérios de qualidade da Diretiva da Comunidade Européia apontam claramente para que as avaliaçóes considerem a técnica radiográfica, a dose em paciente e a qualidade da imagem. Uma técnica radiográfica conhecida e aceita produz um resultado conhecido, em termos de dose e qualidade da imagem. Desse modo, a avaliação dos serviços pode ser implantada em três níveis: o nível 1 envolve rotinas e avaliação de doses em pacientes e os resultados são comparados com o nível de referência diagnóstico aceitável; no nível 2, deve haver a avaliação de dose em conjunto com a avaliação completa do programa de garantia de qualidade; no nível 3, é realizada uma avaliação completa do serviço, incluindo a avaliação da relação necessária de qualidade da imagem e dose no paciente. 



\section{Sistemas de proteção radiológica}

O radiodiagnóstico é de fundamental importância para a saúde pública, quer seja pelo seu papel de suporte diagnóstico/acompanhamento nas mais diversas áreas da medicina, ou por representar a principal fonte de exposição às radiaçóes artificiais. Assim, para que seja possível a utilização das radiaçóes ionizantes, produzindo o máximo benefício com o mínimo prejuízo, fazse necessária a estruturação de sistemas nacionais de proteção radiológica, coordenados por uma Autoridade Reguladora e com legislação específica para a área. ${ }^{26}$ (ARIAS, 2006; INTERNATIONAL ATOMIC ENERGY AGENCY, 1996, 2004, 2006; INTERNATIONAL COMMISSION ON RADIOLOGICAL PROTECTION, 1990, 1996; ORGANIZAÇÃO MUNDIAL DE SAÚDE, 1972, 1982)

No Brasil, assim como em outros países, as primeiras intervençóes estatais no campo das radiaçóes ionizantes voltaram-se à regulamentação das exposiçôes ocupacionais. Em 14 de dezembro de 1950, foi publicada a Lei n. 1.234, que "Confere direitos e vantagens a servidores que operam com Raios-X e substâncias radioativas”. No ano seguinte, o Decreto n. 29.155, de 17 de Janeiro, regulamentou a referida Lei e estabeleceu as primeiras medidas de controle sobre serviços de saúde que utilizavam radiaçôes ionizantes, bem como as primeiras normas de radioproteção, como: a necessidade de utilização de blindagens nos equipamentos, nas salas e no comando; a utilização de luvas de proteção para fluoroscopia; realizaçáo de exames periódicos pelos profissionais expostos às radiaçóes.

${ }^{26} \mathrm{O}$ Brasil é signatário das recomendaçôes da AIEA, IEC e ISO. Logo, as normas nacionais devem refletir as recomendaçóes dessas organizaçóes. Na falta de norma nacional para uma determinada área, as recomendaçóes internacionais devem ser adotadas. 
Em 1962, a Lei n. 4.118 criou a Comissão Nacional de Energia Nuclear (CNEN) e dispôs sobre a política nacional de energia nuclear. A CNEN continua voltada, basicamente, para as aplicaçóes pacíficas da energia nuclear, sendo responsável pelas Normas Básicas de Radioproteção e controle no campo das aplicaçôes médicas da medicina nuclear, radioterapia e monitoração individual. As Normas Básicas de Radioproteção, publicadas pela CNEN, abrangem o radiodiagnóstico, no que se refere ao estabelecimento dos limites de exposição pública e ocupacional, unidades de medida e monitoração individual dos trabalhadores. Nunca foi obrigação da CNEN licenciar e fiscalizar serviços de radiodiagnóstico. (BRASIL, 1974; CNEN 6.02/84; CNEN 3.01/88)

O controle sobre o uso e comercialização dos equipamentos de raios-X começou com a Lei n. 5.991, de 17 de dezembro de 1973, que "Dispóe sobre o controle sanitário do comércio de drogas, medicamentos, insumos farmacêuticos e correlatos, e dá outras providências". Embora não referidos explicitamente na lei, a definição de correlatos abrange os equipamentos de radiodiagnóstico.

Em 1976, foi publicada a Lei n. 6.360, regulamentada pelo Decreto n. 79.094 de 1977, que dispóe sobre a "vigilância sanitária a que ficam sujeitos os medicamentos, as drogas, os insumos farmacêuticos e correlatos, cosméticos, saneantes e outros produtos", estabelecendo que nenhum dos produtos submetidos ao regime de vigilância sanitária poderia ser industrializado, exposto à venda ou entregue ao consumo, antes de ter registro no órgão de vigilância sanitária.

Ainda em 1977, com fins de regulamentar as infrações sanitárias, foi publicada a Lei 6437/77 que estabelecia entre outras infraçóes sanitárias:

III - instalar consultórios médicos, [...], gabinetes ou serviços que utilizem aparelhos e equipamentos geradores de raio-X, [...] sem licença do órgão sanitário competente ou contrariando o disposto nas demais normas legais e regulamentares pertinentes. (Grifo nosso) 
Nesse período, foi criada a Secretaria Nacional de Vigilância Sanitária, no âmbito do Ministério da Saúde, estabelecendo-se em lei, pelo menos há 30 anos, explícita responsabilidade das autoridades sanitárias sobre os equipamentos e serviços de radiodiagnóstico.

Como consequência da tragédia de Goiânia, o Conselho Nacional de Saúde publicou a Resolução n. 6, de 21/12/88, fixando requisitos gerais de proteção radiológica, inclusive para radiodiagnóstico. No entanto, esta Resolução teve caráter amplo, sem maiores implicações nas açôes práticas de vigilância sanitária.

Nesse período, o sistema de saúde brasileiro, incluindo vigilância sanitária, estava iniciando um processo de completa reestruturação, devido à promulgação da Constituição de 1988, que definiu a forma e competência do Sistema Único de Saúde (SUS), entre as quais:

Art. 200. Ao sistema único de saúde compete, além de outras atribuiçóes, nos termos da lei:

I - controlar e fiscalizar procedimentos, produtos e substâncias de interesse para a saúde e participar da produção de medicamentos, equipamentos, imunobiológicos, hemoderivados e outros insumos;

II - executar as açôes de vigilância sanitária e epidemiológica, bem como as de saúde do trabalhador;

[...]

VII - participar do controle e fiscalização da produção, transporte, guarda e utilização de substâncias e produtos psicoativos, tóxicos e radioativos.

Foram necessários mais dois anos para que a Lei n. 8080, de 19 de setembro de 1990, regulamentasse e estruturasse o SUS, definindo qual seria o papel da vigilância sanitária:

Art. 60. Estão incluídas ainda no campo de atuação do Sistema Único de Saúde (SUS): I - a execução de açóes:

a) de vigilância sanitária; 
[...]

$\$ 1^{\circ}$. Entende-se por vigilância sanitária um conjunto de açóes capaz de eliminar, diminuir ou prevenir riscos à saúde e de intervir nos problemas sanitários decorrentes do meio ambiente, da produção e circulação de bens e da prestação de serviços de interesse da saúde, abrangendo:

I - o controle de bens de consumo que, direta ou indiretamente, se relacionem com a saúde, compreendidas todas as etapas e processos, da produção ao consumo; e

II - o controle da prestação de serviços que se relacionam direta ou indiretamente com a saúde.

A definição estabelecida para vigilância sanitária estava muito distante das práticas brasileiras. A tragédia de Goiânia, infelizmente, foi precursora de muitas outras que, na década de 90, mostraram à nação as consequências de se ter um sistema de controle de riscos à saúde ineficiente. Os casos de óbitos da Clínica Santa Genoveva, no Rio de Janeiro, e do Instituto de Doenças Renais de Caruaru, das "pílulas de farinha" da Schering e a crise dos medicamentos falsificados impulsionaram o governo brasileiro a reestruturar a vigilância sanitária, buscando melhorar seus serviços em atenção à crise sanitária e aos novos desafios do país no contexto da economia globalizada. (COSTA, 2004)

No ápice da crise por que passava a área de vigilância sanitária e um ano antes da publicação da Lei n. 9.782/99, que definiu o Sistema Nacional de Vigilância Sanitária e criou a Agência Nacional de Vigilância Sanitária (ANVISA), a Secretaria de Vigilância Sanitária, antiga SNVS, publicou a Portaria 453/98 27 , aprovando um Regulamento Técnico que levou em consideração as principais recomendaçóes das organizaçóes internacionais (OMS,

${ }^{27}$ As Diretrizes de Proteção Radiológica em Radiodiagnóstico Médico e Odontológico, aprovadas pela Portaria SVS 453/98, publicadas no Diário Oficial da União de 2 de junho de 1998, têm seu conteúdo dividido nos seguintes itens: I - Disposiçóes Gerais; II - Sistema de Proteção Radiológica; III - Requisitos Operacionais; IV - Requisitos para Radiodiagnóstico Médico; V - Requisitos para Radiologia Odontológica; VI - Disposiçóes 
OPAS, ICRP e IAEA) e estabeleceu as normas técnicas para o radiodiagnóstico no Brasil.

Nos objetivos do Regulamento, são encontrados os elementos básicos das proposições da OMs, sistematizados na reunião de Neuherberg. (ORGANIZAÇÃO MUNDIAL DE SAÚDE, 1982)

1.2 Atendendo à política nacional de proteção à saúde, o presente Regulamento tem por objetivos:

a) Baixar diretrizes para a proteção da população dos possíveis efeitos indevidos inerentes à utilização dos raios-X diagnósticos, visando minimizar os riscos e maximizar os benefícios desta prática.

b) Estabelecer parâmetros e regulamentar açóes para o controle das exposiçóes médicas, das exposiçóes ocupacionais e das exposiçóes do público, decorrentes das práticas com raios-X diagnósticos.

c) Estabelecer requisitos para o licenciamento e a fiscalização dos serviços que realizam procedimentos radiológicos médicos e odontológicos.

O segundo capítulo apresenta os princípios básicos da radioproteção (Justificação, Otimização, Limitação de doses e Prevenção de acidentes), conforme consolidados nas recomendaçóes internacionais. (INTERNATIONAL ATOMIC ENERGY AGENCY, 1996; INTERNATIONAL COMMISSION ON RADIOLOGICAL PROTECTION, 1991, 1996) salientando que:

2.9 As exposições médicas de pacientes devem ser otimizadas ao valor mínimo necessário para obtenção do objetivo radiológico (diagnóstico e terapêutico), compatível com os padróes aceitáveis de qualidade de imagem. Para tanto, no processo de otimização de exposiçôes médicas, deve-se considerar:

a) A seleção adequada do equipamento e acessórios.

Transitórias; Anexo A - Níveis de Referência; Anexo B - Ficha de Cadastramento; Anexo C - Glossário 
b) Os procedimentos de trabalho.

c) A garantia da qualidade.

d) Os níveis de referência de radiodiagnóstico para pacientes.

Esse é um dos itens mais importantes da norma, representando as dimensôes centrais, que devem ser controladas no radiodiagnóstico, inclusive na radiologia moderna.

O capítulo III, requisitos operacionais, inclui os assuntos: obrigações básicas, registro, licenciamento, responsabilidades, qualificação profissional, controle ocupacional, restriçóes de dose em exposiçóes médicas, características gerais dos equipamentos e garantia de qualidade. Nesse capítulo, são definidas as responsabilidades dos empregadores, dos responsáveis técnicos, dos supervisores de radioproteção e técnicos. Os empregadores são os principais responsáveis pelo cumprimento das disposiçóes estabelecidas com a Portaria, tendo no responsável técnico ${ }^{28}$ a principal responsabilidade pelos procedimentos radiológicos a que são submetidos os pacientes, cujos exames devem ser realizados, considerando os níveis de referência de radiodiagnóstico, apresentados no anexo A.

No capítulo IV, são descritos os requisitos mínimos para o radiodiagnóstico médico, no tocante a ambientes, equipamentos (raios-X, mamografia, tomografia e fluoroscopia), procedimentos e o controle de qualidade. Com relação ao controle de qualidade, foram determinadas a periodicidade e tolerância dos testes que precisam ser realizados.

O capítulo V da Portaria 453/98 trata do radiodiagnóstico odontológico, náo abordado neste estudo, e o sexto capítulo estabelece os prazos para que as novas exigências sejam cumpridas. Os prazos variaram entre um e cinco anos, ou seja, desde 2003 a Portaria SVS 453/98 deve ser integralmente cumprida.

${ }^{28}$ O Regulamento estabelece que o Responsável Técnico em radiodiagnóstico médico tem que ser formado em medicina e ter qualificação para a prática. 
Essa é a única norma Federal que institui a obrigatoriedade de implantação de PGQ na área de equipamentos médicos. O referencial teórico da normativa foi ancorado nas mais sólidas bases da radioproteção moderna, de acordo com as mais recentes recomendaçóes internacionais, como a publicação da International Atomic Energy Agency de 2006 Applying Radiation Safety Standards in Diagnostic Radiology and Interventional Procedures Using $X$ Rays, em conjunto com a OMS, OPAS, OIT, ISRRT, ISR e IOMP. No entanto, são necessárias complementações para responder às necessidades de controle de riscos das novas tecnologias (radiologia digital, tomografia multicortes, PACS, densitometria e teleradiologia) e proibir práticas radiológicas que não são mais recomendáveis, desde os anos 80, a exemplo da utilização de gerador de retificação de onda completa, equipamentos com potência inferior a $4 \mathrm{~kW}$, equipamentos portáteis instalados como fixos e equipamentos inadequados para pediatria.

A Lei 9782/99 que criou a ANVISA, estabelecendo o formato e as responsabilidades do Sistema Nacional de Vigilância Sanitária (SNVS), reafirma a responsabilidade do SNVS na regulação e controle dos equipamentos e serviços de radiodiagnóstico, cabendo a fiscalização aos Estados e Municípios.

Em 2003, a ANVISA publicou a RE n. 64, revogada em 2006 pela RE 1.016, que aprovou o Guia "Radiodiagnóstico Médico - Segurança e Desempenho de Equipamentos". Nos mesmos termos da resolução anterior, esta propóe testes de controle de qualidade e segurança radiológica, cujas metodologias de cálculo, periodicidade dos testes e limites de tolerância divergem dos parâmetros estabelecidos na Portaria 453/98 e na literatura internacional. Um quadro comparativo, entre a Portaria 453/98 e o Guia, é apresentado no anexo I. Como se trata, apenas, de Guia publicado pela ANVISA, não possui caráter regulador.

A última contribuição normativa ao radiodiagnóstico foi implementada pelo Ministério do Trabalho e Emprego (TEM), por meio da Portaria MTE n. 485, de 11 de novembro de 2005, que instituiu a "NR 32 - Segurança e Saúde no Trabalho em Serviços de Saúde". No que se refere a serviços 
de radiodiagnósticos, as diretrizes, basicamente, reforçam as determinaçóes estabelecidas na Portaria 453/98.

Assim, o sistema brasileiro de controle de riscos em radiodiagnóstico tem nas autoridades sanitárias a principal Autoridade Reguladora. Mas também está sujeito a ações regulatórias da CNEN, referentes à radioproteção pública e ocupacional e do MTE, no que concerne à radioproteção ocupacional. 


\section{Avaliando o risco potencial}

A última etapa no paradigma do risco é a avaliação das açôes de controle de riscos realizadas, que podem ser feitas através da avaliação do risco potencial. É uma das etapas básicas e necessárias para o processo de regulação, como destaca Lucchese (2001, cap. 6, p. 5)

[...] é salutar ressaltar que a competência da regulação somente se completa com a avaliação dos resultados, função nova da vigilância sanitária federal, para a qual a agência precisa se adequar.

Como foi discutido anteriormente, o sistema regulador estabelece as normas de controle. Partindo do conceito de risco potencial, buscou-se desenvolver um modelo que analisasse a relaçáo causal entre os indicadores de controle e o risco potencial. Logo, o Modelo de Avaliação de Risco Potencial (MARP) é uma forma de operacionalizar o conceito de risco potencial, possibilitando sua quantificação e classificação, num espaço de aceitabilidade, proporcionando a comparabilidade entre os riscos potenciais avaliados, bem como seus condicionantes.

Inicialmente, será apresentado o formalismo geral do MARP. Em seguida, o MARP será modelado para ser aplicado em serviços de radiodiagnóstico. A particularização do MARP, para uma determinada aplicação, é realizada através da definição dos indicadores ${ }^{29}$ de controle de riscos. Os indicadores definirão o nível de risco potencial, com base numa escala de aceitabilidade previamente estabelecida. Dessa forma, a capacidade do MARP em retratar a situação de risco potencial dependerá da qualidade e adequação dos

${ }^{29}$ Os indicadores são uma tentativa de sintetizar informaçôes sobre uma determinada situação em um número. (TAYRA; RIBEIRO, 2005) 
indicadores selecionados. Entretanto, por mais que sejam estabelecidos critérios para a seleção, é talvez a etapa mais fortemente influenciada pelo juízo de valor. Por fim, o MARP será utilizado para avaliar a situação de risco potencial de serviços de radiodiagnóstico no Estado da Bahia e seus condicionantes.

\section{Modelo de Avaliação de Risco Potencial (MARP)}

O modelo de avaliação de risco potencial (MARP) precisa levar em consideração questóes importantes do radiodiagnóstico, da área de vigilância sanitária, da radioproteçáo e do próprio conceito de risco.

A primeira questão refere-se à faixa de variação. O MARP necessita ser representado por um formalismo matemático, cujos valores de risco potencial (RP) estejam sempre dentro de uma mesma faixa de variação, independente do número de indicadores, e não exista a possibilidade de assumir o valor zero. A questão dos valores estarem dentro de uma mesma faixa de variação possibilita a comparação e o estabelecimento de limites de aceitabilidade, enquanto que a não possibilidade de assumir o valor zero é uma condiçáo do problema, pois os riscos podem ser os menores possíveis, mas nunca serão nulos.

Os níveis de aceitabilidade não devem ter uma fronteira direta entre o aceitável e o inaceitável. Deve haver uma zona de transição, em que a condição de risco seja tolerável em algumas condições ou por algum tempo. Os níveis de aceitabilidade devem possibilitar a sua variação, para mais ou para menos, permitindo a aplicação do princípio da otimização. (SLOVIC, 2000) Por outro lado, o número de indicadores deve ser aberto, possibilitando a inclusão e exclusão de tantos indicadores quantos sejam necessários. Os indicadores são classificados segundo o nível de risco potencial que representam para o sistema.

Neste estudo, os indicadores de controle de riscos estão separados em duas categorias: indicadores críticos e indicadores não-críticos. Indicadores 
críticos são aqueles que estáo associados, diretamente, ao nível de risco potencial inaceitável. Por sua gravidade, comprometem todo o sistema de controle de riscos dos procedimentos. Assim, informam sobre situaçóes críticas, cuja existência, independentemente da existência de quaisquer outras, levam o risco potencial ao nível inaceitável.

O conjunto dos indicadores não-críticos é formado por todos os indicadores que, individualmente, não comprometem, de forma decisiva, o controle de riscos do sistema. O conjunto completo dos indicadores não-críticos atua como se fosse um indicador crítico, ou seja, se todos os indicadores não-críticos forem nulos, o conjunto de indicadores será nulo e assim, somente assim, representarão um comprometimento crítico no sistema de controle de riscos potenciais. Uma vez que se pode construir tantos indicadores de riscos quantos forem necessários ou desejados e o resultado precisa estar dentro de limites fixos, fundamentais para as discussões e estabelecimento de critérios de aceitabilidade dos riscos potenciais, foi necessário desenvolver um formalismo matemático para representar os valores médios dos conjuntos de indicadores (críticos e não-críticos) através de um único valor.

O conjunto de indicadores críticos é formado pelos indicadores $I_{C}$

$$
\left\{\mathrm{I}_{\mathrm{C}_{1}} ; \mathrm{I}_{\mathrm{C}_{2}} ; \mathrm{I}_{\mathrm{C}_{3}} ; \ldots ; \mathrm{I}_{\mathrm{C}_{\mathrm{N}}}\right\}
$$

Dado que os indicadores críticos possuem a capacidade de comprometer todo o controle de riscos potenciais do sistema, bem como necessitam ser representados por uma média, a forma mais apropriada é representá-los como uma média geométrica. A média geométrica é a raiz enésima do produto de $\mathrm{N}$ termos, representando um valor médio do produto. Desse modo, para representar uma média de $\mathrm{N}$ termos, tem-se:

$$
\overline{\mathrm{I}}_{\mathrm{C}}=\sqrt[N]{\prod_{\mathrm{i}=1}^{\mathrm{N}} \mathrm{I}_{\mathrm{C}_{\mathrm{i}}}}
$$


Por exemplo, caso se tenha um conjunto de cinco indicadores críticos, o valor médio dos indicadores será:

$$
\overline{\mathrm{I}}_{\mathrm{C}}=\sqrt[5]{\mathrm{I}_{\mathrm{C}_{1}} x \mathrm{I}_{\mathrm{C}_{2}} x \mathrm{I}_{\mathrm{C}_{3}} x \mathrm{I}_{\mathrm{C}_{4}} x \mathrm{I}_{\mathrm{C}_{5}}}
$$

Assim, caso qualquer um dos indicadores tenha valor zero, o valor de $\bar{I}_{C}$ será zero, independente dos outros indicadores. Por outro lado, o valor máximo será, numericamente, igual ao valor máximo de um indicador, ou seja, independente do número de indicadores que seja selecionado, o resultado sempre estará dentro de uma mesma faixa de variaçấo $0^{30}$, como pode ser verificado, tomando-se o exemplo do conjunto de cinco indicadores críticos e considerando que todos tenham o valor máximo:

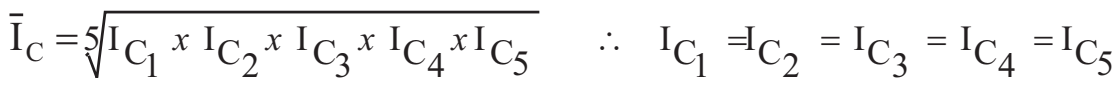

$$
\begin{aligned}
& \overline{\mathrm{I}}_{\mathrm{C}}=\sqrt[5]{\left(\mathrm{I}_{\mathrm{C}_{1}}\right)^{5}} \Rightarrow \overline{\mathrm{I}}_{\mathrm{C}}=\mathrm{I}_{\mathrm{C}_{1}}
\end{aligned}
$$

$\mathrm{O}$ conjunto de indicadores não-críticos é formado pelos indicadores $I_{N C}$

$$
\left\{\mathrm{I}_{\mathrm{NC}_{1}} ; \mathrm{I}_{\mathrm{NC}_{2}} ; \mathrm{I}_{\mathrm{NC}_{3}} ; \ldots ; \mathrm{I}_{\mathrm{NC}}\right\}
$$

Uma vez que os indicadores não-críticos não possuem a capacidade de, individualmente, representar o comprometimento de todo o controle de riscos potenciais do sistema, não podem ter sua média representada por um produtório. No entanto, também necessitam ser representados por uma

${ }^{30}$ Considerando que todos os indicadores são avaliados dentro de uma mesma faixa. 
média, para que o valor representativo do conjunto seja, no máximo, igual ao valor máximo de um de seus elementos e esteja dentro de uma faixa de variação conhecida.

Desse modo, a melhor forma de representá-los é através de uma média aritmética. Os indicadores não-críticos $\left(I_{N C}\right)$ podem ser representados por uma média aritmética simples, pois só será nulo, caso todos os indicadores de controle sejam nulos.

$$
\overline{\mathrm{I}}_{\mathrm{NC}}=\frac{\sum_{j=1}^{M} \mathrm{I}_{\mathrm{N} C_{\mathrm{j}}}}{\mathrm{M}}
$$

Como exemplo, caso se tenha um conjunto de quatro indicadores não críticos, o valor médio destes indicadores será:

$$
\overline{\mathrm{I}}_{\mathrm{NC}}=\frac{\mathrm{I}_{\mathrm{NC}_{1}}+\mathrm{I}_{\mathrm{NC}_{2}}+\mathrm{I}_{\mathrm{NC}_{3}}+\mathrm{I}_{\mathrm{NC}_{4}}}{4}
$$

Também como exemplo, caso todos tenham o valor máximo:

$$
\begin{gathered}
\overline{\mathrm{I}}_{\mathrm{NC}}=\frac{\mathrm{I}_{\mathrm{NC}_{1}}+\mathrm{I}_{\mathrm{NC}_{2}}+\mathrm{I}_{\mathrm{NC}_{3}}+\mathrm{I}_{\mathrm{NC}_{4}}}{4} \therefore \mathrm{I}_{\mathrm{NC}_{1}}=\mathrm{I}_{\mathrm{NC}_{2}}=\mathrm{I}_{\mathrm{NC}_{3}}=\mathrm{I}_{\mathrm{NC}_{4}} \\
\overline{\mathrm{I}}_{\mathrm{NC}}=\frac{4 \mathrm{xI}_{\mathrm{NC}_{1}}}{4} \Rightarrow \overline{\mathrm{I}}_{\mathrm{NC}}=\mathrm{I}_{\mathrm{NC}_{1}}
\end{gathered}
$$


A função controle de risco $\left(C_{R}\right)$, que representa o resultado dos indicadores de controle de riscos, deve ser representada como a média geométrica, ou seja:

$$
C_{R}\left(I_{C}, I_{N C}\right)=\sqrt{\bar{I}_{C} \times \bar{I}_{N C}}
$$

Mais uma vez utilizou-se a média geométrica, para que o controle de risco $\left(C_{R}\right)$ esteja numa faixa de variação conhecida previamente e que depende apenas da variação de $\overline{\mathrm{I}}_{\mathrm{C}}$ e $\overline{\mathrm{I}}_{\mathrm{NC}}$.

Tomando-se o controle de risco $\left(C_{R}\right)$ como a variável independente, a função que melhor representa a relação de causa e efeitos entre controle de risco e risco potencial é a função exponencial, com a seguinte forma:

$$
\mathrm{R}_{\mathrm{P}}\left(C_{R}\right)=e^{-C_{R}}
$$

Sendo,

$R_{p}\left(C_{R}\right)$ - Função risco potencial, que é dependente da função controle de risco, será referenciada como $\mathrm{R}_{\mathrm{P}}$;

$\mathrm{C}_{\mathrm{R}}$ - Controle de risco, função que determina o risco potencial e que, por sua vez, é determinada pelos indicadores de controle de risco.

A forma da função exponencial, com um rápido decrescimento, representa um bom modelo para fenômenos críticos, como é o caso do sistema de controle de riscos em radiodiagnóstico. A complexa relação entre os diversos fatores que influenciam no controle de riscos exibe uma espécie de soma náo extensiva, em que o risco potencial para um evento, que envolva a junção entre dois fatores, pode ser maior que a soma do risco potencial dos dois fatores isoladamente. Esse tipo de comportamento acaba gerando um aumento brusco do risco potencial, ao se somar muitos elementos ou alguns críticos, sendo perfeitamente representado pelo rápido decrescimento da função exponencial. As variáveis de controle de riscos vão desde o controle do sistema, como a licença sanitária, até as variáveis de controle de riscos 
relacionados diretamente aos efeitos das radiaçóes ionizantes, passando pelas variáveis de controle da qualidade e visualização da imagem radiográfica.

Outro comportamento importante da função exponencial, para representar o risco potencial, é que ela possui um valor máximo finito e o valor mínimo tende a zero, sem necessariamente assumir o valor zero. $\mathrm{O}$ risco potencial de um sistema não pode aumentar indefinidamente, nem pode ser zero. A sua possibilidade de ocorrência é finita e, por maior e melhor que seja o sistema de controle de riscos, não se pode alcançar uma situação de inexistência de risco potencial.

A função proposta, representada pela equação (6), permite que o risco potencial varie entre o valor máximo 1 e o valor mínimo que será definido pelo indicador de controle de risco. O valor mínimo, nunca será zero e, independente do número de indicadores que seja utilizado, a função risco potencial terá valores máximos e mínimos fixos.

Uma questão importante nesse modelo é estabelecer a escala de variação dos indicadores de controle de riscos, pois o valor máximo da escala define o valor mínimo que a funçáo risco potencial $\left(R_{p}\right)$ pode assumir e, consequentemente, sua faixa de variação. Vale salientar que as avaliaçóes de risco potencial com este modelo só podem ser comparadas caso utilizem a mesma escala de variação dos indicadores de controle de riscos. Os indicadores $\mathrm{I}_{\mathrm{C}}$ e $\mathrm{I}_{\mathrm{NC}}$ foram avaliados, numa escala de zero a cinco, onde zero representa controle de risco inexistente ou inadequado e cinco representa controle de risco excelente, com a seguinte graduação: $\mathbf{0}$ - inexistente ou inadequado; $\mathbf{1}$ - sofrível; $\mathbf{2}$ - razoável; $\mathbf{3}$ - bom; $\mathbf{4}$ - ótimo e $\mathbf{5}$ - excelente. Deve-se considerar que o cumprimento da norma está associado ao valor 3. Logo, independente do número de indicadores críticos e não críticos, a função controle de risco $\left(C_{R}\right)$ assumiu valores, necessariamente, entre 0 e 5 . Então, os valores máximo e mínimo do risco potencial $\left(R_{p}\right)$ foram:

$$
\begin{aligned}
& \mathrm{R}_{\mathrm{p}}\left(\mathrm{C}_{\mathrm{R}}=0\right)=\mathrm{e}^{-0}=1,000 \\
& \mathrm{R}_{\mathrm{P}}\left(\mathrm{C}_{\mathrm{R}}=5\right)=\mathrm{e}^{-5}=0,007
\end{aligned}
$$


Quando $C_{R}=0$, que significa a ausência do conjunto de controles de riscos não-críticos ou a ausência de um dos controles de riscos críticos, o risco potencial foi $\mathrm{R}_{\mathrm{p}}(0)=1$, ou seja, tem-se uma situação plena de risco potencial. Podem-se descrever os possíveis danos em potencial; contudo, não se pode especificar um dano e a respectiva probabilidade de ocorrência. Por outro lado, por maior que sejam os controles, o risco potencial $\left(\mathrm{R}_{\mathrm{p}}\right)$ nunca assumirá o valor zero. Assim, pode-se inserir ou retirar tantos indicadores de controle de riscos quantos sejam necessários, independente de serem indicadores críticos ou não, que não haverá modificação na variação da função $\left(0,007 \leq R_{p} \leq 1,000\right)$. A função exponencial mostra-se adequada para descrever sistemas de controle de riscos, pois reflete bem a concepçáo de riscos intrínsecos às tecnologias ${ }^{31}$, ou seja, o risco pode e deve ser minimizado cada vez mais, mas não pode ser totalmente eliminado, pois faz parte da própria tecnologia. Isto é, mesmo que se tenham implantado todos os mecanismos de controle de riscos, tem-se um valor de risco potencial mínimo (intrínseco), que não pode ser eliminado, sendo que os benefícios justificam a utilização da referida tecnologia para saúde.

A função $C_{R}$ também pode ser entendida como a relação entre indicadores macro e micro do serviço. As médias $\overline{\mathrm{I}}_{\mathrm{C}}$ e $\overline{\mathrm{I}}_{\mathrm{NC}}$ contêm todas as informaçóes do serviço, de forma que se comportam como se fossem os estados dos micro sistemas, que compóem um dado serviço de saúde, como o de radiodiagnóstico, determinados pelos indicadores individuais $\mathrm{I}_{\mathrm{C}}$ e $\mathrm{I}_{\mathrm{NC}}$. Através deles, pode-se saber qual a situação dos equipamentos, dos recursos humanos ou dos procedimentos, enquanto $C_{R}$ informa um valor macro, agregado, indicando a situação do controle de riscos total do serviço, mas nada sobre seus componentes, especificamente. Os dois, $\mathrm{C}_{\mathrm{R}}$ e $\mathrm{I}_{\mathrm{C} \text { ou }} \mathrm{I}_{\mathrm{CN}}$, são de fundamental importância para o conhecimento da situaçáo de controle de risco, dependendo de quem está analisando e o que se deseja analisar.

31 Tecnologias, entendidas, no sentido mais amplo, como equipamentos, produtos, processos ou práticas. 
O risco potencial $\left(R_{p}\right)$ não deve ser entendido apenas como um número adimensional. Para representar uma situação de risco potencial, são necessárias mais informaçôes para subsidiar uma tomada de decisão. Como forma de agregar a dimensão aceitabilidade, o risco potencial deve ser representado num espaço de aceitabilidade com os respectivos limites, conforme Figura $3^{32}$. A idéia de aceitabilidade foi proposta, inicialmente, por Slovic e outros (1979), para realizar uma comparação da percepçáo de diferentes tipos de riscos, e como especialistas e leigos percebem os riscos, utilizando a psicometria para quantificar as variáveis qualitativas. A psicometria é um dos métodos mais utilizados nos estudos de percepção de riscos. (COVELLO; MUMPOWER, 1985, FISCHHOFF et al., 1983, FISCHHOFF; BOSTRUM; QUADREL, 2005, HAMPEL, 2006, INTERNATIONAL COMMISSION ON RADIOLOGICAL PROTECTION, 1991, OMENN; FAUSTMAN, 2005)

A IRGC International Risk Governance Council no white paper $n^{\circ}$ 2, de 2006, propóe uma representação gráfica bidimensional para classificar os níveis de risco das nanotecnologias, utilizando uma representação nãolinear, faixas de aceitabilidade e uma regiáo indefinida entre o limite inferior da curva e o eixo x. É uma representação qualitativa sem estimativa de valores, que tem o objetivo de representar a forma do comportamento dos riscos em nanotecnologia e sua aceitabilidade. (INTERNATIONAL RISK GOVERNANCE COUNCIL, 2006) O trabalho aponta para a necessidade de representação gráfica quantitativa, que parece ter esbarrado na dificuldade de formular matematicamente o modelo. Essa dificuldade foi superada com a formulação de risco potencial apresentada.

${ }^{32}$ Como existe a possibilidade de mais de uma avaliação com o mesmo valor de risco potencial, provocando uma superposição de pontos na representação espacial, será acrescentado um gráfico tipo pizza, para que seja possível visualizar o número de serviços/ procedimentos avaliados. 
FIGURA 3 - ESPAÇO DE ACEITABILIDADE

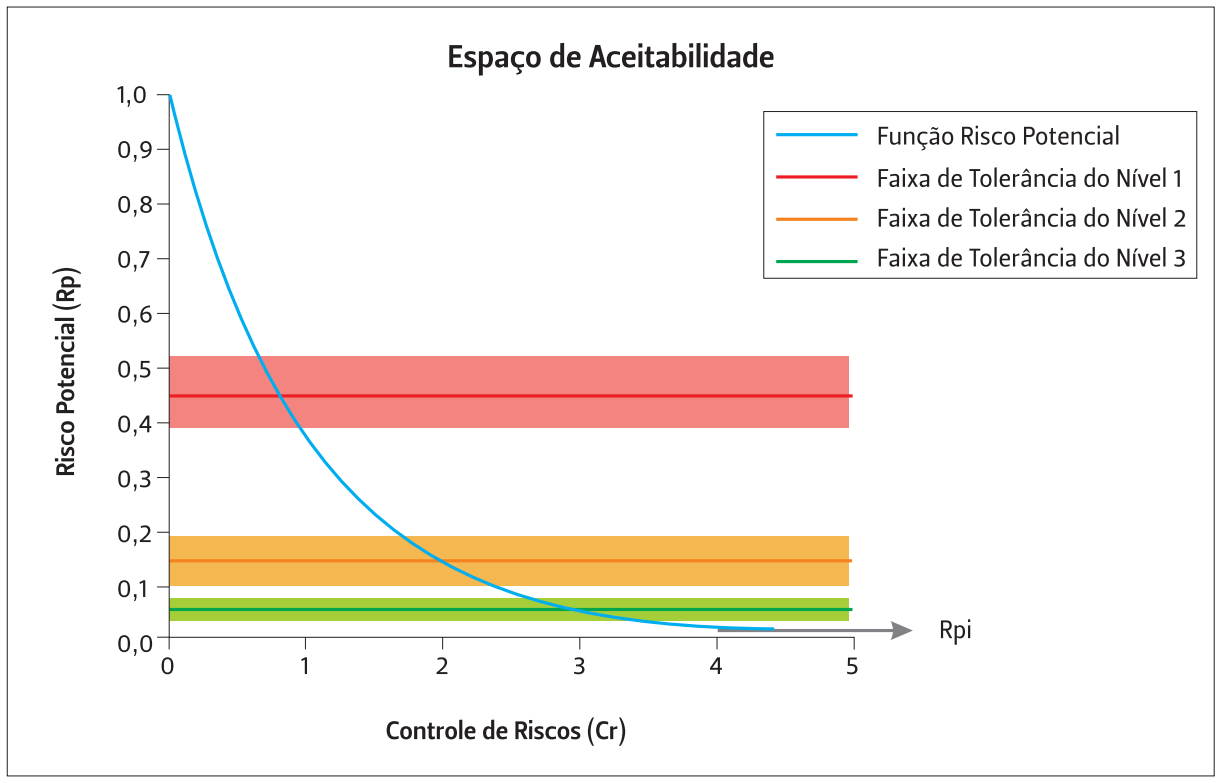


As faixas de aceitabilidade do risco potencial são classificadas como:

Risco Potencial Intrínseco $\left(\mathbf{R}_{\mathrm{P}_{\mathrm{P}}}\right)$ : Nesta faixa, o valor do risco potencial $\left(\mathrm{R}_{\mathrm{p}}\right)$ mínimo é 0,007 $\left(\mathrm{R}_{\mathrm{p}}(5)\right)$. É um limite inferior, impossível de ser ultrapassado, pois não se pode eliminar todos os riscos de um sistema.

Risco Potencial Aceitável ( $\left.\mathbf{R}_{\mathrm{pa}}\right)$ : Nesta faixa, o valor do risco potencial $\left(R_{\mathrm{p}}\right)$ varia de 0,007 até um valor definido. Os serviços e procedimentos avaliados, que possuem estes valores de $\mathrm{R}_{\mathrm{p}}$ são classificados como de risco potencial aceitável, pois cumpriram as normas de regulação de riscos. Os benefícios associados às práticas, possivelmente, superam os riscos e, assim, os procedimentos representam maior benefício para o indivíduo e para a sociedade do que os possíveis detrimentos, considerando os aspectos científicos, econômicos e sociais.

Risco Potencial Tolerável $\left(\mathbf{R}_{\mathrm{p}}\right)$ : Nesta faixa, o valor do risco potencial $\left(\mathrm{R}_{\mathrm{p}}\right)$ varia entre os limites de aceitável e inaceitável. Os serviços e procedimentos avaliados, que adquirem esses valores de $R_{p}$ sáo classificados como de risco potencial tolerável, pois cumpriram o mínimo das normas de regulação de riscos. Contudo, pequenas variaçóes dos indicadores podem levá-los à faixa de riscos potenciais inaceitáveis. Neste caso, os benefícios associados às práticas estáo próximos dos riscos potenciais. Desse modo, tais serviços necessitam de acompanhamento e prazos reduzidos para melhoria das práticas de forma a conduzi-los à faixa de riscos potenciais aceitáveis.

Risco Potencial Inaceitável $\left(\mathbf{R}_{\text {pin }}\right)$ : Nesta faixa, o valor do risco potencial $\left(\mathrm{R}_{\mathrm{p}}\right)$ está acima do limite de aceitabilidade. Os serviços e procedimentos avaliados com estes valores de $\mathrm{R}_{\mathrm{p}}$ devem ser classificados como de risco potencial inaceitável, pois náo cumpriram nem o mínimo das normas de regulação de riscos. Neste caso, os benefícios associados às práticas 
são presumidamente inferiores aos riscos potenciais que representam, requerendo imediata intervenção.

Os níveis de aceitabilidade podem ser reduzidos, tanto quanto razoavelmente exeqüíveis, conduzindo à evolução contínua do sistema de controle de riscos. Os níveis de controle de riscos desejáveis podem ser estabelecidos previamente e cada nível de controle terá sua faixa de tolerância. Para simplificar o modelo, o nível de controle de risco desejável será associado a um valor do indicador de controle de risco. Por exemplo, o nível 1 de controle terá como limite de aceitabilidade o risco potencial $\left(R_{P}\right)$ determinado por $\mathrm{C}_{\mathrm{R}}=1$, ou seja, $R_{P}=0,368$. Nesse nível de controle, a faixa de tolerância é estabelecida e, consequentemente, as outras faixas são definidas.

Caso seja utilizada uma tolerância de $20 \%$ para o limite de aceitabilidade, as faixas serão definidas como:

$$
\begin{aligned}
& \text { Risco Potencial }\left(\mathrm{R}_{\mathrm{P}}\right) \quad \begin{array}{l}
\text { Tolerável }: 0,368<\mathrm{R}_{\mathrm{P}}<0,449 \\
\text { Aceitável }: \mathrm{R}_{\mathrm{P}} \leq 0,368
\end{array}
\end{aligned}
$$

Dessa forma, pode-se estabelecer o nível de controle que se deseja avaliar. A Figura 4 representa as faixas de aceitabilidade nos níveis de controle 1 $\left(C_{R}=1\right), 2\left(C_{R}=2\right)$ e $3\left(C_{R}=3\right)$, todos com faixa de tolerância de $20 \%$.

O espaço de aceitabilidade pode ser utilizado para avaliar os riscos potenciais de cada indicador ou o risco potencial do conjunto dos indicadores. Caso o objetivo seja avaliar o serviço como um todo, o risco potencial será representado como um ponto no espaço de aceitabilidade, possibilitando a comparaçáo com outros serviços, bem como a evoluçáo temporal do sistema. Essa é uma informação importante para o sistema regulador, no caso a VISA, pois possibilita planejar as açóes, direcionando-as para os serviços de maior risco potencial e acompanhar a evolução temporal dos serviços, com 
FIGURA 4 - FAIXAS DE ACEITABILIDADE PARA OS TRÊS NÍVEIS DE CONTROLE

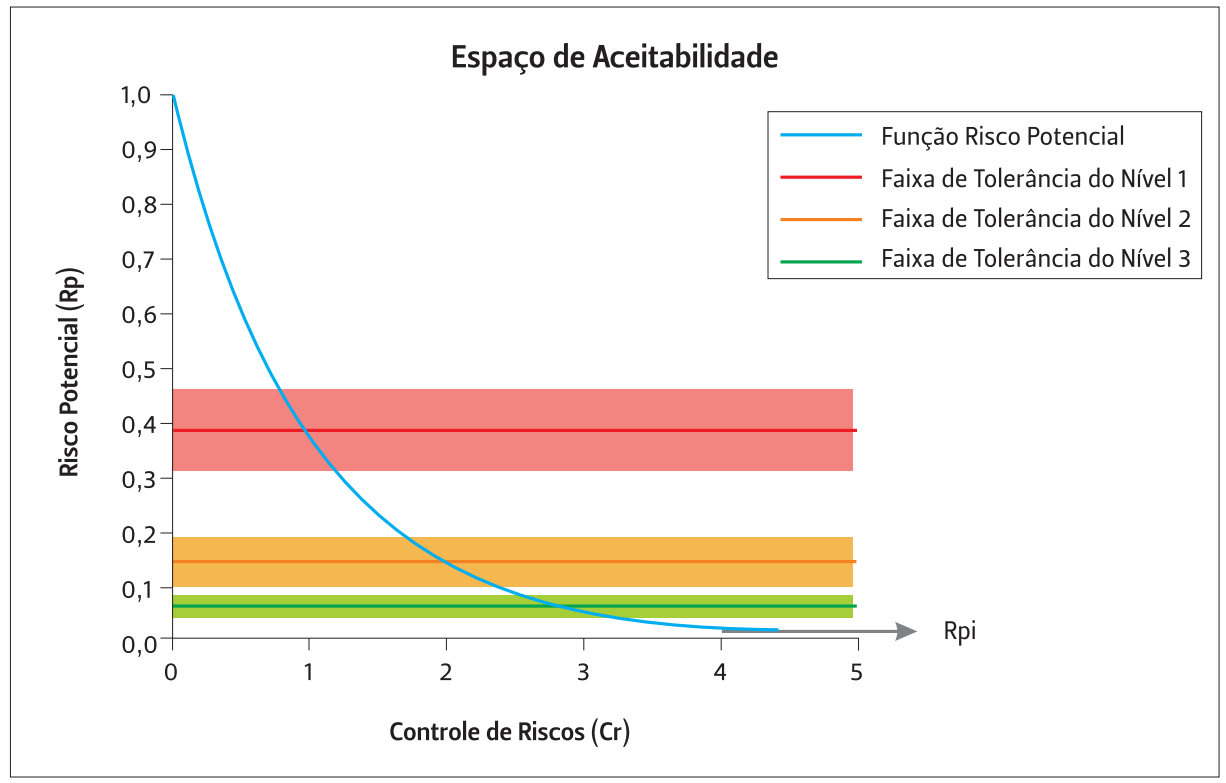


a possibilidade de avaliar o sistema, numa perspectiva histórica e náo apenas pontual.

Ademais, a VISA ou o próprio serviço de saúde pode desejar saber qual o comportamento de cada elemento do sistema de controle de risco. Para isso, basta representar, no gráfico, o valor do risco potencial de cada indicador, produzindo-se um espaço de aceitabilidade interno do serviço e a possibilidade de aplicar o princípio da otimização, internamente, atuando nas situaçóes de maior risco potencial.

A formulação teórica do MARP foi desenvolvida na perspectiva de utilização pelo sistema de vigilância sanitária, desde as açôes rotineiras de inspeção sanitária periódica até a análise do sistema de regulação de riscos. Para que as finalidades sejam alcançadas, o MARP precisa ser concretizado em métodos simples e práticos, para serem utilizados pelos diversos atores que compóem o sistema VISA. No próximo tópico, é apresentada a formulação do MARP para avaliação de risco potencial em radiodiagnóstico, sendo operacionalizado através de uma matriz simples e compacta que, com o auxílio do software Excel $^{\triangleright}$, possibilitou a realização das avaliaçóes sem a necessidade de cálculos pelo operador.

Uma vez que o objetivo foi analisar o controle de riscos em radiodiagnóstico e seus condicionantes, foram necessários indicadores que informassem sobre o ciclo de controle de riscos desta tecnologia, desde a produçáo dos equipamentos até os exames diagnósticos, e indicassem os condicionantes do controle, equivalentes à última etapa do gerenciamento de riscos. As áreas de avaliação de serviços de saúde e avaliação de riscos ganham bastante proximidade, como pode ser observado na conceituação de Vieira-da-Silva (2005) e Koh e Jeyaratnam (2005). Para Vieira-da-Silva (2005), a avaliação pode ser considerada um julgamento sobre uma prática social ou sobre qualquer dos seus componentes, com o objetivo de auxiliar na tomada de decisóes, enquanto que, para Koh e Jeyaratnam (2005), avaliação de riscos é o processo de estimar a magnitude dos riscos e julgar se o risco é aceitável, tolerável ou inaceitável. 


\section{MARP para serviços de radiodiagnóstico}

A operacionalização do MARP para o radiodiagnóstico é realizada através do estabelecimento de indicadores de controle associados aos riscos potenciais básicos, a saber: riscos potenciais de controle administrativo, riscos potenciais de proteção radiológica e riscos potenciais de qualidade da imagem, que estão relacionados, respectivamente, ao controle e coordenação do sistema pela autoridade reguladora, à otimizaçáo das doses em pacientes, trabalhadores e indivíduos do público e à qualidade da imagem e do exame diagnóstico. Assim, o controle de riscos em radiodiagnóstico deve ser avaliado levando em consideração todos os atores que atuam nesta área, e tendo a perspectiva da responsabilidade individual ou institucional com a realizaçáo de um diagnóstico adequado às necessidades da atenção à saúde humana.

Os indicadores de controle de riscos foram elaborados com base na Portaria SVS 453/98 e nas recomendaçôes internacionais da OMS/IAEA (INTERNATIONAL ATOMIC ENERGY AGENCY, 2006), tendo como propósito desenvolver um instrumento prático, para ser utilizado pelo sistema regulador. Os indicadores de controle de riscos (críticos e não-críticos) foram relacionados aos riscos potenciais, aos responsáveis diretos e indiretos por esses controles e aos responsáveis pelas ações de controle. Entretanto, tão importante quanto estabelecer os indicadores a serem utilizados é definir o local onde serão analisados e a forma como serão analisados, pois é necessário definir os indicadores adequados a um determinado local e com um objetivo específico. Um lugar privilegiado para verificar estes indicadores, são os serviços de radiodiagnóstico, tendo como forma de observação a inspeção sanitária. A inspeção sanitária em serviços de saúde é um dos momentos, se não o único, de materialização de práticas que sintetizam todo o controle de riscos do sistema de vigilância sanitária. É o momento de verificar registro de equipamentos, licença sanitária do estabelecimento, certificados de qualificação de profissionais, adequação de equipamentos, ambientes e procedimentos. (COSTA, 2004) 
Os indicadores foram selecionados, visando analisar o controle de riscos potenciais em radiodiagnóstico e seus condicionantes, através das informaçóes que podem ser verificadas na inspeção sanitária. Previamente à escolha e categorização dos indicadores de controle de riscos devem ser estabelecidos os níveis de avaliação do controle de riscos e as faixas de aceitabilidade dos riscos potenciais.

Os níveis de avaliação do controle foram definidos, com a perspectiva de evolução do sistema, refletindo o princípio da otimização. Assim, de forma semelhante aos níveis de controle proposto por Moores, Cannolly e Cole (1998), tem-se:

Nível 1 - Avalia a implantação do marco regulatório e a adequação dos serviços de radiodiagnóstico aos parâmetros estabelecidos na legislação. É o nível de controle utilizado neste trabalho. Os níveis 2 e 3 podem ser utilizados em estudos futuros, bem como para estabelecer metas de controle para o sistema de vigilância sanitária. O limite de aceitabilidade foi estabelecido através do risco potencial $\mathrm{R}_{\mathrm{P}}$ determinado pelo menor valor náo nulo dos indicadores de controle de riscos, ou seja, quando $\overline{\mathrm{I}}_{\mathrm{C}}=\overline{\mathrm{I}}_{\mathrm{NC}}=1$, implicando em $\mathrm{C}_{\mathrm{R}}=1$.

Nível 2 - Além do cumprimento da legislação, avalia o programa de garantia de qualidade utilizado, bem como das técnicas radiográficas. Esse limite foi estabelecido utilizando-se $\overline{\mathrm{I}}_{\mathrm{C}}=\overline{\mathrm{I}}_{\mathrm{NC}}=2$, implicando $\mathrm{C}_{\mathrm{R}}=2$.

Nível 3 - É o nível máximo e desejável de um sistema de controle de riscos em radiodiagnósticos. Neste nível, além dos indicadores dos Níveis 1 e 2, incluem-se as avaliaçóes de dose em pacientes, comparandoas com as referências, bem como as técnicas utilizadas e a qualidade da imagem. Neste nível, a relação entre técnica-dose-qualidade passa a ser avaliada de forma indissociável. O nível 3 de controle pode ser avaliado com $\overline{\mathrm{I}}_{\mathrm{C}}=\overline{\mathrm{I}}_{\mathrm{NC}}=3$, implicando $\mathrm{C}_{\mathrm{R}}=3$. 
As faixas de aceitabilidade foram definidas com base nos desvios máximos permitidos nos testes de controle de qualidade de radiodiagnósticos. Conforme estabelecido na Portaria SVS 453/98, o desvio máximo aceitável é de $20 \%$, do controle de riscos, para radiografia/fluoroscopia e $10 \%$ para mamografia/tomografia. Aplicando esses valores de tolerância no nível 1 de controle, foram estabelecidas as faixas de aceitabilidade utilizadas neste trabalho, como segue:

Risco Potencial Intrínseco ( $\left.\mathbf{R}_{\mathrm{p}}\right)$ : Nesta faixa, o valor do risco potencial $\left(\mathrm{R}_{\mathrm{p}}\right)$ máximo é $0,007\left(\mathrm{R}_{\mathrm{p}}(5)\right)$.

Risco Potencial Aceitável ( $\left.\mathbf{R}_{\mathrm{p} \mathbf{2}}\right)$ : Nesta faixa, o valor do risco potencial $\left(R_{\mathrm{P}}\right)$ varia entre 0,007 e $0,301\left(\mathrm{R}_{\mathrm{p}}(1,2)\right)$. Esses serviços necessitam de acompanhamento para se observar a tendência de $\mathrm{R}_{\mathrm{p}}$, no tempo, bem como aplicar o princípio da otimizaçáo para que se tenha o maior benefício possível com o menor risco.

Risco Potencial Tolerável $\left(\mathbf{R}_{\mathrm{p}}\right)$ : Nesta faixa, o valor do risco potencial $\left(\mathrm{R}_{\mathrm{p}}\right)$ varia entre 0,301 $\left(\mathrm{R}_{\mathrm{p}}(1,2)\right)$ a $0,449\left(\mathrm{R}_{\mathrm{p}}(0,8)\right)$ para radiografia $\mathrm{e}$ fluoroscopia e $0,407\left(\mathrm{R}_{\mathrm{p}}(0,9)\right)$ para mamografia e tomografia. Nesse caso, estima-se que os benefícios associados às práticas estão próximos dos riscos potenciais inaceitáveis. Assim, necessitam de acompanhamento e estabelecimento de prazos para otimização das práticas de forma a conduzi-los à faixa de riscos potenciais aceitáveis. Esses serviços requerem açáo direta e constante do sistema de visA.

Risco Potencial Inaceitável $\left(\mathbf{R}_{\text {pin }}\right)$ : Nesta faixa, o valor do risco potencial $\left(\mathrm{R}_{\mathrm{P}}\right)$ varia entre $0,449\left(\mathrm{R}_{\mathrm{p}}(0,8)\right)$ e $1,000\left(\mathrm{R}_{\mathrm{p}}(0)\right)$ para radiografia e fluoroscopia e entre $0,407\left(\mathrm{R}_{\mathrm{p}}(0,9)\right)$ e $1,000\left(\mathrm{R}_{\mathrm{p}}(0)\right)$ para mamografia e tomografia. Nesse caso, os benefícios associados às práticas são presumivelmente inferiores aos riscos potenciais. Desse modo, necessitam de imediata intervenção do sistema regulador. Esses 
serviços não devem continuar funcionando ou voltar a funcionar na condição de risco potencial tolerável.

Após a definição do nível de controle utilizado (nível 1) e o consequente estabelecimento das faixas de aceitabilidade, foram elaborados indicadores de controle de riscos para: fluoroscopia, mamografia, raios-X convencional e tomografia, categorizados da seguinte forma:

a) Local de verificação

Para simplificar o processo de identificação e análise dos indicadores, esses foram agrupados por local de verificação.

Administrativo (Geral)

Sala de Exames

Sala de Revelação

Sala de Laudos

b) Escala de avaliação

Os indicadores foram quantificados numa escala de 0 a 5, sendo: 0 - inexistente ou inadequado; 1 - sofrível; 2 - razoável; 3 - bom (O mínimo que a norma determina) ; 4 - ótimo, 5 - excelente e NA - não avaliado

c) Grupos de risco potencial associado ao indicador de controle

Os riscos potenciais foram agrupados segundo a possibilidade de dano:

1. Risco potencial tipo controle (CL): associado ao controle do sistema de regulação. Não está relacionado a nenhum agravo direto à saúde humana e sim a um dano ao controle do sistema. São indicadores tais como licença sanitária e registro de equipamentos.

2. Risco potencial tipo proteção radiológica (PR): São os riscos relacionados à proteção radiológica, ou seja, estão associados 
ao aumento das exposiçóes de pacientes, trabalhadores ou indivíduos do público. $\mathrm{O}$ aumento da magnitude da dose está associado ao aumento da probabilidade dos efeitos estocásticos das radiaçóes ionizantes ou à possibilidade de ocorrência de efeitos determinísticos.

3. Risco potencial tipo qualidade da imagem (QI): São os riscos que estão relacionados à qualidade da imagem e à possibilidade de erros de diagnóstico.

d) Qualificação dos indicadores

indicadores de controle de riscos foram qualificados em críticos e não- críticos:

1. Indicadores críticos: São os indicadores que têm a característica de aumentar os riscos sem agregar nenhum benefício, ou de provocar situaçóes potencialmente inaceitáveis, tais como equipamentos sem registro ou sem filtros e/ou colimadores.

2. Indicadores não críticos: São os indicadores que têm a característica de não provocar situaçóes potencialmente inaceitáveis ou não são definidos na legislação nacional. São indicadores como contrato de manutenção e dose de referência.

e) Responsabilidade direta

Segundo a Portaria 453/98 e recomendações internacionais, a responsabilidade direta por tudo que acontece no serviço de radiodiagnóstico é do responsável legal.

f) Responsabilidade compartilhada

Diz respeito aos atores, individuais ou coletivos, que, mesmo não sendo responsáveis legais do serviço, possuem responsabilidades objetivas e legais sobre a matéria. 
g) Controle sanitário

Refere-se à autoridade reguladora responsável, diretamente, por determinado controle de risco.

g) Controle sanitário compartilhado

Refere-se à autoridade reguladora responsável, complementarmente, pela ação de determinado controle de risco.

Com base nessas categorias, que permitem estabelecer o nível de aceitabilidade do risco potencial de um serviço e indicar os responsáveis pelas não conformidades, foram desenvolvidas matrizes, utilizando o software Excel $^{\oplus} 2003$, representadas nos quadros 1 a 4 .

Para o levantamento das informaçóes de cada procedimento avaliado, é necessário, aproximadamente, uma hora de inspeção visual e avaliação documental e, entre meia a uma hora para a realização das medidas. As medidas foram realizadas nos negatoscópios, na sala de laudos, na processadora e no equipamento emissor de raios-X. Para a avaliação do equipamento emissor de raios-X, são produzidos, em média, entre 10 e 60 disparos consecutivos. Assim, são necessárias informaçóes restritas do serviço, interrupção dos exames e utilização dos equipamentos no limite de sua capacidade. 


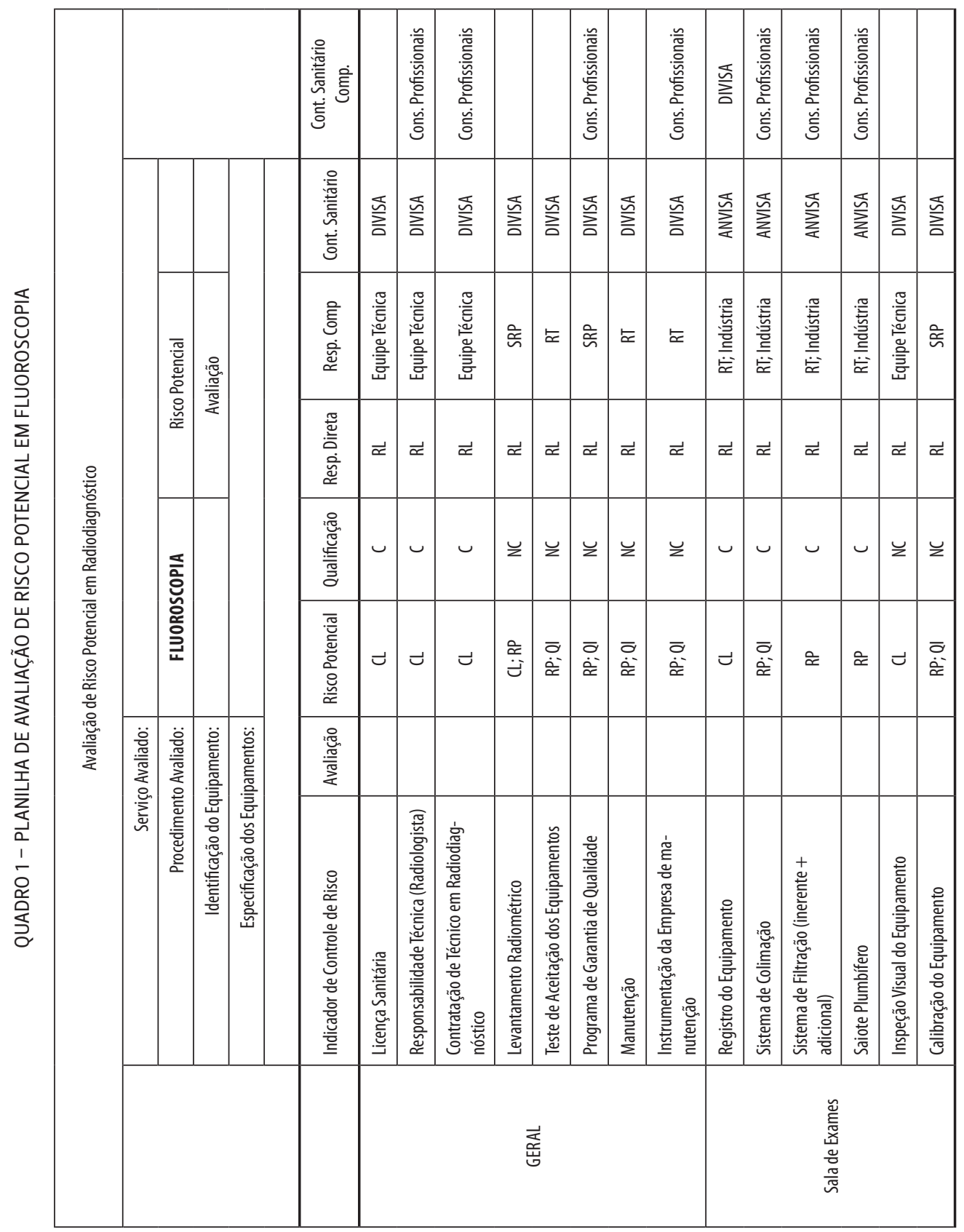




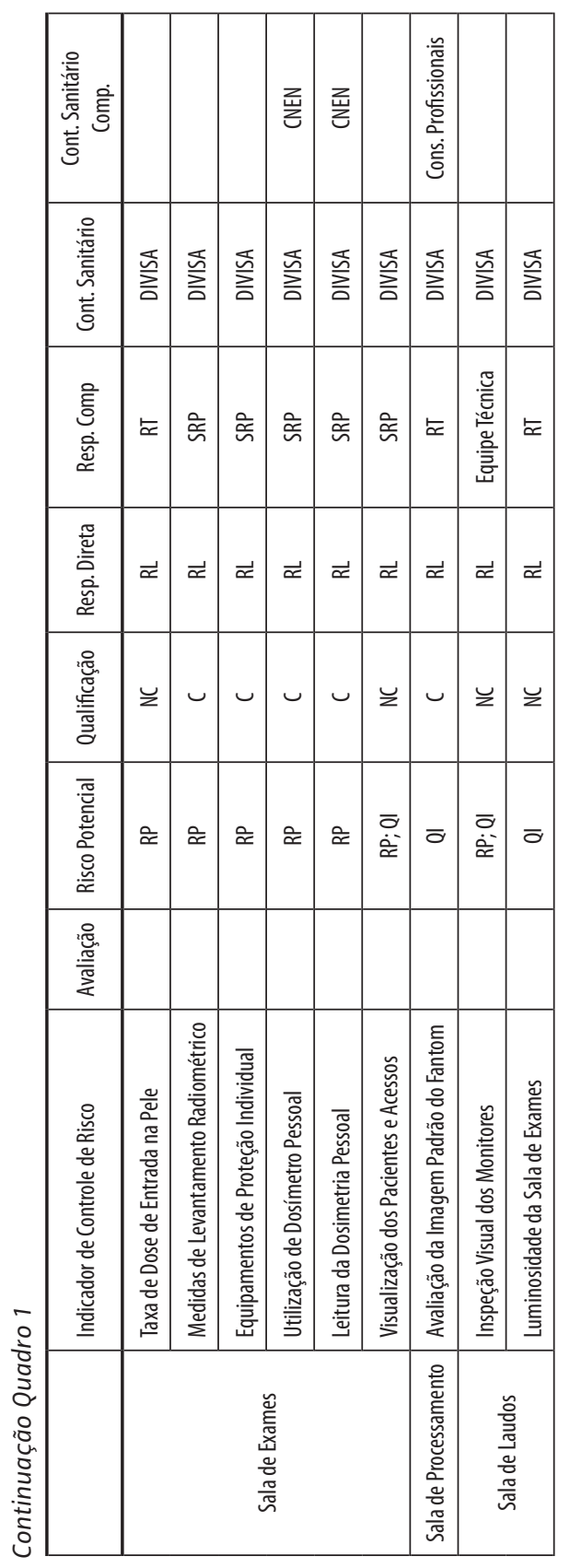




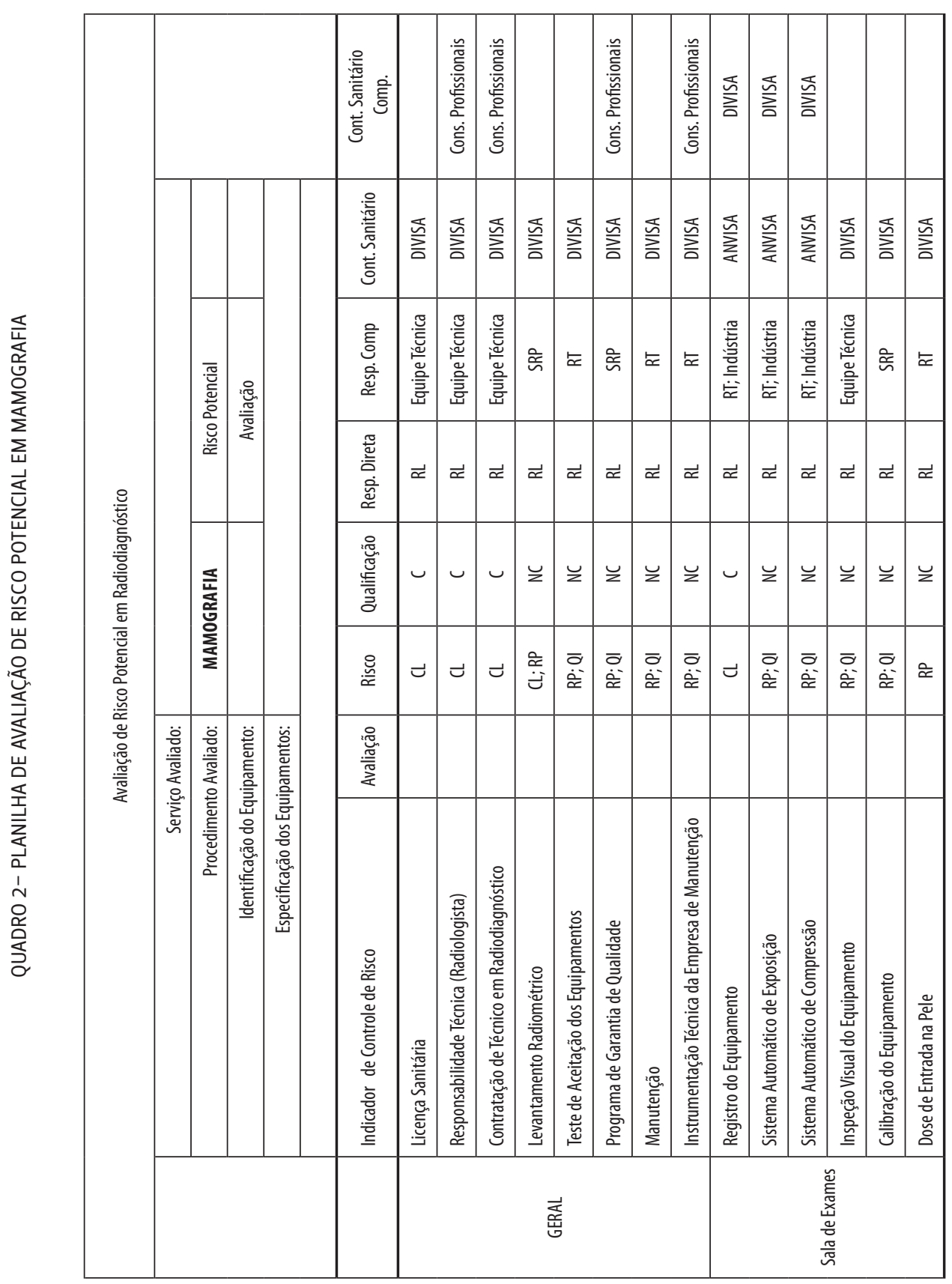




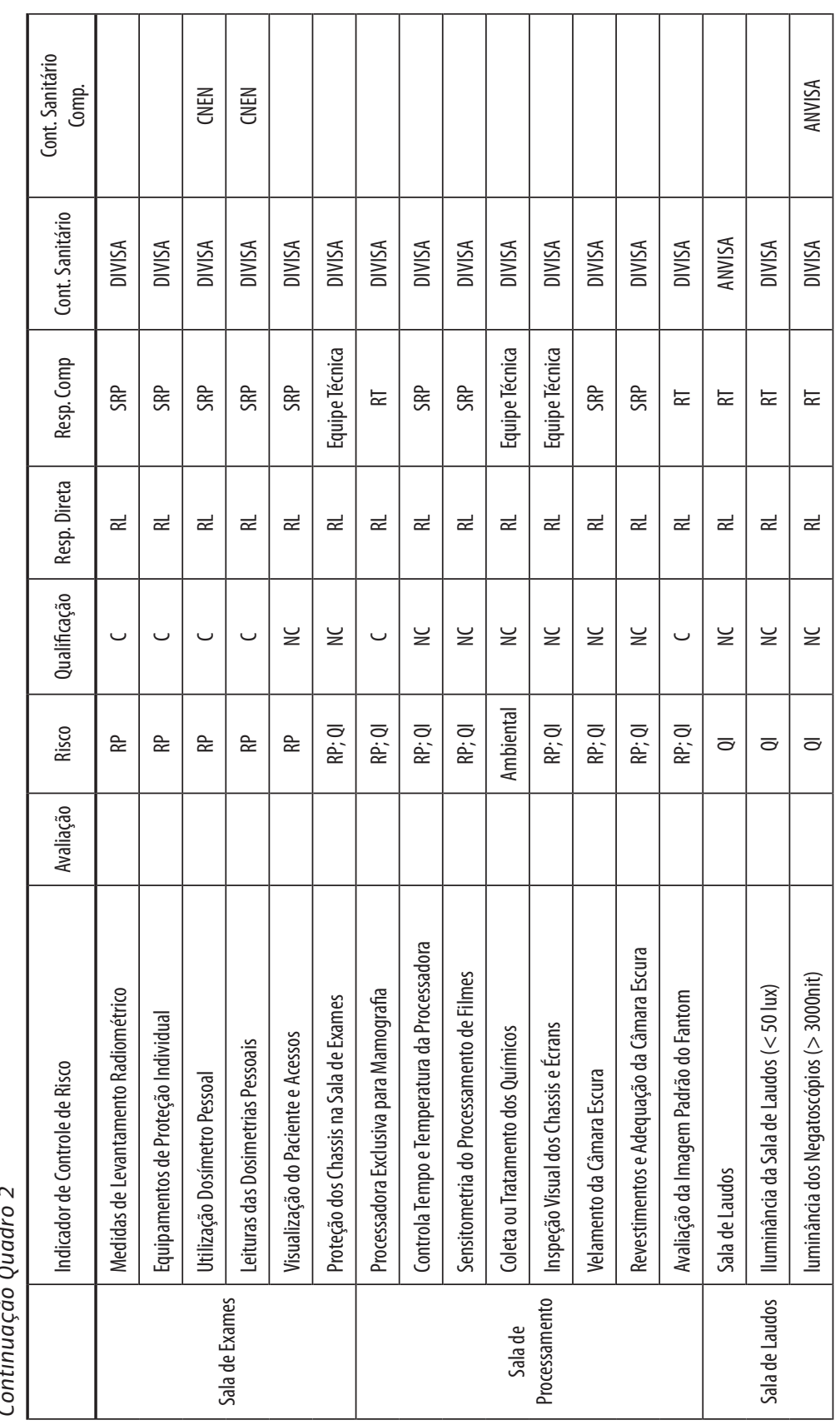




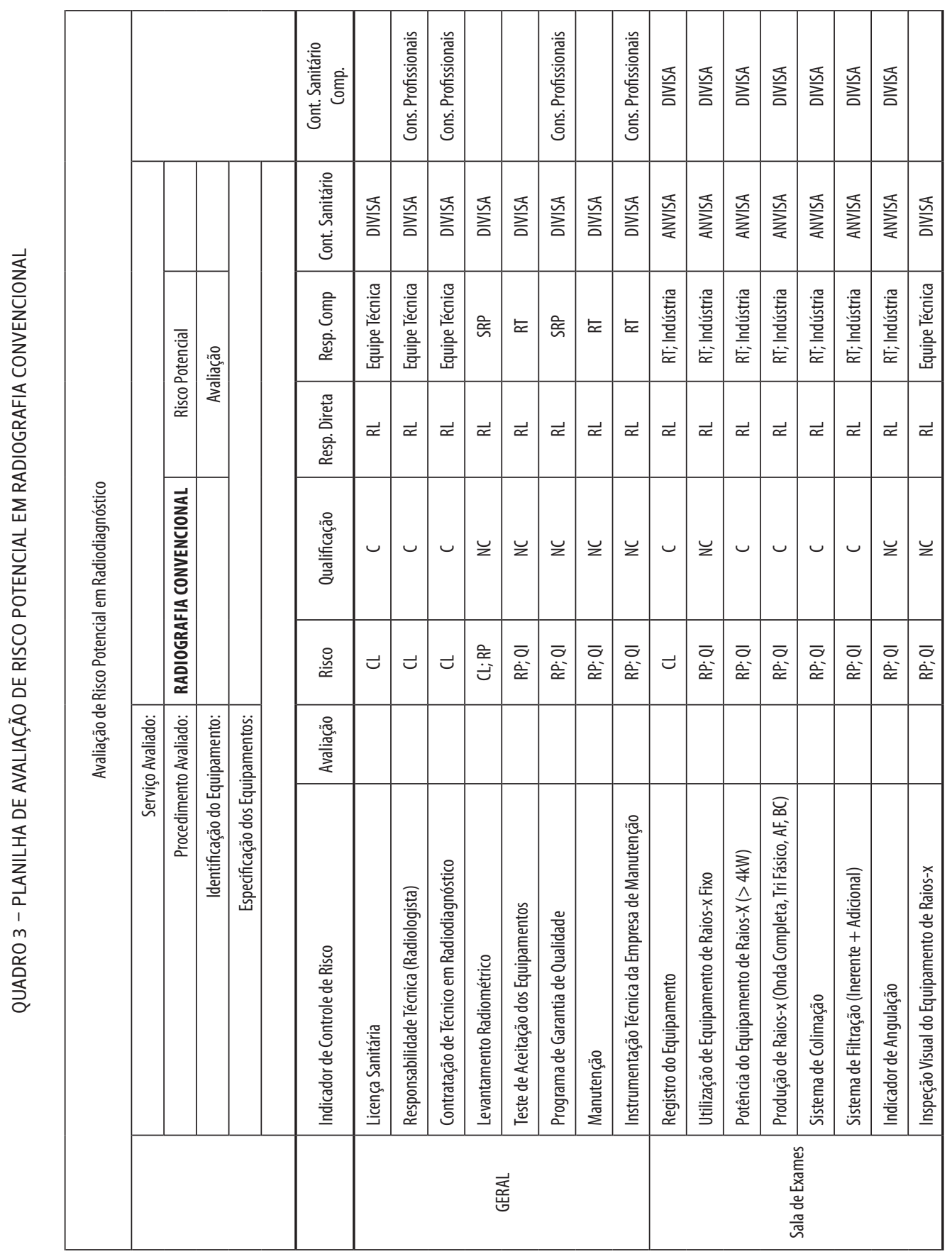




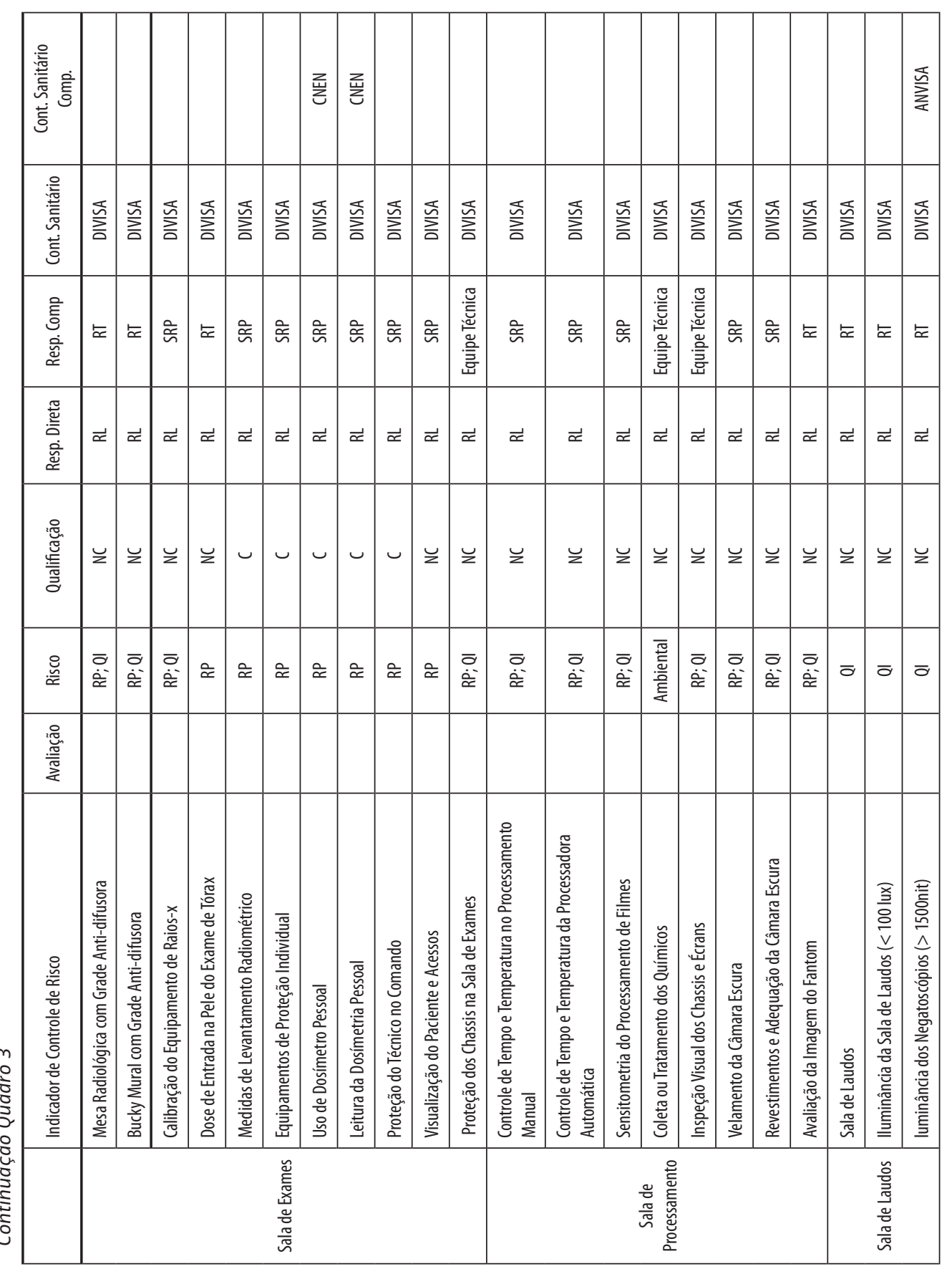




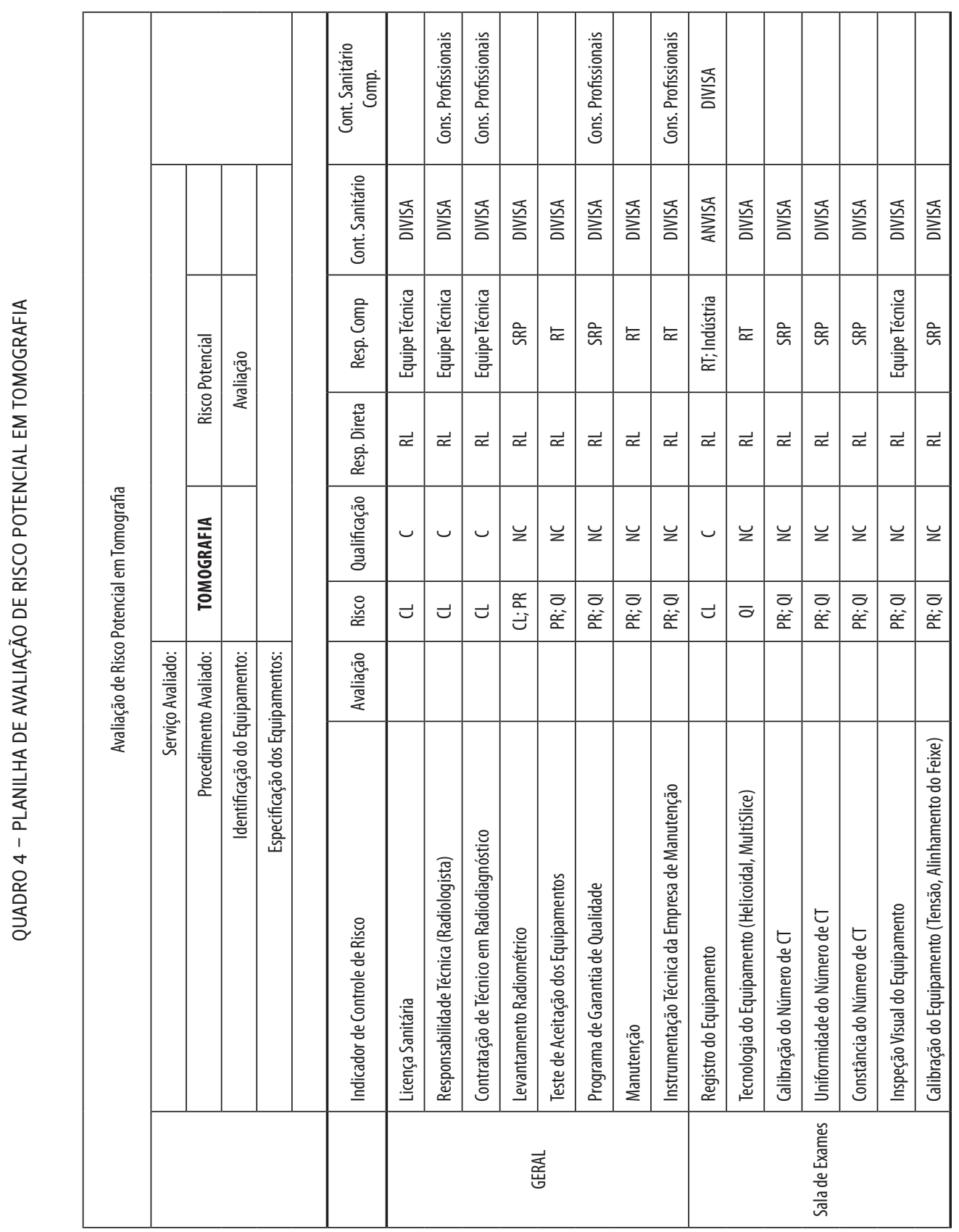




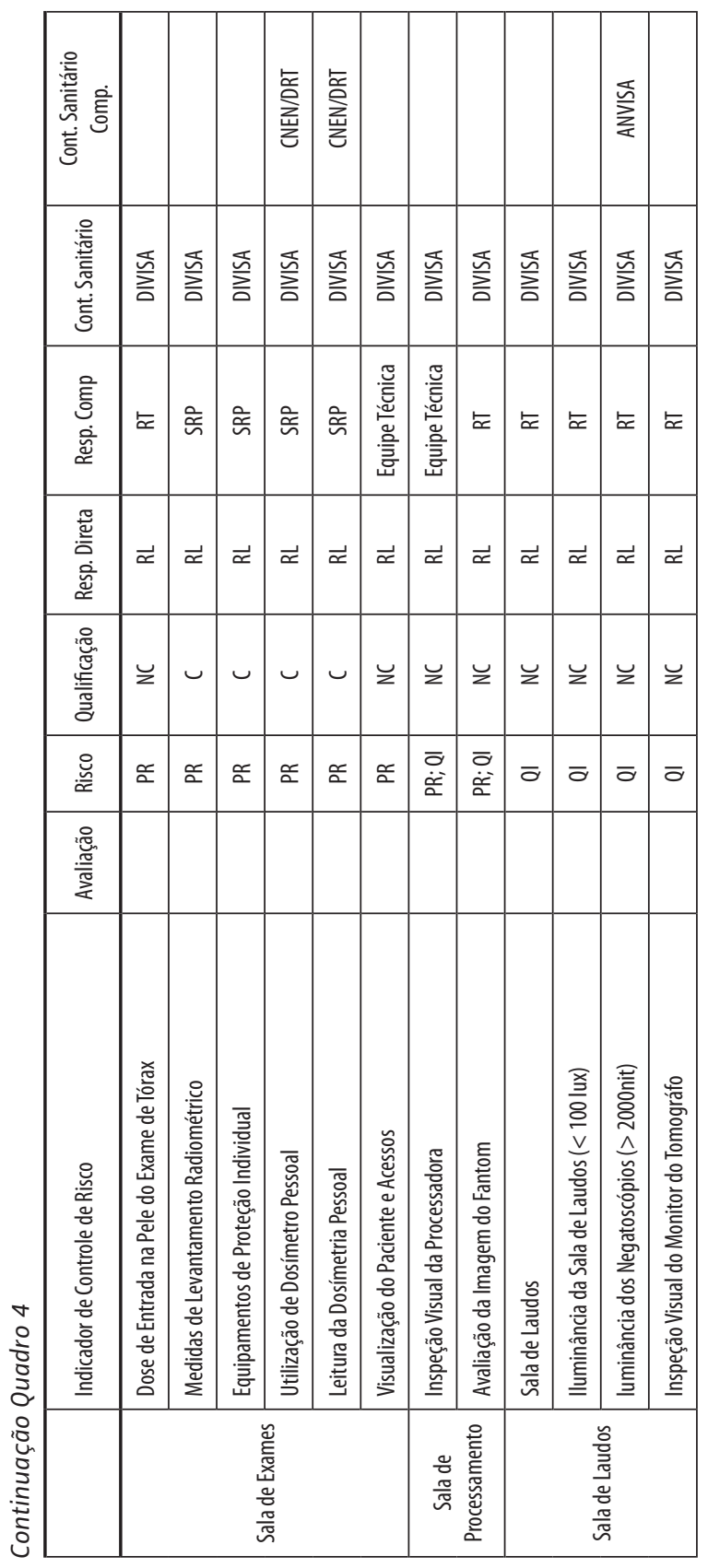


As planilhas de avaliação foram desenvolvidas, retratando a seqüência de ações de uma inspeção sanitária em radiodiagnóstico, visando adequar o instrumento de coleta de dados aos procedimentos que são realizados. Na primeira etapa da inspeção sanitária (Geral), é realizada a avaliação documental do serviço (licença sanitária, certificado de qualificação dos profissionais, contrato de trabalho, teste de aceitação, levantamento radiométrico, assentamento de PGQ e contrato de manutenção).

$\mathrm{Na}$ segunda etapa (Sala de Exames), são verificados os indicadores relativos ao equipamento de raios-X, mesa radiográfica, grade antidifusora, filme radiográfico, chassis, écran e ambiente.

A terceira etapa (Sala de Processamento) verifica se estão satisfeitas as condiçóes necessárias, para que todas as informações diagnósticas, que foram produzidas na realização do exame, estejam visíveis na radiografia. Para isto, avaliam-se a processadora automática ou tanque de revelaçáo, químicos para revelação e fixação da imagem, secadora e escurecimento da câmara escura.

Por fim, na quarta e última etapa (Sala de Laudos) é verificado o ambiente utilizado por médicos para visualizar a imagem radiográfica e obter a maior quantidade de informação diagnóstica possível. Para tanto, é necessário utilizar negatoscópios com luminância adequada e com limitação do campo luminoso ao tamanho do filme, numa sala de iluminância apropriada a impedir a reflexão da luz ambiente no filme.

Após o levantamento dos dados, a situação de risco potencial dos serviços é representada nos espaços de aceitabilidade, classificando e dimensionando o nível de aceitabilidade de cada procedimento. Como pode existir mais de um procedimento avaliado com o mesmo valor de risco potencial, causando superposição de pontos no gráfico, é adicionado ao espaço de aceitabilidade um gráfico tipo pizza com o número de serviços avaliados. Em seguida, as análises dos indicadores de controle de riscos possibilitam a caracterizaçáo dos condicionantes da situação encontrada. 


\section{Aplicando o MARP em serviços de radiodiagnóstico}

A aplicaçáo do MARP em radiodiagnóstico foi realizada com base nos indicadores de controle de riscos que são utilizados nas inspeçóes sanitárias dos serviços. Conforme discutido anteriormente, a obtençâo de tais informaçôes sobre as unidades públicas, privadas ou filantrópicas, torna-se quase impossível fora do contexto de uma inspeção sanitária. E compor uma equipe para esse fim, requer atenção aos requisitos legais e éticos.

Por esses motivos, todos os indicadores que constam nas planilhas de avaliaçáo são do escopo da inspeçáo sanitária e integram os formulários e roteiros utilizados nessas açóes. Dessa forma, o autor deste estudo acompanhou as açôes dos técnicos da Diretoria de Vigilância e Controle Sanitário do Estado da Bahia (DIVISA), realizando medidas de desempenho dos equipamentos (emissores de raios-X, formaçáo da imagem, processadora de filmes e negatoscópio) e proteção radiológica (levantamento radiométrico). Todas as medidas foram realizadas seguindo os requisitos técnicos e metodológicos da Portaria 453/98 e foram utilizados instrumentos de medidas adequados e calibrados para os fins de radiodiagnóstico.

Nessas bases, foi possível utilizar o MARP para avaliar o risco potencial dos procedimentos de radiodiagnóstico de serviços de saúde, públicos e privados, do Estado da Bahia. Um serviço de saúde pode possuir mais de um tipo de procedimento de radiodiagnóstico (fluoroscopia, mamografia, radiografia e tomografia). Cada procedimento é constituído por um equipamento emissor de raios-X (raios-X com fluoroscopia, mamógrafo, raios-X convencional ou tomógrafo), um sistema de revelaçáo (câmara escura, processadora de filme manual, automática ou a laser) e uma sala de laudos com um ou mais negatoscópios. Dessa forma, sáo geralmente independentes, podendo ocorrer, por exemplo, da avaliaçáo de dois procedimentos do mesmo serviço indicar que um está com nível de risco potencial aceitável, enquanto o outro apresentar nível de risco potencial inaceitável.

Portanto, através do acompanhamento das inspeçōes sanitárias, foi possível avaliar os riscos potenciais de 94 procedimentos (60 de radiografia, 
7 de fluoroscopia, 14 de mamografia e 13 de tomografia) em 38 serviços (13 públicos e 25 privados) de 15 cidades, distribuídas em cinco regióes do Estado da Bahia, descritos na Tabela 1.

TABELA 1 - PROCEDIMENTOS DE RADIODIAGNÓSTICO AVALIADOS

\begin{tabular}{ccccc|c|c}
\hline & \multicolumn{3}{c|}{} & \multicolumn{3}{c}{ Total } \\
\hline & Fluoroscopia & Mamografia & Radiografia & Tomografia & $\mathrm{N}$ & $\%$ \\
\hline Público & 1 & 3 & 22 & 4 & 30 & 31,9 \\
Privado & 6 & 11 & 38 & 9 & 64 & 68,1 \\
\hline Total & 7 & 14 & 60 & 13 & 94 & 100 \\
\hline
\end{tabular}

Os dados mais recentes sobre o número de equipamentos de radiodiagnóstico no Estado da Bahia estáo representados na Tabela 2 e mostram que existem 1.292 equipamentos, sendo: 28 raios-X com fluoroscopia, 191 mamógrafos, 992 raios-X convencionais e 81 tomógrafos. Como pode ser observado, os procedimentos avaliados neste estudo representam 7,3\% do total de equipamentos do Estado e o número de cada equipamento representa, aproximadamente, a mesma proporçáo observada no nível estadual e nacional.

As planilhas que foram utilizadas, representadas nos Quadros 1 a 4, refletem as especificidades técnicas e normativas de cada tipo de procedimento de radiodiagnóstico, possibilitando avaliá-los, indicando os responsáveis, diretos e complementares, por cada um dos indicadores de controle de risco, que estabelecem a situaçáo de risco potencial do procedimento. Através da análise dos indicadores, será possível discutir e indicar os condicionantes, gerais e específicos, da situação de risco potencial verificada nos procedimentos. 
TABELA 2 - EQUIPAMENTOS EXISTENTES EM ESTABELECIMENTOS DE SAÚDE, POR TIPO DE EQUIPAMENTO, SEGUNDO AS GRANDES REGIÕES E UNIDADES DA FEDERAÇÃO- BRASIL IBGE - 2005

\begin{tabular}{|c|c|c|c|c|c|c|c|}
\hline \multirow{2}{*}{$\begin{array}{l}\text { Grandes Regiões, } \\
\text { Unidades da } \\
\text { Federação } \\
\text { e Municípios das } \\
\text { Capitais }\end{array}$} & \multicolumn{7}{|c|}{ Equipamentos existentes em estabelecimentos de saúde } \\
\hline & $\begin{array}{l}\text { Raios X com } \\
\text { Fluoroscopia }\end{array}$ & Mamógrafos & $\begin{array}{c}\text { Raio X até } \\
100 \mathrm{~mA}\end{array}$ & $\begin{array}{c}\text { Raio X de } \\
100 \text { a } 500 \\
\text { mA }\end{array}$ & $\begin{array}{l}\text { Raio } X \text { mais } \\
\text { de } 500 \mathrm{~mA}\end{array}$ & Tomógrafos & Total \\
\hline Norte & 30 & 125 & 345 & 417 & 96 & 71 & 1.084 \\
\hline Rondônia & 2 & 29 & 22 & 55 & 15 & 10 & 133 \\
\hline Acre & 1 & 5 & 9 & 23 & 3 & 4 & 45 \\
\hline Amazonas & 4 & 22 & 87 & 81 & 28 & 14 & 236 \\
\hline Roraima & - & 4 & 5 & 17 & 6 & 2 & 34 \\
\hline Pará & 17 & 48 & 162 & 192 & 36 & 34 & 489 \\
\hline Amapá & 1 & 6 & 12 & 16 & 2 & 3 & 40 \\
\hline Tocantins & 5 & 11 & 48 & 33 & 6 & 4 & 107 \\
\hline Nordeste & 110 & 573 & 1.101 & 1.542 & 429 & 294 & 4.049 \\
\hline Maranhão & 6 & 31 & 110 & 171 & 31 & 24 & 373 \\
\hline Piauí & 11 & 34 & 73 & 109 & 28 & 24 & 279 \\
\hline Ceará & 18 & 75 & 170 & 192 & 45 & 44 & 544 \\
\hline Rio Grande do Norte & 5 & 33 & 69 & 93 & 32 & 19 & 251 \\
\hline Paraíba & 11 & 36 & 99 & 93 & 33 & 17 & 289 \\
\hline Pernambuco & 19 & 103 & 187 & 241 & 69 & 55 & 674 \\
\hline Alagoas & 8 & 37 & 53 & 55 & 22 & 15 & 190 \\
\hline Sergipe & 4 & 33 & 32 & 52 & 21 & 15 & 157 \\
\hline Bahia & 28 & 191 & 308 & 536 & 148 & 81 & 1.292 \\
\hline Sudeste & 794 & 1.738 & 2.805 & 4.499 & 1.247 & 1.088 & 12.171 \\
\hline Minas Gerais & 185 & 379 & 630 & 972 & 271 & 199 & 2.636 \\
\hline Espírito Santo & 23 & 49 & 96 & 161 & 52 & 36 & 417 \\
\hline Rio de Janeiro & 138 & 397 & 777 & 1.118 & 236 & 262 & 2.928 \\
\hline São Paulo & 448 & 913 & 1.302 & 2.248 & 688 & 591 & 6.190 \\
\hline Sul & 221 & 523 & 823 & 1.267 & 496 & 342 & 3.672 \\
\hline Paraná & 73 & 166 & 406 & 455 & 160 & 125 & 1.385 \\
\hline Santa Catarina & 35 & 93 & 144 & 260 & 132 & 61 & 725 \\
\hline Rio Grande do Sul & 113 & 264 & 273 & 552 & 204 & 156 & 1.562 \\
\hline
\end{tabular}


Continuação Tabela 2

\begin{tabular}{|l|c|c|c|c|c|c|c|}
\hline \multicolumn{1}{|c|}{ Centro-0este } & 98 & 286 & 463 & 660 & 243 & 166 & 1.916 \\
\hline Mato Grosso do Sul & 13 & 41 & 100 & 110 & 38 & 17 & 319 \\
\hline Mato Grosso & 23 & 49 & 97 & 149 & 33 & 37 & 388 \\
\hline Goiás & 34 & 117 & 214 & 298 & 101 & 61 & 825 \\
\hline Distrito Federal & 28 & 79 & 52 & 103 & 71 & 51 & 384 \\
\hline Brasil & 1.253 & 3.245 & 5.537 & 8.385 & 2.511 & 1.961 & 22.892 \\
\hline
\end{tabular}

Fonte: IBGE, Diretoria de Pesquisas, Coordenação de População e Indicadores Sociais, Pesquisa de Assistência Médico-Sanitária 2005.

\section{Avaliação de riscos potenciais em serviços de radiodiagnóstico no Estado da Bahia}

Conforme sintetizado na Tabela 3, a avaliação dos 94 procedimentos e 38 serviços, revelou que 30 (32\%) (4 de fluoroscopia, 6 de mamografia, 12 de radiografia e 8 de tomografia) tinham níveis de risco potencial aceitável, 18 (19\%) (1 de fluoroscopia, 3 de mamografia, 11 de radiografia e 3 de tomografia) níveis de risco potencial tolerável e 46 (49\%) (2 de fluoroscopia, 5 de mamografia, 37 de radiografia e 2 de tomografia) tinham níveis de risco potencial inaceitável.

TABELA 3 - SÍNTESE DA AVALIAÇÃO DOS PROCEDIMENTOS

\begin{tabular}{|c|c|c|c|c|c|c|c|}
\hline & \multicolumn{5}{|c|}{ Procedimentos Avaliados } & \multicolumn{2}{|c|}{ Total } \\
\hline & & Fluoroscopia & Mamografia & Radiografia & Tomografia & $\mathrm{N}$ & $\%$ \\
\hline \multirow{3}{*}{ Público } & Aceitável & - & 2 & 4 & 2 & 8 & 8,5 \\
\hline & Tolerável & 1 & 1 & 7 & 2 & 11 & 11,7 \\
\hline & Inaceitável & - & - & 11 & - & 11 & 11,7 \\
\hline \multirow{3}{*}{ Privado } & Aceitável & 4 & 4 & 8 & 6 & 22 & 23,4 \\
\hline & Tolerável & - & 2 & 4 & 1 & 7 & 7,4 \\
\hline & Inaceitável & 2 & 5 & 26 & 2 & 35 & 37,2 \\
\hline Total & & 7 & 14 & 60 & 13 & 94 & 100 \\
\hline
\end{tabular}


Com relação aos serviços de radiodiagnóstico, cuja síntese encontrase na Tabela 4, apenas 2 unidades (5,3\%), uma pública e uma privada, estavam com todos os procedimentos em nível de risco potencial aceitável. $9(23,7 \%)$ serviços estavam com, pelo menos, um procedimento com nível de risco potencial tolerável e 27 (71\%) serviços possuíam, pelo menos, um procedimento com nível de risco potencial inaceitável.

TABELA 4 - SÍNTESE DA AVALIAÇÃO DOS SERVIÇOS

\begin{tabular}{|c|c|c|c|c|c|}
\hline & & & \multicolumn{3}{|c|}{ Total } \\
\hline & & & $\mathrm{N}$ & $\%$ & $\%$ rel \\
\hline \multirow{3}{*}{ Público } & Aceitável & 1 & \multirow{3}{*}{13} & 2.6 & 7.7 \\
\hline & Tolerável & 5 & & 13.2 & 38.5 \\
\hline & Inaceitável & 7 & & 18.4 & 53.8 \\
\hline \multirow{3}{*}{ Privado } & Aceitável & 1 & \multirow{3}{*}{25} & 2.6 & 4.0 \\
\hline & Tolerável & 4 & & 10.5 & 16.0 \\
\hline & Inaceitável & 20 & & 52.6 & 80.0 \\
\hline \multicolumn{3}{|l|}{ Total } & 38 & 100 & - \\
\hline
\end{tabular}

A descrição detalhada da situação de risco potencial foi realizada, como forma de sistematização, segundo os tipos de procedimentos avaliados e na seqüência em que os indicadores são apresentados na planilha de avaliação. Além da informação básica de quantos indicadores obtiveram valor zero (Quadros 5 a 8), que significa ausência completa de controle, foram consideradas as informaçóes gerais das planilhas de avaliação, os relatórios de inspeção e as informaçóes anotadas, de forma não sistematizada, durante a realização das inspeçóes. 


\section{Fluoroscopia}

Este estudo considerou 07 procedimentos de fluoroscopia de 05 instituiçóes, sendo um procedimento em unidade pública e seis em unidades privadas. Conforme representado na Figura 5, dos sete procedimentos avaliados, 4 (57\%) estavam em situação de risco potencial aceitável, 1 (14\%) com risco potencial tolerável e $2(29 \%)$ com risco potencial inaceitável. Uma síntese dos indicadores, que apresentaram valor menor que o nível de controle aceitável (nível 1 de controle significa $C_{R}=1$ ), está representada no Quadro 5. Estes indicadores, críticos ou não-críticos, tiveram valor zero.

A ausência de saiote de chumbo em um equipamento e de seu registro na ANVISA, assim como, a ausência de colimadores, filtração adicional e licença sanitária, em outro, provocaram as duas situaçóes de risco potencial inaceitável. O procedimento classificado como de risco potencial tolerável encontrava-se com o equipamento nas condiçôes mínimas de calibração e não havia informaçóes sobre a licença sanitária. Apenas dois serviços apresentaram licença sanitária dentro do prazo de validade, que é de um ano.

É importante ressaltar que nenhum serviço possui programa de garantia de qualidade, nem realizou teste de aceitação dos equipamentos, antes de iniciar a operação. Com relação aos outros indicadores, 3 procedimentos estavam com a qualidade da imagem em boas condiçóes, 3 estavam em condiçóes sofríveis e em um procedimento não foi avaliada a condição da imagem. O procedimento que possuía equipamento sem registro, sem filtro, sem colimador e também sem licença sanitária não teve o equipamento submetido a testes. 


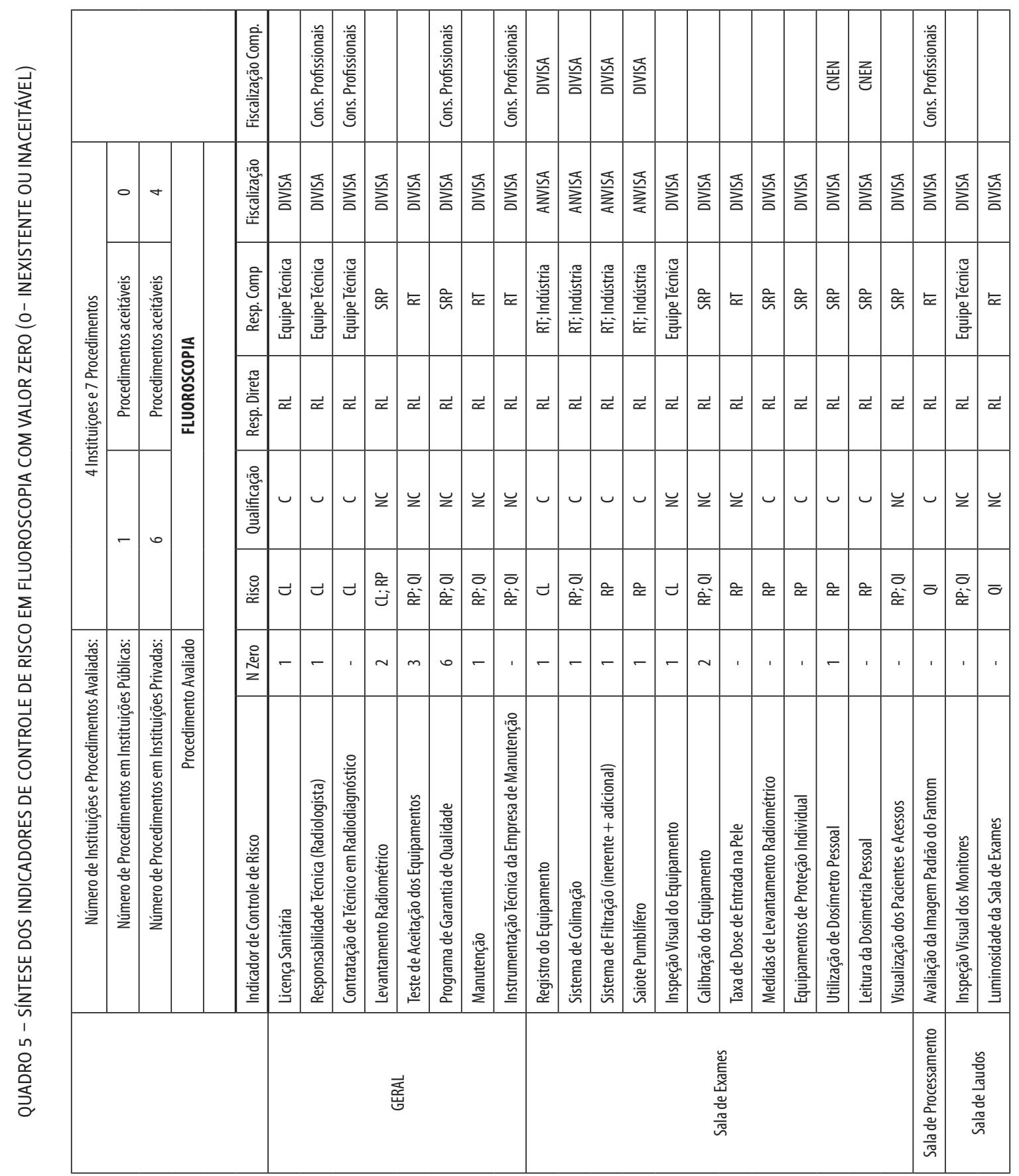


FIGURA 5 - GRÁFICO DO ESPAÇO DE ACEITABILIDADE EM PROCEDIMENTO DE FLUOROSCOPIA

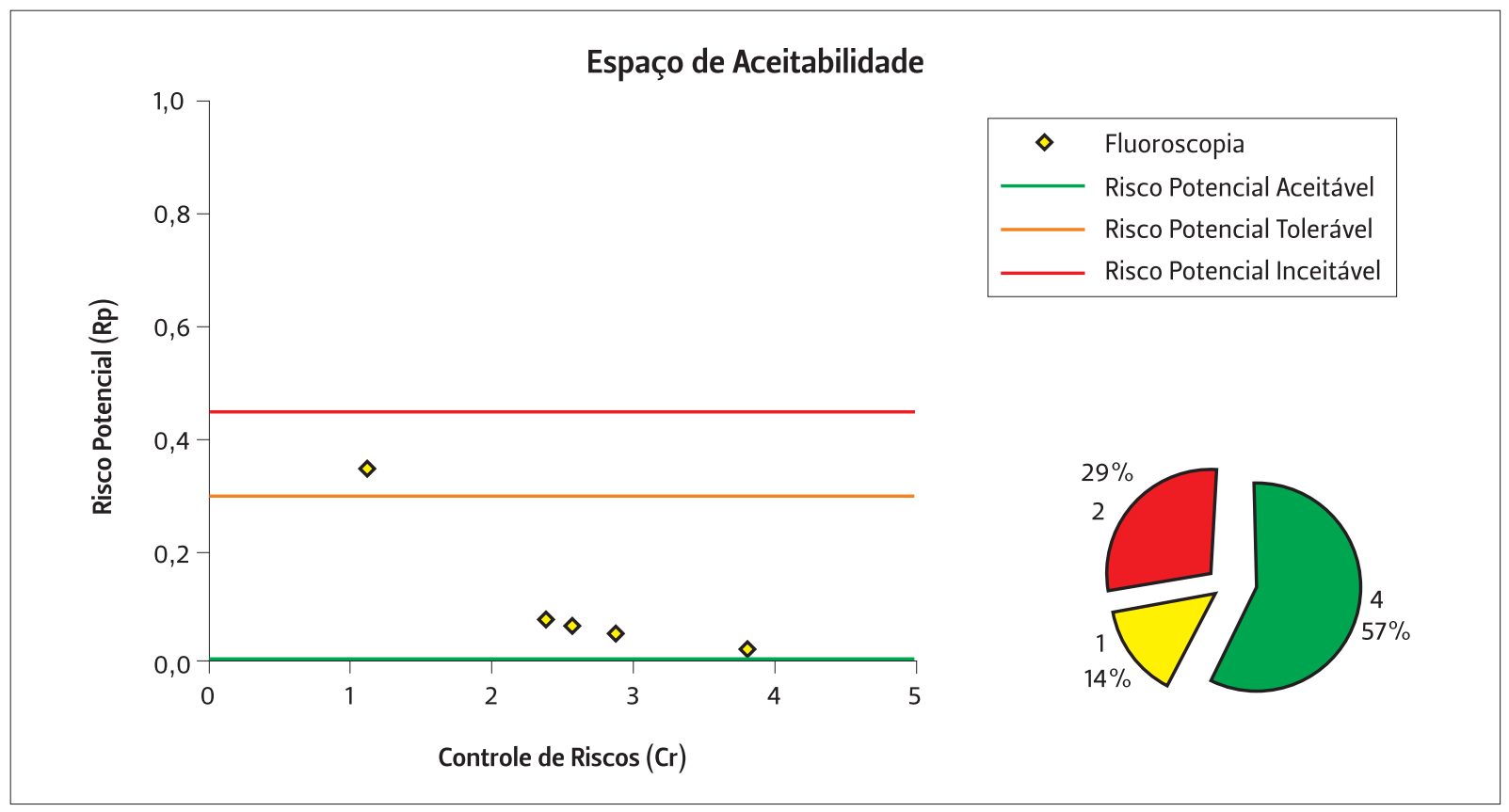




\section{Mamografia}

De acordo com a Tabela 3, foram avaliados 14 procedimentos de mamografia em 13 instituiçóes, estando três funcionando em unidades públicas e onze em unidades privadas. Conforme representado na Figura 6, dos catorze procedimentos de mamografia avaliados, 6 (43\%) estavam em situação de risco potencial aceitável, $3(21 \%)$ em risco potencial tolerável e $5(36 \%)$ em situação de risco potencial inaceitável.

Uma síntese dos indicadores que apresentaram valor menor que o nível de controle aceitável (nível 1 de controle significa $\mathrm{C}_{\mathrm{R}}=1$ ) está representada no Quadro 6. Estes indicadores, críticos ou não-críticos, tiveram valor zero.

As principais inadequaçóes relativas aos procedimentos com situação de risco potencial inaceitável foram relativas à inexistência de responsável técnico, 2 (14\%), ausência de processadora exclusiva, $4(28,5 \%)$, e dois equipamentos estavam com registro vencido. Os equipamentos com os registros vencidos não possuíam sistema automático de exposição, de compressão da mama e grade antidifusora, além de um deles encontrar-se com o filtro adicional fixado com uma fita adesiva.

Com relaçáo aos outros equipamentos do procedimento, 5 (36\%) câmaras escuras estavam com entrada de luz, 6 (43\%) das salas de laudo tinham luminosidade superior ao recomendado e 13 (93\%) dos negatoscópios apresentaram luminância inferior a 1.000 nit, quando o limite mínimo é 3.000 nit.

Quanto aos procedimentos, 6 (42\%) utilizavam guarda de chassis no interior da sala de exames sem nenhuma proteção, 10 (72\%) não realizavam avaliação periódica da imagem do phantom e $11(79 \%)$ das imagens do phantom possuíam artefatos e manchas no filme; além disso, não foi possível visualizar todos os conjuntos mínimos de objetos de testes.

É fundamental ressaltar que apenas uma instituição possuía programa de garantia de qualidade, ainda em fase de implantação. Encontrou-se coleta ou tratamento dos químicos utilizados na revelaçấo dos filmes táo somente em $4(28,5 \%)$ das processadoras analisadas. 


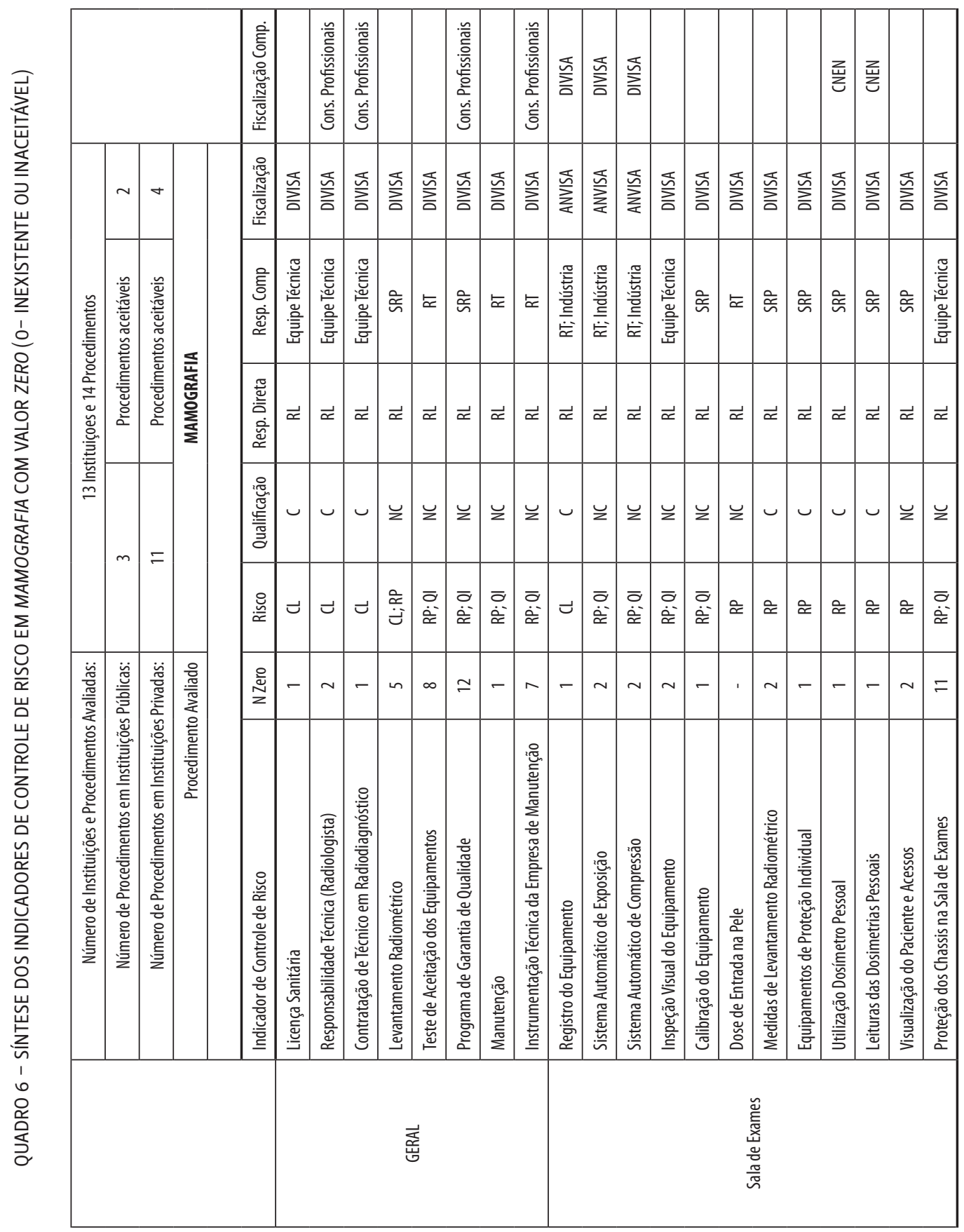




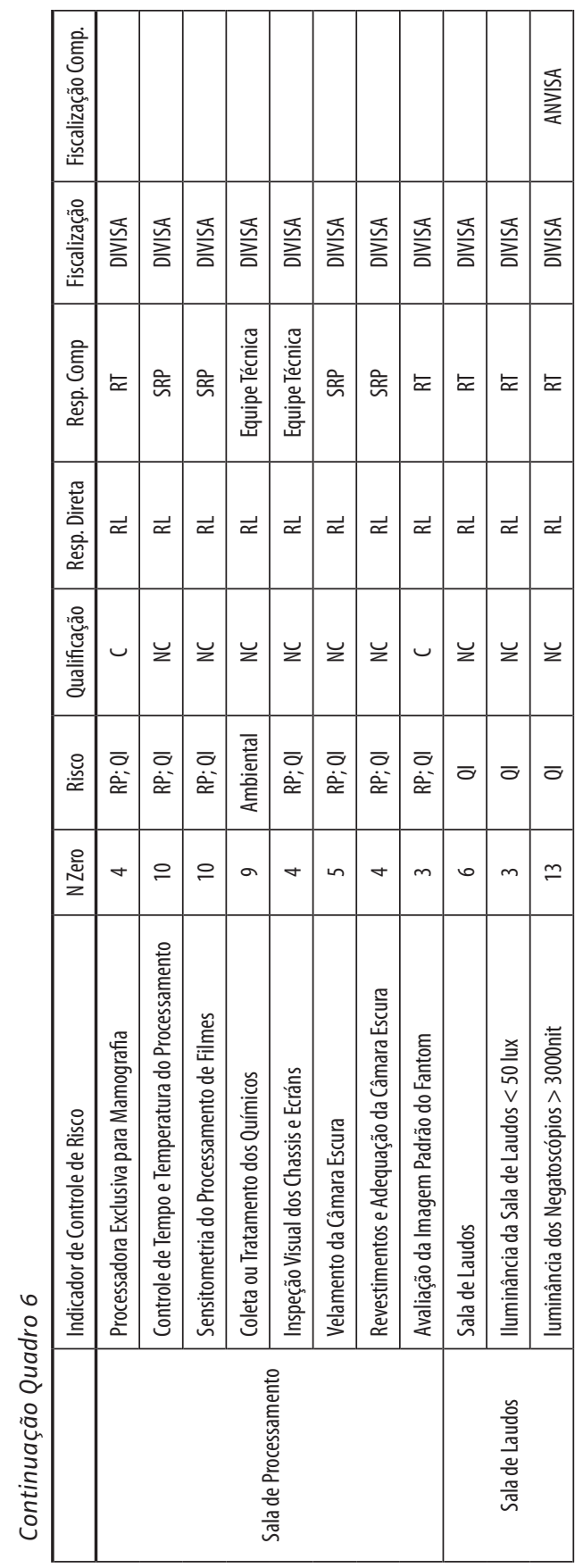


FIGURA 6 - GRÁFICO DO ESPAÇO DE ACEITABILIDADE EM PROCEDIMENTO DE MAMOGRAFIA

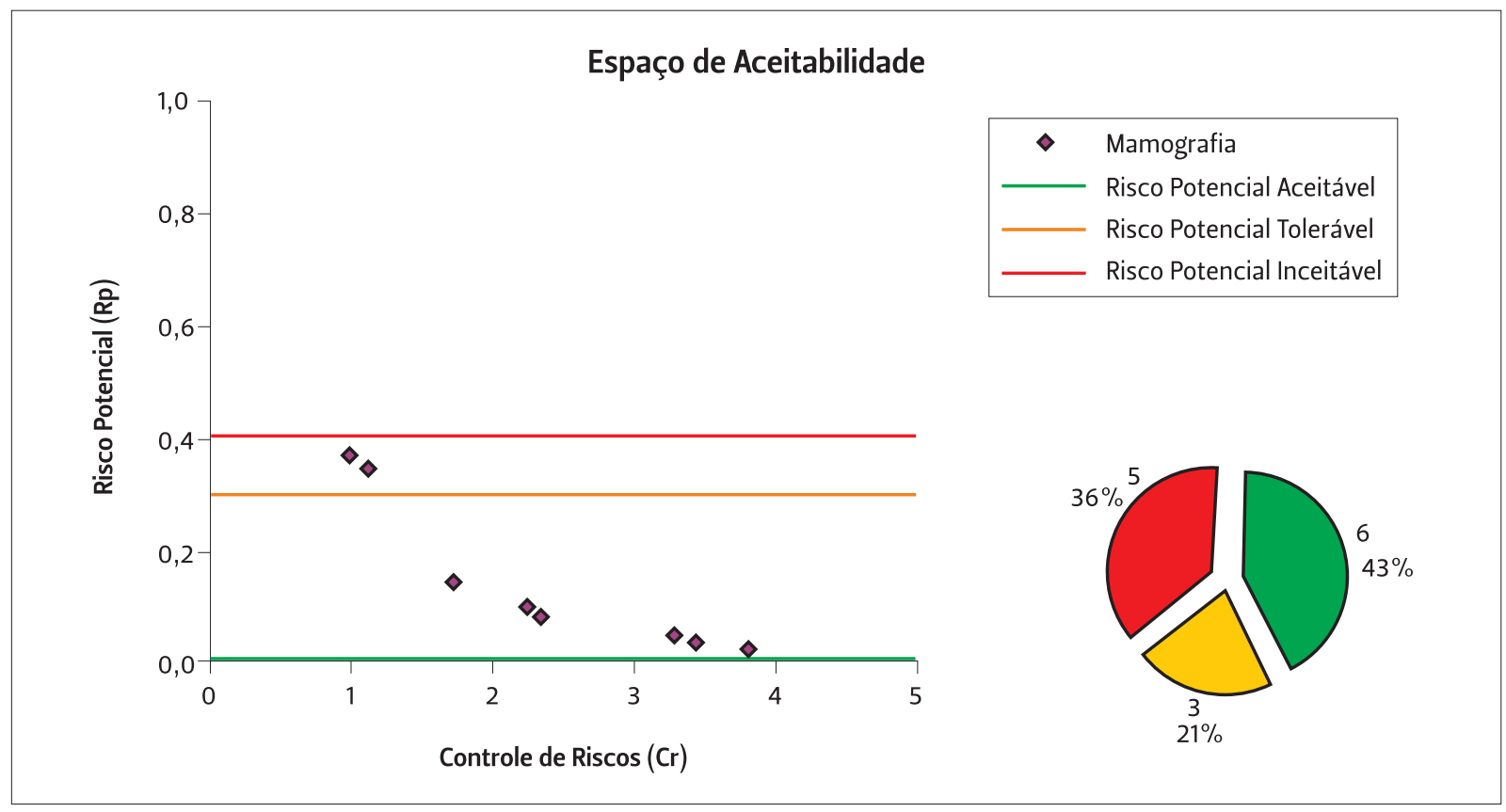


Outra questão importante observada na avaliação é que 6 (42\%) dos equipamentos avaliados são do mesmo fabricante e todos apresentaram as mesmas não conformidades no sistema de compressão da mama e do tamanho de campo. A compressão da mama deveria estar entre 11 e 18 kgf, mas encontrava-se acima de $25 \mathrm{kgf}$, chegando a $42 \mathrm{kgf}$ em um equipamento.

\section{Radiografia Convencional}

Conforme Tabela 3, foram avaliados 60 equipamentos de raios-X convencional de 38 instituiçóes, 22 funcionavam em serviços públicos e 38 em serviços privados. Entre os procedimentos avaliados, 12 (20\%) estavam com avaliação de risco potencial aceitável, 11(18\%) tolerável e 37 (62\%) inaceitável, segundo representaçáo na Figura 7. Entre os 37 procedimentos em situação de risco potencial inaceitável, 11 eram de instituiçôes públicas e 26 de unidades privadas.

Uma síntese dos indicadores que apresentaram valor menor que o nível de controle aceitável (nível 1 de controle significa $C_{R}=1$ ) é representada no Quadro 7. Estes indicadores, críticos ou não-críticos, tiveram valor zero.

As principais não conformidades de indicadores críticos foram com a ausência de equipamentos de proteção individual em 20 (33,3\%) salas de exames, a potência dos equipamentos em 19 (32\%) (igual ou inferior a $4 \mathrm{~kW}$ - <100mA, todos com gerador monofásico de retificaçáo de meia-onda) e 11 $(18,3 \%)$ não possuíam filtro e colimador.

Com relação às salas de exames, 12 (20\%) não possuíam bucky com grade antidifusora e $26(43,3 \%)$ tinham guarda de chassis em seu interior sem nenhuma proteção; $12(20 \%)$ serviços utilizavam processamento manual sem controle de tempo e temperatura e 30 (50\%) utilizavam chassis danificados. Nas salas de laudos, 51 (85\%) dos negatoscópios estavam com luminância inferior a 800 nit, quando o mínimo recomendado é 1500 nit.

No que se refere aos procedimentos, 21 (35\%) produziram imagens de phantom que não tinham condiçôes de avaliação, pois apresentavam baixa densidade ótica $(-0,4)$ e $14(23,3 \%)$ dos equipamentos portáteis 


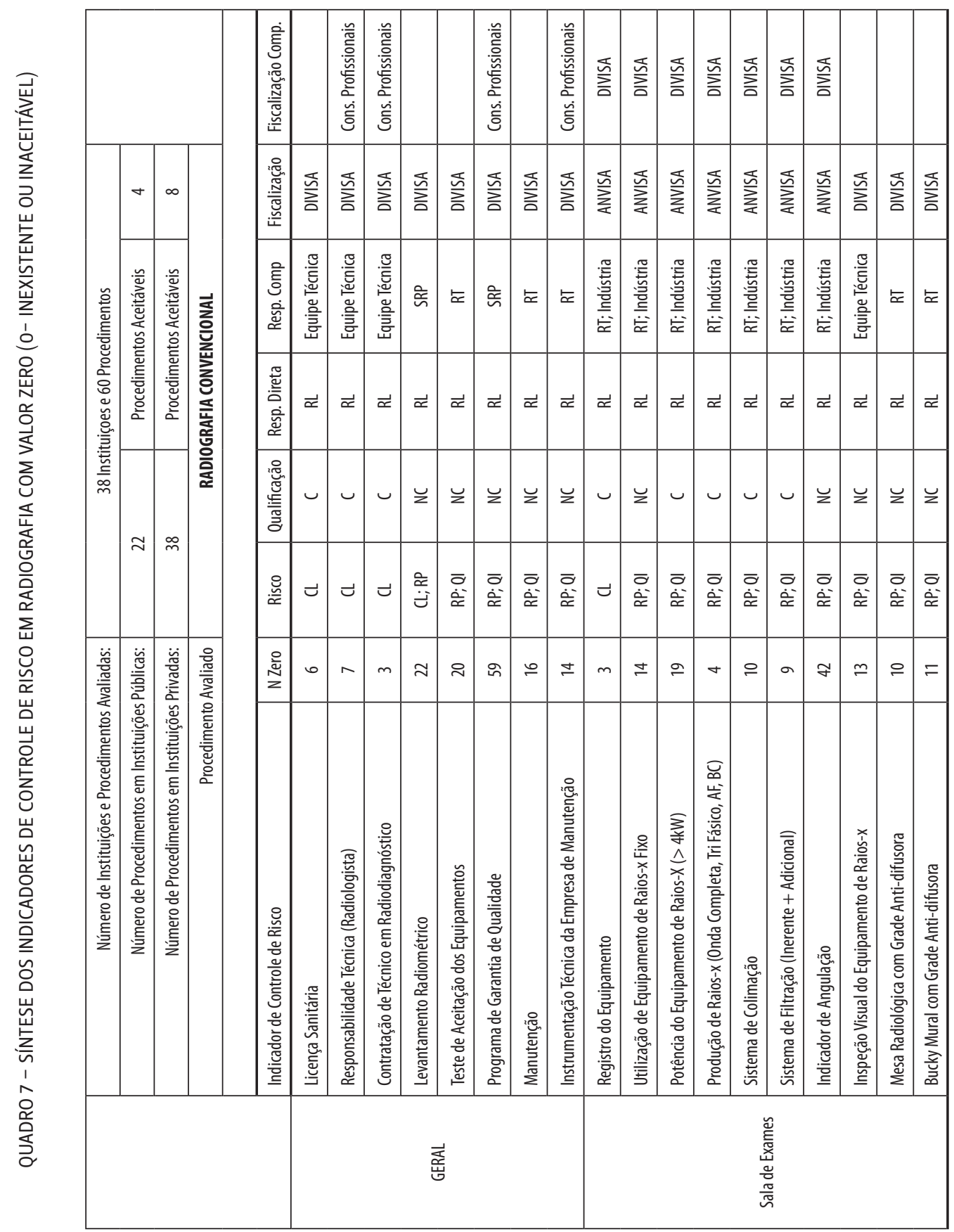




\begin{tabular}{|c|c|c|c|c|c|c|c|c|c|c|c|c|c|c|c|c|c|c|c|c|}
\hline & & & & & 妾 & 总 & & & & & & & & & & & & & & $\sum_{\sum}^{\underline{c}}$ \\
\hline 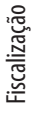 & 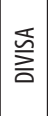 & 芯 & 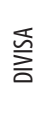 & 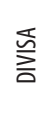 & 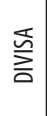 & 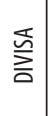 & 芯 & $\stackrel{\overleftarrow{n}}{\sum_{\bar{亠}}}$ & 芯 & 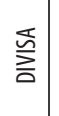 & 言 & 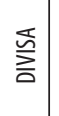 & 㐫 & 芯 & 高 & $\stackrel{\overleftarrow{\Lambda}}{\grave{\Delta}}$ & 兵 & 㐫 & 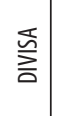 & 言 \\
\hline 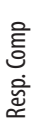 & ণ্ণি & t's & ळิ & ळิ & ळิ & 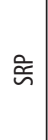 & 灾 & 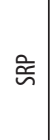 & 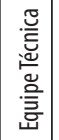 & $\stackrel{\tilde{\aleph}}{\tilde{n}}$ & 灾 & 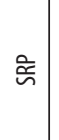 & 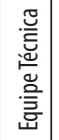 & 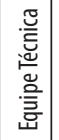 & ๗્ઞ & 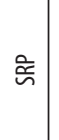 & $\bar{x}$ & $\stackrel{t}{x}$ & $\bar{c}$ & $\bar{c}$ \\
\hline 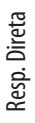 & $\overrightarrow{\propto ⿻}$ & $\vec{\sim}$ & $\vec{\propto}$ & $\vec{\propto}$ & $\vec{x}$ & $\vec{\propto}$ & $\vec{\sim}$ & $\vec{\propto}$ & $\vec{\sim}$ & $\vec{\propto}$ & $\vec{\sim}$ & $\vec{\alpha}$ & $\vec{\propto}$ & $\vec{\alpha}$ & $\vec{\alpha}$ & $\vec{\propto}$ & $\vec{\alpha}$ & $\vec{x}$ & $\vec{\propto}$ & $\vec{\propto}$ \\
\hline 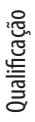 & $\check{z}$ & $\check{z}$ & $\smile$ & $\smile$ & $\smile$ & $\smile$ & $\checkmark$ & $\breve{z}$ & $\check{z}$ & $\check{z}$ & $\check{z}$ & $\check{z}$ & $\check{z}$ & $\check{z}$ & $\check{z}$ & $\check{z}$ & $\breve{z}$ & $\breve{z}$ & $\check{z}$ & $\check{z}$ \\
\hline 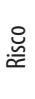 & $\begin{array}{l}\bar{\alpha} \\
\dot{\alpha} \\
\dot{\alpha}\end{array}$ & ฉิ & ฉิ & $\bar{\approx}$ & $\approx$ & ळ & ఇ & $\approx$ & $\begin{array}{l}\bar{\alpha} \\
\dot{\alpha} \\
\dot{\alpha}\end{array}$ & $\begin{array}{l}\bar{\alpha} \\
\dot{\alpha}\end{array}$ & $\mid \begin{array}{l}\overline{0} \\
\dot{\alpha} \\
\dot{\alpha}\end{array}$ & $\begin{array}{l}\bar{\alpha} \\
\dot{\alpha}\end{array}$ & 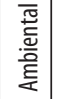 & $\begin{array}{l}\overline{0} \\
\dot{\alpha} \\
\dot{\alpha}\end{array}$ & $\begin{array}{l}\bar{\alpha} \\
\dot{\alpha}\end{array}$ & $\begin{array}{l}\overline{0} \\
\dot{\alpha}\end{array}$ & $\begin{array}{c}\bar{\alpha} \\
\dot{\alpha}\end{array}$ & $\bar{\sigma}$ & $\bar{\sigma}$ & $\overline{0}$ \\
\hline$\stackrel{\stackrel{\circ}{*}}{z}$ & $\simeq$ & 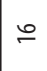 & $\sim$ & ని & 0 & - & in & $=$ & 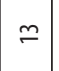 & $m$ & $\Re$ & $\bar{n}$ & $\stackrel{\infty}{m}$ & p) & $F$ & $F$ & $\sim$ & $\widehat{m}$ & in & in \\
\hline 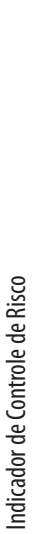 & 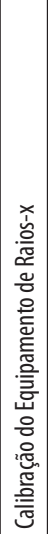 & 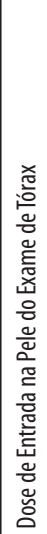 & 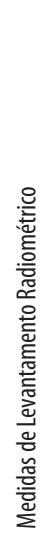 & 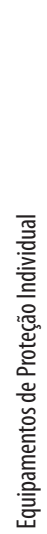 & 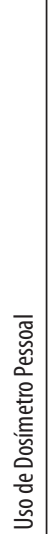 & 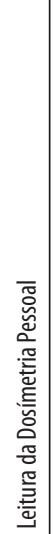 & 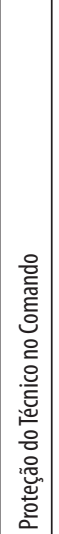 & 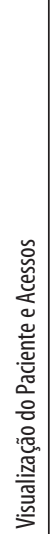 & 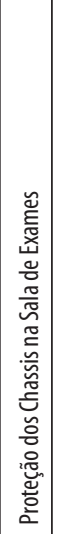 & 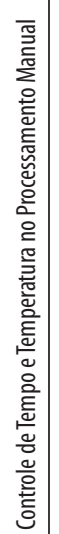 & 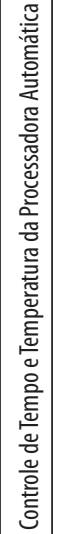 & 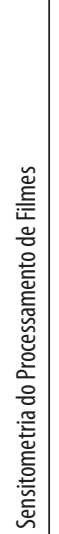 & 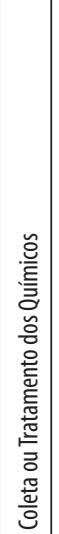 & 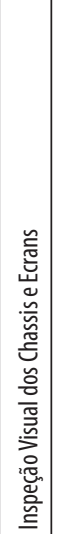 & 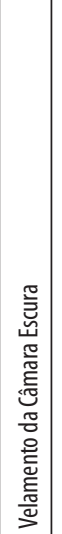 & 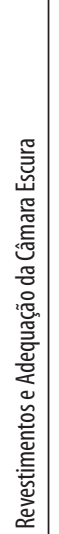 & 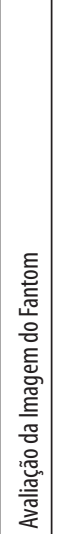 & 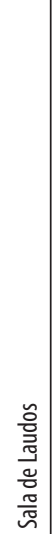 & 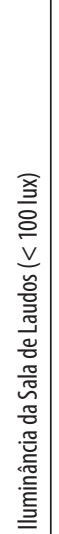 & 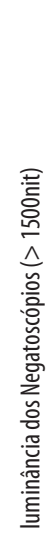 \\
\hline & & & & & 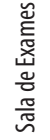 & & & & & & & & 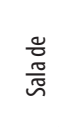 & & & & & & 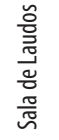 & \\
\hline
\end{tabular}


FIGURA 7 - GRÁFICO DO ESPAÇO DE ACEITABILIDADE PARA PROCEDIMENTO DE RADIOGRAFIA

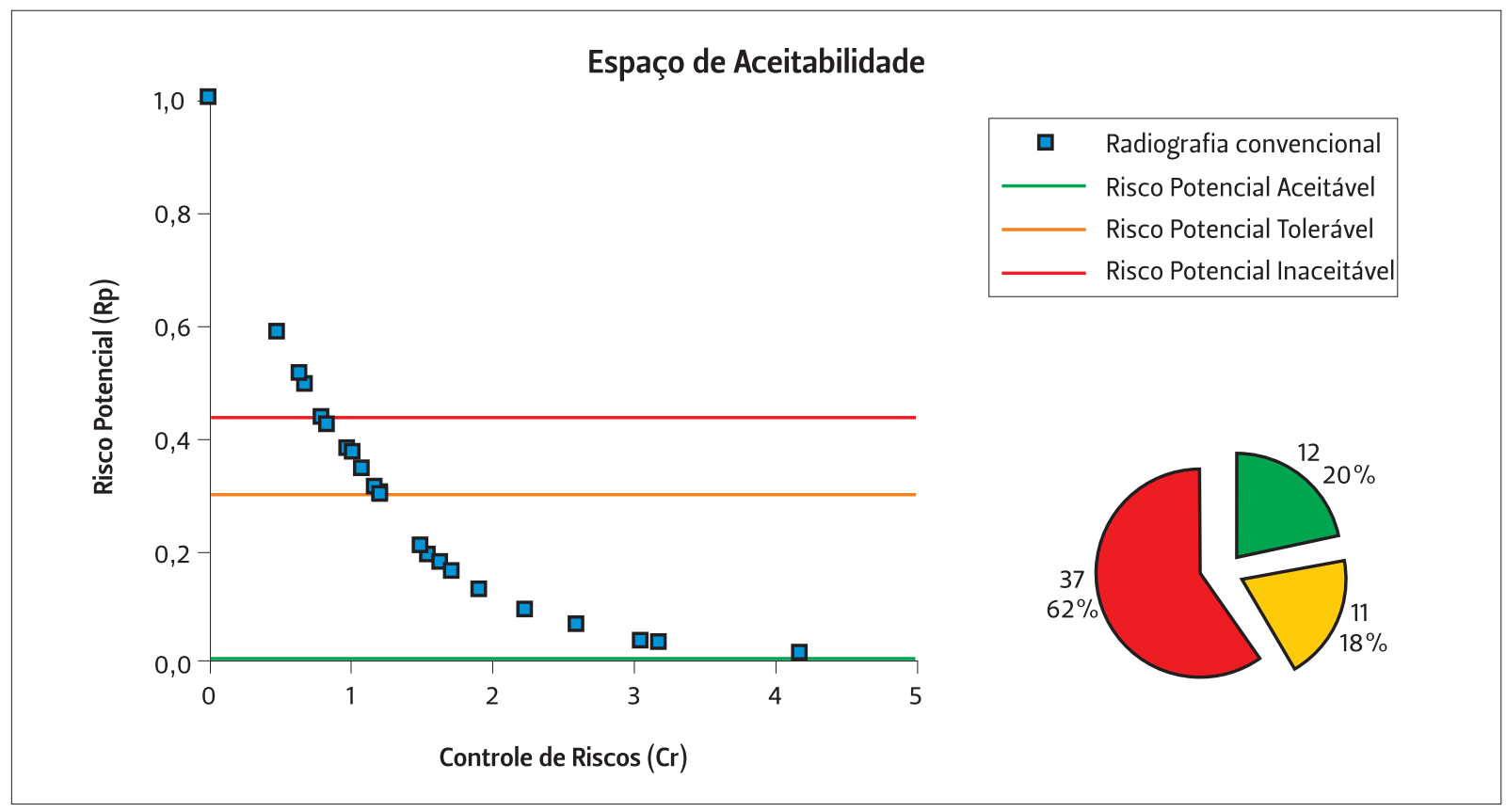


eram utilizados como fixo. A utilização de raios-X portátil como fixo não é recomendada pela Portaria 453/98.

As não conformidades encontradas na radiografia convencional podem ser consideradas muito graves, conforme apresentado, e serão discutidas posteriormente. Entretanto, a radiografia convencional pediátrica apresentou uma situação de inadequação de equipamentos e procedimentos ainda mais graves. Foram avaliados 6 equipamentos que eram utilizados em pediatria, incluindo UTI neo-natal. Todos os equipamentos eram de até $100 \mathrm{~mA}$ (quando o recomendado é de $500 \mathrm{~mA}$ ) e não possuíam filtro nem colimador, de utilização obrigatória. Mais uma vez, vale salientar que apenas uma instituição possuía programa de garantia de qualidade.

\section{Tomografia}

A tomografia está representada na Tabela 3 e evidencia que foram avaliados 13 procedimentos em 12 instituiçóes: 4 instalados em unidades públicas e 9 em instituiçóes privadas. Dos 13 procedimentos de tomografia avaliados, 8 (61\%) estavam com avaliação de risco potencial aceitável, 3 (23\%) tolerável e $2(15 \%)$ inaceitável, conforme mostrado no espaço de aceitabilidade da Figura 8. Entre os equipamentos em situação de risco potencial inaceitável, um estava em funcionamento em unidade pública e o outro em unidade privada. A principal não-conformidade encontrada referese à calibraçáo da uniformidade e do número de CT, que estavam fora dos padrôes estabelecidos na Portaria 453/98 em 8 (61\%) dos equipamentos.

Uma importante informação sobre os tomógrafos refere-se à geração tecnológica que está sendo utilizada. Dos 13 equipamentos avaliados um era duo slice, 6 helicoidais e 6 não-helicoidais, ou seja, 92\% dos tomógrafos são da geração de equipamentos produzidos entre o início da década de 1980 e o início da década de 1990. Tal como aconteceu com os outros procedimentos, apenas uma instituição possuía programa de garantia de qualidade. 


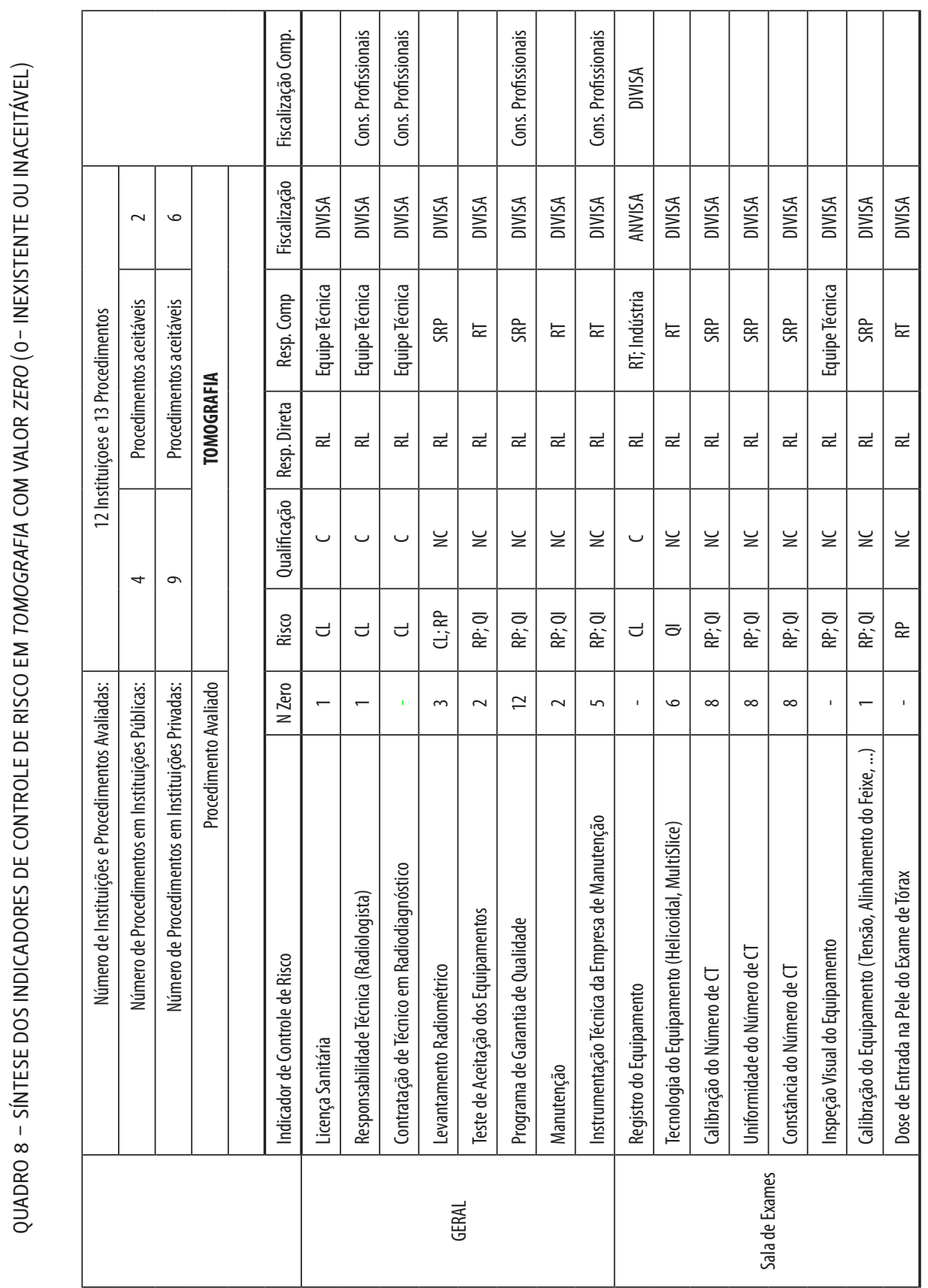




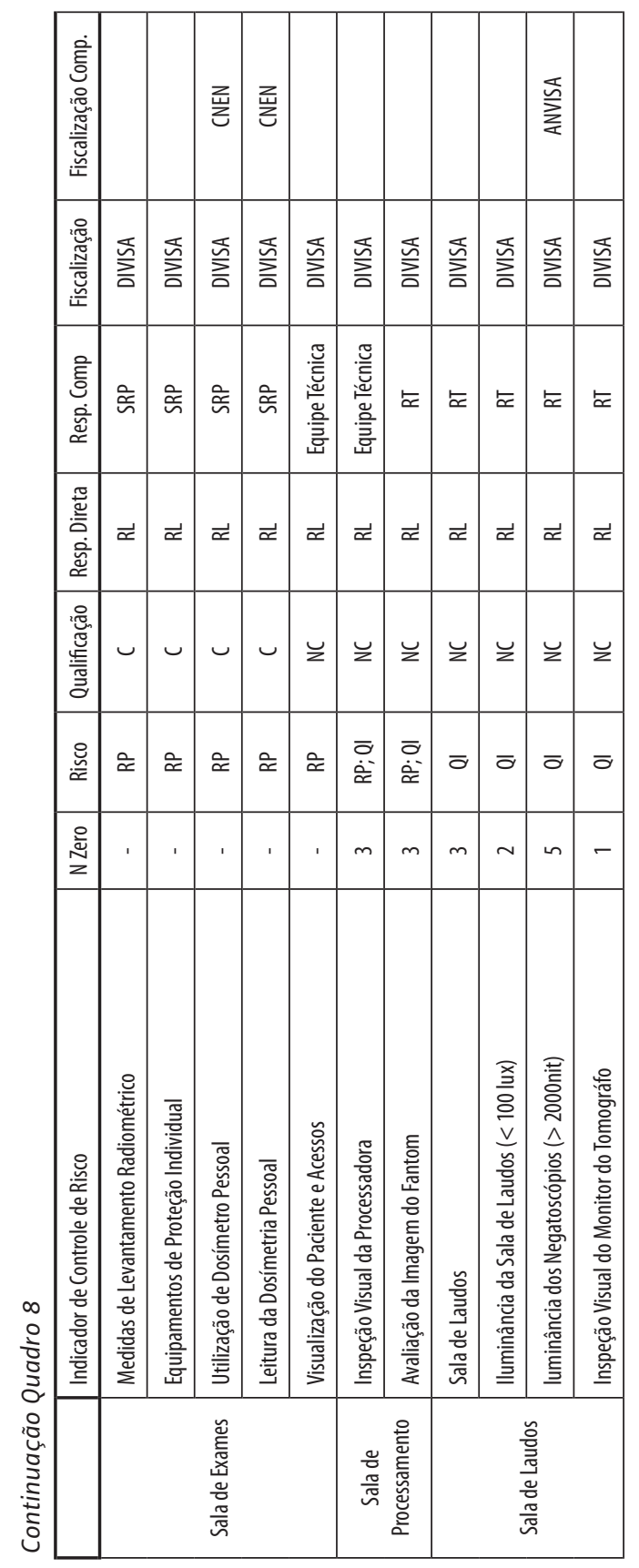


FIGURA 8 - GRÁFICO DO ESPAÇO DE ACEITABILIDADE PARA PROCEDIMENTO DE TOMOGRAFIA

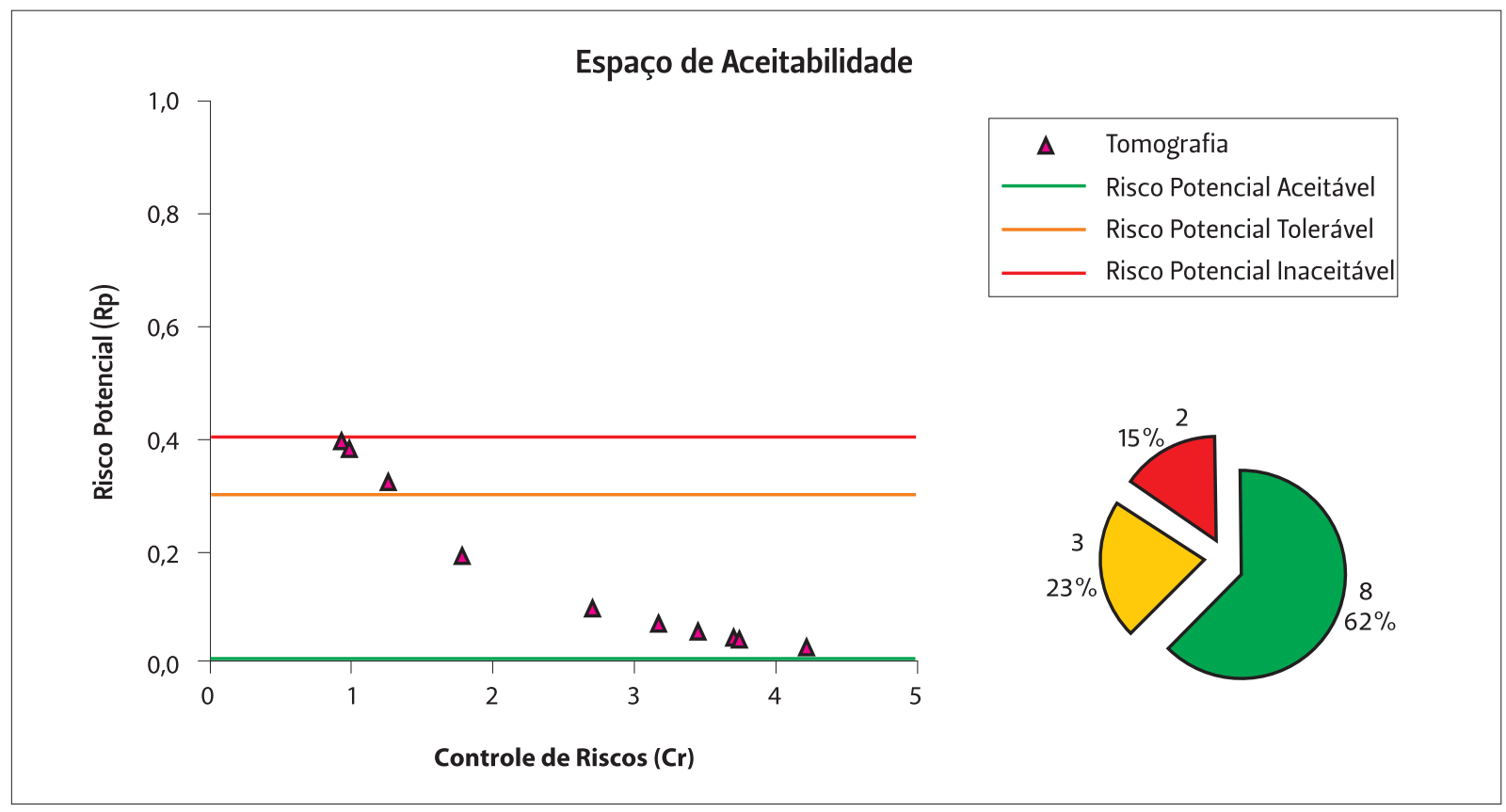





\section{Análise da situação de risco potencial}

Embora utilizando o MARP no primeiro nível de avaliação, nível 1, os resultados desse estudo apresentam uma situação preocupante de risco potencial nos procedimentos de radiodiagnóstico na Bahia e apontam para um grave problema de saúde pública. Conforme descrito na Tabela 3, dos 94 procedimentos avaliados, apenas 30 ( 4 de fluoroscopia, 6 de mamografia, 12 de radiografia e 8 de tomografia) encontravam-se em nível de risco potencial aceitável, representando $32 \%$ dos procedimentos avaliados. Assim, 68\% dos procedimentos avaliados estão funcionando em situação de risco potencial inaceitável (49\%) ou tolerável (19\%). Cada um dos 64 procedimentos, nesta situação, realiza uma média diária de 5 exames, o que representa uma estimativa anual total de 240.000 exames realizados sem as condiçôes mínimas de segurança e qualidade; dito, de outra forma, exames em condiçôes sofríveis.

Resultados semelhantes foram relatados em outros estudos realizados em países em desenvolvimento e, em particular, no Brasil. (AZEVEDO et al., 2005, D'IPPOLITO; MEDEIROS, 2005, FERNANDES; CARVALHO; AZEVEDO, 2005, INTERNATIONAL ATOMIC ENERGY AGENCY, 2004, KOTSUBO; MARCHIORI; AZEVEDO, 2003, LIMA; CARVALHO; AZEVEDO, 2004, MAGALHÃES; AZEVEDO; CARVALHO, 2002, 2004, MEDEIROS; ALVES; RUBERTY, 2003, OLIVEIRA; AZEVEDO; CARVALHO, 2003, OLIVEIRA; KHOURY, 2003, ORGANIZAÇÃO MUNDIAL DE SAÚDE, 2001; ORGANIZAÇÃO PANAMERICANA DE SAÚDE, 2001, SILVA; CARVALHO; AZEVEDO, 2004, SNIUREVICIUTE; ADLIENCE, 2005)

Um aspecto deste trabalho ainda não abordado em estudos brasileiros foi a comparação entre unidades públicas e privadas. Como visto, dos 94 procedimentos avaliados, 30 estavam em unidades públicas e 64 em unidades 
particulares. Entre as unidades públicas, foi verificado que $8(30 \%)^{33}$ estavam em situação de risco potencial aceitável, 11 (35\%) em situação de risco potencial tolerável e $11(35 \%)$ em situação de risco potencial inaceitável. Com relação às unidades privadas, essas tiveram $22(34 \%)$ em situação de risco potencial aceitável, 7 (11\%) em situação de risco potencial tolerável e 35 (55\%) em situação de risco potencial inaceitável. Ao final, estes resultados mostram uma situação ainda mais grave das unidades privadas.

Após descrever a situação do radiodiagnóstico nos serviços e procedimentos avaliados, faz-se necessário identificar e discutir os condicionantes da situação encontrada. A primeira questão refere-se à licença sanitária: dos 94 procedimentos avaliados $9(9,6 \%$, sendo $6 \mathrm{Rx}, 1$ fluoro, 1 mamo e 1 TC) não estavam licenciados pela Vigilância Sanitária; apenas 26 (27,7\%, sendo $16 \mathrm{Rx}, 2$ fluoro, 4 mamo e $4 \mathrm{TC}$ ) possuíam licença sanitária dentro do prazo de validade e 59 (62,3\%, sendo $28 \mathrm{Rx}$, 4 fluoro, 9 mamo e 8 TC) estavam com a licença sanitária vencida. Entre os procedimentos licenciados, 6 funcionavam com licença sanitária expedida pela Vigilância Sanitária municipal, ou pela Diretoria Regional de Saúde (DIRES), sem o conhecimento da Vigilância Sanitária estadual.

Um elemento da licença sanitária a ser considerado é o prazo de validade, que é de um ano. A Portaria 453/98 determina que a licença sanitária tenha validade de até dois anos e a OMS (INTERNATIONAL ATOMIC ENERGY AGENCY, 2006) recomenda que uma nova inspeção seja realizada no serviço, no máximo, a cada quatro anos. Mesmo sem discutir as questôes de recursos humanos e infra-estrutura da Vigilância Sanitária estadual, não parece ser racional que todos os serviços do Estado tenham que ser inspecionados todos os anos. Um planejamento direcionando as inspeçóes sanitárias para os serviços de maior risco e a extensão do prazo de validade da licença para os serviços em situação de baixo risco, deve melhorar o controle do sistema. Observou-se também que 10\% dos procedimentos funcionavam,

${ }^{33}$ Está sendo considerado o percentual, apenas, entre as unidades públicas. Assim, como foram avaliados 30 procedimentos, 8 representam, aproximadamente, $30 \%$. 
e continuaram funcionando sem licença sanitária, indicando deficiências na atuação da VISA, pois este é um dos requisitos para o funcionamento do serviço.

O indicador responsabilidade técnica (RT) aponta para um dos mais importantes condicionantes da situação encontrada. Entre os procedimentos avaliados, $10 \%$ não possuíam nenhum médico responsável, quase 30\% possuíam médico radiologista como responsável técnico e, em quase 60\%, os responsáveis eram clínicos gerais, ortopedistas ou pediatras. Contudo, apesar de $90 \%$ dos procedimentos serem realizados sob responsabilidade de médicos, a realização de exames com equipamentos e práticas inadequadas era praticada em $68 \%$ dos procedimentos. A formaçáo desses profissionais parece compor a explicação para a situação encontrada. Na Europa e nos EUA a radiologia começou a ser introduzida nas escolas médicas em 1897 (GLASSER, 1993; ROSENBUSCH; OUDKERK; AMMANN, 1995), tendo a OMS realizado a primeira publicação específica, em 1958, ressaltando a importância da introdução deste tema na graduação de medicina. Enquanto no Brasil, esse aspecto da formaçáo profissional está muito distante das diretrizes básicas da graduação e residência médica, formuladas pelo Ministério da Educação e Conselho Nacional de Residência Médica (CNRM). A qualificação profissional para a prescrição e avaliação do exame compóe o princípio da justificação para os exames de radiodiagnóstico. (INTERNATIONAL COMMISSION ON RADIOLOGICAL PROTECTION, 1996)

A Resolução CNE/CES ${ }^{34}$ n. 4, de 7 de novembro de 2001, que institui as Diretrizes Curriculares Nacionais do Curso de Graduação em Medicina, não inclui a radiologia (radiodiagnóstico, qualidade da imagem, radioproteção e programas de garantia de qualidade) como conteúdo teórico e prático, na base de formação desses profissionais. Por outro lado, tâo problemático quanto à inexistência do conteúdo de radiologia nas referidas diretrizes é o papel secundário deste importante tema nos Cursos de Residência Médica.

34 Conselho Nacional de Educação (CNE) / Câmara de Educação Superior (CES). 
A Comissão Nacional de Residência Médica (CNRM) publicou a Resolução CNRM n. 02, de 17 de maio de 2006, que dispóe sobre os requisitos mínimos dos Programas de Residência Médica. Analisando o programa, mínimo de quatro especialidades (Radiologia, Clínica Médica, Ortopedia e Pediatria), pode-se verificar quão superficial é a abordagem do radiodiagnóstico e suas técnicas.

A Residência em Radiologia e Diagnóstico por Imagem parece estar pautada nos conceitos de radioproteção do início do século passado, pois temas como dose de referência, qualidade da imagem, programa de garantia de qualidade, controle de qualidade e radiologia pediátrica náo são abordados no programa mínimo para a residência, em desacordo com as recomendaçóes internacionais. (INTERNATIONAL ATOMIC ENERGY AGENCY, 2006; INTERNATIONAL COMMISSION ON RADIOLOGICAL PROTECTION, 1996; ORGANIZAÇÃOMUNDIALDESAÚDE, 1958a, 1958b, 1965, 1972, 1982, 2001; ORGANIZAÇÃO PANAMERICANA DE SAÚDE, 1997) Os conteúdos abordados são:

52 - Radiologia e Diagnóstico por Imagem - R1, R2 e R3

a) Treinamento em serviço de radiologia geral: radiologia geral e contrastada, ultra-sonografia, mamografia, tomografia computadorizada, densitometria óssea, ressonância magnética, radiologia intervencionista, técnicas de exame, urgências e emergências: mínimo de $80 \%$ da carga horária anual;

b) Estágio opcional: medicina nuclear;

c) Cursos obrigatórios: física médica e proteção radiológica e reanimação cardio-respiratória;

d) Instalaçóes e equipamentos:

1. radiologia convencional com mesa de Bucky e Bucky vertical;

2. radiologia contrastada com mesa basculante e intensificação de imagem;

3. mamógrafo;

4. ultra-som de rotina e endocavitário com transdutores convexos e lineares;

5. Doppler colorido

6. tomógrafo computadorizado; 
e) Número mínimo de procedimentos e/ou laudos-relatórios exigidos por ano de treinamento para cada residente: 5000 .

Nas residências de Clínica Médica e Ortopedia, a radiologia é abordada apenas como conteúdo do estágio opcional. Assim, o profissional pode iniciar sua atuação profissional sem ter o radiodiagnóstico e suas especialidades em sua formação, de graduação e residência. Vale salientar que esses profissionais atuam em unidades de urgência/emergência e tomam decisóes (ver Figura 1) com base em informaçóes diagnósticas produzidas, na maioria das vezes, por exames de radiodiagnóstico. No caso da Ortopedia, o acompanhamento do procedimento também é realizado com raios-X.

Na Residência Médica em Pediatria, a situação é ainda mais grave, pois nos dois anos do curso, o radiodiagnóstico não é recomendado sequer como tema opcional. Essa parece ser a explicação para que os serviços de pediatria, avaliados neste estudo, apresentassem a situação de maior risco potencial. Nos seis serviços avaliados, os equipamentos e procedimentos utilizados remontam às práticas de radiodiagnóstico anteriores à Segunda Guerra, produzindo doses 40 vezes maior que a referência, no centro do campo, podendo chegar a 4.000 vezes maior em gônadas. ${ }^{35}$ (EUROPEAN COMISSION, 1996b; INTERNATIONAL ATOMIC ENERGY AGENCY, 2006)

Devido às especificidades da área, que dizem respeito não apenas ao tamanho do paciente, foram desenvolvidos, na década de 50, os primeiros dispositivos de proteção com fins pediátricos. No início da década de 1970, foram produzidos os primeiros equipamentos de radiografia e fluoroscopia específicos para pediatria. Os equipamentos e procedimentos da radiologia pediátrica devem possibilitar a realização de exames com maior rapidez, de preferência $<10 \mathrm{~ms}$, com as menores doses possíveis e com a área de irradiação limitada ao estritamente necessário. Assim, a utilização de equipamentos de alta potência (corrente de tubo > $500 \mathrm{~mA}$ ) e sistemas de proteção do pa-

${ }^{35}$ Essas doses podem ser alcançadas nos casos de equipamentos sem sistema de colimação regulável. Nesses casos, as gônadas passam a estar diretamente sob o feixe de radiação. 
ciente (incluindo gônadas, quando a região não for de interesse radiográfico) devem ser procedimentos básicos na radiologia pediátrica. Os Quadros 9 e 10 mostram uma comparação entre a situação de equipamentos e procedimentos encontrada nos seis serviços avaliados e a Diretriz da Comunidade Européia, publicada há mais de dez anos. (EUROPEAN COMISSION, 1996b)

QUADRO 9 - COMPARAÇÃO DAS ESPECIFICAÇÕES TÉCNICAS DOS EQUIPAMENTOS UTILIZADOS EM RADIOLOGIA PEDIÁTRICA NO ESTADO DA BAHIA, EM 2006, E A DIRETRIZ EUROPEIA

\begin{tabular}{ccc}
\hline Parâmetro Técnico & 6Serviços da Bahia/2006 & EUR 16261/1996 \\
\hline Sistema de Retificação & Onda Completa & 12 pulsos, AF ou BC \\
Potência & $\leq 4 \mathrm{~kW}$ & $\geq 30 \mathrm{~kW}$ (Fixo) \\
Tensão do Tubo & $40 \mathrm{a} 100 \mathrm{kV}$ & $\geq 10 \mathrm{~kW}$ (Móvel) \\
Tempo de Exposição Mínimo & $100 \mathrm{~ms}$ & $45 \mathrm{a} 120 \mathrm{kV}$ \\
Corrente do Tubo & $\leq 100 \mathrm{~mA}$ & $1 \mathrm{~ms}$ \\
mAs Mínimo & 10 & $\geq 500 \mathrm{~mA}$ \\
Ponto Focal & - & 0,5 \\
Filtração & Não possui & $\leq 1,3 \mathrm{~mm}$ \\
Filtração Adicional & Não possui & $2,7 \mathrm{~mm}$ Al a 100 kV \\
Grade Anti-espalhamento & Não possui & $1,0 \mathrm{~mm}$ Al e $0,1 \mathrm{~mm}$ Cu \\
Sistema Automático de Exposição & Não possui & Grade removível \\
Sistema Tela Filme & - & Específico de pediatria \\
Medidor de Dose x Área & - & Velocidade entre 400-800 \\
Colimador & Não possui & Medida e Visualização \\
Distância FF & 30 a $100 \mathrm{~cm}$ & Tolerância de $2 \mathrm{~cm}$ e $1 \mathrm{~cm}$ para neonatos \\
Processadora & Manual e/ou Aut & $\geq 80 \mathrm{~cm}$ \\
Luminância do Negatoscópio & $\leq 800$ nit & Automática c/ sensit diária \\
Iluminância da Sala de Laudos & $2000-4000$ nit \\
\hline
\end{tabular}


Como pode ser observado no Quadro 9, as especificaçóes técnicas dos equipamentos utilizados nos serviços avaliados, no Estado da Bahia, são bastante inferiores às especificaçóes da Comunidade Européia. As situaçóes mais críticas são relativas à inexistência de filtros, colimadores e sistema automático de exposição. Como resultado da utilização de equipamentos inadequados, o Quadro 10 mostra que os exames são realizados com parâmetros que não são apropriados para a radiologia pediátrica, produzindo doses elevadas e tempos de exposição Ioo vezes maiores que o recomendado, prejudicando a qualidade da imagem.

QUADRO 10 - COMPARAÇÃO ENTRE EXAMES DE TÓRAX EM RADIOLOGIA PEDIÁTRICA

\begin{tabular}{ccc}
\hline & 6 Serviços da Bahia/2006 & EUR 16261/1996 \\
\hline Dose de Referência (DEP) & 600 a $3200 \mu G y$ & $80 \mu G y$ \\
Distância FF & $50 \mathrm{~cm}$ & $100 \mathrm{~cm}$ \\
Potência & $1 \mathrm{a} 3,6 \mathrm{~kW}$ & $\geq 10 \mathrm{~kW}$ \\
Tensão do Tubo & $40 \mathrm{a} 60 \mathrm{kV}$ & $60 \mathrm{a} 65 \mathrm{kV}$ \\
Tempo de Exposição & $100 \mathrm{a} 200 \mathrm{~ms}$ & $4 \mathrm{~ms}$ \\
Corrente & 25 a $100 \mathrm{~mA}$ & $500 \mathrm{~mA}$ \\
mAs & 5 a 10 & 2 \\
Proteção & Nenhuma & Ao redor do campo \\
Tamanho do Campo & $\sim 45$ cm de diâmetro & No máximo 1cm maior que a área de interesse \\
\hline
\end{tabular}

Pode-se verificar que todos os serviços avaliados possuíam médico pediatra e dois também possuíam radiologistas. Contudo, nos seis procedimentos avaliados, os equipamentos com menor potência, mais velhos e obsoletos, foram destinados à pediatria e, dependendo do tamanho da criança, todo o corpo era irradiado, devido à falta de colimadores nos equipamentos. Outro importante aspecto, refere-se aos requisitos legalmente estabelecidos para o exercício da responsabilidade técnica. A Portaria MS 453/98 estabelece que, 
para cada setor de radiodiagnóstico médico, o titular deve designar um médico com conhecimento em física de radiodiagnóstico e proteção radiológica, para responder pelos procedimentos radiológicos, o responsável técnico (RT). Assim, os serviços de ortopedia, urgência/emergência e pediatria também devem ter responsáveis técnicos com formação em radiodiagnóstico, e esses RT só podem assumir responsabilidade por dois serviços. A responsabilidade do Conselho Profissional de Medicina, em fiscalizar o exercício da responsabilidade técnica, não pode ser negligenciada ou minimizada, diante da responsabilidade da autoridade reguladora fiscalizar estes aspectos. As normas foram elaboradas, no processo de evoluçáo do radiodiagnóstico, com base nos avanços e demandas estabelecidas também pelos médicos e seus colégios de especialistas, ou seja, os próprios profissionais da área de radiologia demandaram, historicamente, as normas. (ORGANIZAÇÃO MUNDIAL DE SAÚDE, 1982; ROSENBUSCH; OUDKERK; AMMANN, 1995)

$\mathrm{O}$ aspecto da formação profissional também reflete fortemente nos outros indicadores do conjunto de indicadores gerais. Apesar de constar na formação do técnico em radiologia, conforme determinado pelo Ministério da Educação (MEC) nos referenciais curriculares (BRASIL. Ministério da Educação, 2000), os padrôes de qualidade da imagem são temas ainda ausentes no processo de qualificação desses profissionais. No Estado da Bahia, por exemplo, dos 10 cursos de formação de técnico em radiologia constantes do cadastro nacional de cursos técnicos (CNCT), nenhum possui laboratório de qualidade da imagem, nem de controle de qualidade em geral. Embora a qualidade da imagem seja subjetiva, existem diversos métodos e equipamentos para avaliação das condições mínimas de qualidade da imagem. (ADAMNS; ARORA, 1994, BRITISH INSTITUTE OF RADIOLOGY, 2001, BRASIL. Ministério da Saúde. Secretaria de Vigilância Sanitária, 1998, GRAY, 1983, STEVENS 2001)

Quanto aos profissionais que realizam os serviços de manutenção, proteção radiológica e controle de qualidade, a questão da qualificaçáo está relacionada à ausência de formação específica na área e de controle no exercício das atividades. As empresas de manutenção não estão submetidas 
a nenhum controle, no tocante à instrumentação e capacitação de seus profissionais. Por outro lado, os físicos não possuem profissão regulamentada, nem controle sobre suas ações em radiodiagnóstico. Os físicos, engenheiros e técnicos de manutenção que atuam na área médico-hospitalar precisam ser incluídos no escopo da relação dos profissionais integrantes da área da saúde e ter seu exercício profissional fiscalizado pelo sistema regulador. Uma solução para esse problema poderia ser o estabelecimento de critérios para que tais empresas e/ou profissionais sejam certificados pela Rede Brasileira de Laboratórios Analíticos em Saúde (REBLAS/ANVISA).

Um dos requisitos fundamentais para o bom funcionamento de um serviço de radiodiagnóstico é o programa de garantia de qualidade que só foi encontrado em uma unidade da capital, mesmo assim, em estágio incipiente. Esse é um dos itens que dependem bastante da formação dos profissionais, tanto no relativo às questóes técnicas quanto de cultura de regulação e programas de qualidade. (INTERNATIONAL ATOMIC ENERGY AGENCY, 1996)

Outro indicador que está relacionado a condicionantes situados no nível nacional do Sistema Nacional de Vigilância Sanitária (SNVS) é o registro de equipamentos. Foram encontrados, sem registro, cinco equipamentos comercializados em 2006. Uma primeira análise poderia indicar um número relativamente baixo de equipamentos comercializados sem registro. Contudo, esses equipamentos representam todos os novos equipamentos que foram inspecionados. Quatro deles são de um fabricante, com sede no Estado de São Paulo, que já não possui mais nenhum equipamento com registro válido na ANVISA. O quinto equipamento sem registro era um Arco-C que não possuía colimadores e filtração adicional. Essa foi a situação mais grave de toda a avaliação, referente à dose em paciente. Esse equipamento é utilizado em procedimentos de fluoroscopia que, utilizando longos períodos de exposiçáo sem filtro e sem colimador, possibilita a ocorrência de efeitos determinísticos. Situação inaceitável, que denota a falta de formação técnica e/ou ética de profissionais e empresas. $\mathrm{O}$ equipamento foi interditado e o fato comunicado à ANVISA. 
Em consulta realizada ao banco de dados da ANVISA, relativo a produtos registrados, em dezembro de 2006, constatou-se que cinco empresas nacionais não possuem mais nenhum equipamento com registro válido. Contudo, essas empresas continuam expondo seus produtos nas feiras de equipamentos médicos e em seus sites, como foram verificados nas listas de expositores e na internet, em dezembro de 2006. Esta análise sobre o registro dos equipamentos em nada retira a responsabilidade dos responsáveis legais em adquirir equipamentos registrados e da autoridade reguladora local em fiscalizar. O que se está alertando é que a origem do problema é o livre funcionamento de empresas que não possuem equipamentos registrados. Nos cinco casos aqui relatados, sobre equipamentos novos instalados e sem registro, os equipamentos foram interditados e a vigilância sanitária estadual encaminhou notificação para a ANVISA, informando, inclusive, o número das notas fiscais que indicavam a comercialização de 40 equipamentos entre agosto e novembro de 2006.

Os equipamentos com potência igual ou inferior a $4 \mathrm{~kW}(\sim<100 \mathrm{~mA})$, com gerador monofásico de retificação de meia-onda e sem filtro e colimador, conforme descrito anteriormente, apresentavam características de equipamentos do primeiro período (1895 a 1915), pois em 1915 foi desenvolvido o equipamento trifásico e, devido à necessidade de melhorar a qualidade da imagem, já eram utilizados filtros e colimadores reguláveis no início do século passado. (ROSENBUSCH; OUDKERK; AMMANN, 1995) Os 19 equipamentos nessa condição são portáteis e foram produzidos até a década de 70, para fins de realização de exames de extremidades e/ou exames em leitos hospitalares.

Dado que os equipamentos são de baixa potência, para que possam realizar outros tipos de exame (bacia, coluna etc.), o filtro e o colimador são retirados de forma permanente. Além de péssima imagem radiográfica, também produzem um campo, circular, de aproximadamente $75 \mathrm{~cm}$ de diâmetro e uma dose de até $10 \mathrm{mGy}$, para raios-X de tórax. Essa dose é 25 vezes maior que a dose de referência para tórax. Uma vez que a ausência de colimação pode aumentar em 100 vezes a dose em gônadas 
(INTERNATIONAL ATOMIC ENERGY AGENCY, 2006), isso significa que a diferença entre a dose média em gônadas pode chegar a 2.500 vezes! Ressalta-se que a utilização obrigatória de filtros, colimadores reguláveis e potência $>4 \mathrm{~kW}$ é determinada pela Portaria SVS 453/98. Os equipamentos portáteis, com tecnologia de alta freqüência, foram lançados no início da década de 70. (ROSENBUSCH; OUDKERK; AMMANN, 1995) Essa situação não parece ser uma característica apenas da amostra estudada, pois dados do Instituto Brasileiro de geografia e Estatística (IBGE) de 2005, informam que aproximadamente 34\% (5.537) dos equipamentos de radiografia convencional do Brasil estão nessa situação e apenas 15\% (2.511) possuem corrente do tubo maior que $500 \mathrm{~mA}$, conforme mostra a tabela 2 .

Outra questáo refere-se aos negatoscópios químicos para revelação dos filmes radiográficos, processadoras, chassis e écrans, que não são considerados produtos para a saúde, sendo isentos de registro ou de controle do sistema regulador (ANVISA, 2003). Por melhor que esteja uma imagem radiográfica, as informaçôes radiológicas dificilmente serão visualizadas sem a luminância adequada dos negatoscópios. É preciso que o sistema regulador e o segmento regulado atentem para que os exames de radiodiagnóstico não se resumam ao equipamento emissor de raios-X e que a realização de um exame em condiçóes inadequadas pode causar bem mais danos do que a exposição às radiaçóes em si. (INTERNATIONAL ATOMIC ENERGY AGENCY, 1996, 2006; INTERNATIONAL COMMISSION ON RADIOLOGICAL PROTECTION, 1996; ORGANIZAÇÃO MUNDIAL DE SAÚDE, 1982)

Um indicador de controle de risco, relacionado à proteção radiológica, aponta uma não conformidade grave e de risco potencial inaceitável: a inexistência de biombos para o comando do equipamento ou utilização de biombos com dimensóes inadequadas. A proteção dos técnicos foi uma das primeiras açóes de radioproteção, iniciadas ainda no segundo período da radioproteçáo (1915 a 1945), cuja Lei 1.234, de 14 de novembro de 1950, regulamentou essa prática no Brasil. 
Uma das mais importantes aplicaçóes do radiodiagnóstico moderno, o screening de mamografia, é um dos principais métodos de detecção precoce do câncer de mama, caso seja realizado de forma adequada. Nessas condiçóes, o procedimento de mamografia contribui para a detecção de lesốes mamárias, ainda em estágios iniciais, possibilitando o aumento da probabilidade de cura ou do tempo e qualidade de vida (FEIG, 2006). A mamografia também é um dos poucos casos em que a exposição às radiaçóes ionizantes é justificada, sem suspeita de diagnóstico. Assim, para que os programas de screening sejam realizados com a segurança recomendável, os testes de controle de qualidade de mamografia devem possuir periodicidade e nível de tolerância mais restritos. No entanto, a ANVISA editou uma cartilha (ANVISA, 2005) que reproduz a RE 64/2003, recomendando que todos os testes de controle de qualidade de mamografia sejam realizados com a periodicidade de um ano. Isso vai de encontro à Portaria MS 453/98 e a todas as recomendaçóes internacionais da área. (INTERNATIONAL ATOMIC ENERGY AGENCY, 2006; NCRP 99, 1982; ORGANIZAÇÃO MUNDIAL DE SAÚDE, 1982; ORGANIZAÇÃO PANAMERICANA DE SAÚDE, 1987) 


\section{Perspectivas e considerações}

O modelo teórico elaborado e testado no presente estudo permitiu avaliar os riscos potenciais associados ao radiodiagnóstico em distintos níveis de aceitabilidade. Por seu lado, a operacionalização do conceito de risco potencial possibilitou avançar, no sentido de melhor entender especificidades e possibilidades de açáo do sistema de vigilância sanitária, como autoridade reguladora, no controle de riscos em radiodiagnóstico.

Embora tenha sido formulado com o objetivo de analisar o controle de riscos em radiodiagnóstico e seus condicionantes, a partir dos indicadores de controle de riscos, avaliados nos serviços, a formulação teórica do MARP foi desenvolvida de forma genérica. Desse modo, o modelo aqui desenvolvido pode ser adaptado para avaliar riscos potenciais em outras áreas da vigilância sanitária. Assim, pode ser útil nos diversos campos da vigilância sanitária e, a depender de como seus indicadores sejam construídos, poderá ser aplicado em diversos níveis e objetivos de avaliação.

Os resultados do estudo mostraram que a utilização do modelo MARP possibilitou ir além da simples descrição situacional, indicando os possíveis fatores explicativos da situação sanitária encontrada. Algumas vantagens são introduzidas nesta abordagem, em comparação com outros trabalhos que trataram do tema. Uma delas diz respeito à representação gráfica do risco potencial dos procedimentos em cada um dos serviços. Isso possibilita ao sistema regulador classificar e comparar os procedimentos avaliados, para que possa planejar e direcionar as açóes para os serviços cujos procedimentos se encontram em nível de risco potencial inaceitável ou tolerável, estabelecendo prioridades.

Outra vantagem refere-se à possibilidade de se aplicar o princípio da otimizaçáo no sistema de controle de risco, permitindo acompanhar a evolução contínua do sistema. Neste estudo, utilizou-se o nível 1 de controle. 
Caso fosse utilizado o nível 3, por exemplo, apenas seis procedimentos (3 de tomografia, 1 de mamografia, 1 de fluoroscopia e 1 de radiografia) estariam com nível de risco potencial aceitável, representando apenas 6,4\% dos procedimentos avaliados.

Uma outra vantagem do MARP diz respeito à identificação dos condicionantes da situaçâao encontrada, pois os riscos potenciais estão associados aos indicadores e aos responsáveis pelo controle. Neste estudo, os principais possíveis condicionantes identificados foram:

- Ausência da obrigatoriedade dos temas relativos ao radiodiagnóstico (procedimentos disponíveis, técnicas, qualidade da imagem, dose de referência e programa de garantia da qualidade) nas diretrizes do curso de graduação em medicina e em especialidades como clínica médica, ortopedia e pediatria.

- Ausência dos conceitos de radiodiagnóstico moderno, quarto período (1980-2006), nas diretrizes da residência médica em radiologia.

- Ausência de controle, por parte do sistema de regulação, das empresas e profissionais que prestam serviços de manutenção, radioproteção e controle de qualidade em radiodiagnóstico.

- Dificuldade da autoridade reguladora estadual em fiscalizar os serviços de radiodiagnóstico, pelo menos uma vez ao ano.

- Superposiçáo de competências para licenciar os estabelecimentos (VISA estadual, DIRES e VISA municipal), aliada à não utilizaçấo de sistemas de informação, o que contribui para a fragilidade do controle das atividades do segmento regulado.

- Deficiência do sistema regulador, SNVS, em dar continuidade às açôes de controle sanitário e penalizar as empresas e profissionais que infringem as normas sanitárias.

- Fragilidade no processo de registro de equipamentos e fiscalizaçáo da indústria, por parte da ANVISA.

- Dispensade registro, por partedaANVISA, de todososequipamentos e produtos para radiodiagnóstico (grade anti-difusora, chassi, écrans, 
filmes, processadora, químicos para revelação e negatoscópios), com exceção do equipamento emissor de raios-X.

- Utilização de equipamentos e procedimentos inadequados, verificada em $68 \%$ dos procedimentos avaliados, o que torna a realização desses exames inaceitável frente aos riscos potenciais, associados à baixa qualidade da imagem e às exposiçôes injustificadas às radiações ionizantes.

- Desresponsabilização, quase que completa, por parte do SNVS dos diversos atores do campo do radiodiagnóstico: responsável legal, responsável técnico, técnicos de raios-X, empresas de manutenção e controle de qualidade, físicos, técnicos de manutenção, conselhos profissionais (CFM, CONTER e CREA), colégios profissionais (CBR, SBP, SBOT), centros de formação e de pesquisa.

Uma potencialidade do MARP, não explorada neste trabalho, é sua utilização para avaliar a evolução histórica do controle de riscos dos serviços de radiodiagnóstico. $\mathrm{O}$ acompanhamento da evolução temporal poderá mostrar avanço ou retrocesso quanto ao risco potencial, alertando a VISA antes do serviço passar para uma faixa de maior grau de risco, possibilitando açóes de prevenção de riscos, através da antecipação e interrupçáo de uma tendência. Assim, a Vigilância Sanitária tem a possibilidade de agir na prevenção do risco e não apenas no controle. A evolução temporal pode ser utilizada facilmente, com auxílio computacional, para o acompanhamento dos serviços de forma individual ou coletiva.

Ressalte-se que a utilização do MARP para o acompanhamento da evolução temporal dos riscos potenciais, bem como para comparação e avaliação dos riscos, deve ser realizada empregando as mesmas escalas de avaliação dos indicadores e as mesmas faixas de aceitabilidade. Caso contrário, o MARP perde a comparabilidade. 
Embora esse estudo constitua um dos maiores já realizados no Brasil, em número de equipamentos, distribuição geográfica e itens verificados, algumas limitaçóes devem ser assinaladas. A primeira relaciona-se à amostra: devido à natureza dos indicadores de controle de risco potencial utilizados, a amostra estudada foi resultante do acompanhamento das inspeçóes da Vigilância Sanitária Estadual. Assim, foram utilizadas, apenas, as informações referentes às inspeçôes em radiodiagnóstico, realizadas entre julho e dezembro de 2006. A segunda limitação diz respeito aos testes realizados e está relacionada à dimensão geográfica e à situação de conservação das estradas do Estado da Bahia. Foram necessários longos deslocamentos (aproximadamente 10.000 $\mathrm{km}$ ), em estradas de péssima pavimentação, dificultando o transporte e utilização das ferramentas de testes disponíveis. Esse fato teve maior influência nos procedimentos de avaliação de tomografia e do ponto focal de mamografia que, para serem completos, demandavam a utilizaçáo de phantoms de dose e de qualidade de imagem que são grandes, pesados e frágeis. Outra limitação do estudo refere-se ao tempo disponível para realizar as inspeçóes que não permitiu, de forma mais detalhada, realizar medidas relativas à dose de entrada na pele dos exames de radiodiagnóstico. Essa seria uma informaçáo relevante, no sentido de iniciar estudos para proposiçáo das doses de referência, que são de fundamental importância para a qualidade da imagem.

Considerando que os principais condicionantes da situação encontrada apontaram para possíveis condicionantes de responsabilidade da esfera Federal e Estadual e que, os estudos realizados em outros Estados indicaram situaçóes semelhantes, tem-se um indicativo que os resultados retratam, em maior ou menor grau, a situação do radiodiagnóstico no estado e no país. Algumas proposiçóes podem ser sinalizadas com vistas a contribuir para reduzir esse grave problema de saúde pública:

- Introdução dos conceitos básicos de proteção radiológica e qualidade da imagem nas diretrizes dos cursos de graduaçáo e residência médica. 
- Estabelecimento de critérios e normas de procedimentos para a radiologia pediátrica.

- Ampliaçáo do prazo de validade das licenças sanitárias para 2 anos, sem necessariamente significar ausência de inspeçóes dos serviços no período.

- Avaliação e classificação dos serviços por nível de risco potencial, para orientar as açôes de vigilância sanitária e definir prioridades.

- Efetivas açóes de controle do registro e comercialização dos equipamentos e estabelecimento de critérios para registro e controle sanitário de chassis, filmes, écrans, processadoras, químicos para revelação e negatoscópios.

- O SNVS desenvolver, incentivar e estimular a cultura da regulação e controle de riscos em serviços de saúde, com efetiva cobrança de cumprimento das normas.

- O SNVS não publicar normas/recomendações conflitantes.

- Retirada imediata de funcionamento dos equipamentos com potência insuficiente e que não possuem filtro adicional nem colimador.

- Estabelecimento da obrigatoriedade de credenciamento, na ANVISA, dos profissionais e empresas prestadoras de serviços de manutenção e controle de qualidade.

- Estabelecimento de critérios para registro de equipamentos e incentivos à produção e utilização de equipamentos simples, robustos e de qualidade, tipo o WISH-RAD (World Health Imaging System for Radiography), recomendado pela Organização Mundial de Saúde, em 1988.

- Estruturação de uma ação conjunta e ampla, coordenada pela ANVISA, com a participação dos diversos atores envolvidos nos procedimentos de radiodiagnóstico, no sentido de desenvolver açóes imediatas e estabelecer metas para melhorar a situação geral do radiodiagnóstico. 
Por fim, um caminho natural, será aplicar o MARP para a realização de estudos semelhantes na radiologia intervencionista, radioterapia, medicina nuclear e outras áreas que apresentam lacunas quanto ao conhecimento científico no que concerne à regulação e vigilância sanitária. 


\section{Referências}

ABDULLAH, B. J. J.; K-H, N. G. In the eyes of the beholder: what we see is not what we get. The British Journal of Radiology, v. 74, p. 675-676, 2001.

ABRAMS, H. History of Cardiac Radiology. American Journal of Roentgenology, v. 166 , p. $255-258,1996$.

ADAMS, H. G.; ARORA, S. Total quality in radiology: a guide to implementation. Delray Beach, Florida: St Lucie, 1994. 203p.

AICHINGER, H. Radiation exposure and image quality in X-ray diagnostic radiology. Germany: Springer, 2004.

ALEMANHA. Verordnung über den Schutz vor Schäden durch Röntgenstrahlen (Röntgenverordnung-RöV) - (BGBL. I S. 114), 1987.

AMMANN, E.; KUTSCHERA, W. X-Ray tubes: contínuos innovate tecnology. The British Journal of Radiology, v. 70, S1-S9, 1997.

ARGENTINA. Ministerio de la Salud. Normas relativas a la instalación y funcionamento de equipos generadores de raios-X. Buenos Aires, 1993.

ARIAS, A. C. La Regulación de la Protección Radiológica y la Función de las Autoridades de Salud. Rev. Panam Salud, v. 20, n. 2-3, 2006.

AZEVEDO, A. C. P. et al. Estudo comparativo das técnicas radiográficas e doses entre o Brasil e a Austrália. Radiologia brasileira, v. 38, n. 5, p. 343-346, 2005.

BAUER, H.; DEMEREC, M.; KAUFMANN, B. P. X-Ray induced chromosomal alterations in drosophila melanogaster. Genetics, v. 23, n. 6, p. 610 - 630, 1938.

BECK, U. Risk Society. London: Sage, 1992. . World Risck Society. Cambridge: Polity, 2003. 
BENVENISTE, A. P. A.; FERREIRA, A. H. P. G.; AGUILAR, V. L. N. Dupla leitura no rastreamento mamográfico. RadiologiaBrasileira, v. 39, n. 2, p. 272-276, 2006.

BERG, Van Der L. et al. Guidelines for quality control of equipament used in diagnostic radiology in the netherlands. Radiation Protection Dosimetry, v. 80, n. 1-3, p. 95-97, 1998.

BRITISH INSTITUTE OF RADIOLOGY. Assurance of quality in the diagnostic imaging department. London, 2001.

BRANDAN, M. et al. Evaluation of equipment performance, patient dose, imaging quality and diagnostic coincidence in five mexico city mammography services. Archieves of Medical Research, v. 35, n. 1, p. 24-30, 2004.

BRASIL. Ministério da Saúde. Secretaria de Vigilância Sanitária. Diretrizes de Proteção Radiológica em Radiodiagnóstico Médico e Odontológico: Portaria n. 453, de 1 de junho de 1998. Aprova o Regulamento Técnico que estabelece as diretrizes básicas de proteção radiológica em radiodiagnóstico médico e odontológico, dispóe sobre o uso dos raios-X diagnósticos em todo território nacional e dá outras providências. Diário Oficial da Uniāo, Brasília, DF, 2 jun. 1998.

BUNGER, R. E. et al. The need for quality assurance in diagnostic radiology. Health Physics, v. 31, n. 6, p. 565, 1976. Abstract presented at the Ninth Annual Midyear Topical Symposium of the Health Physics Society, 9-12 February, 1976, Boulder, Colorado.

BURKHART, L. Quality assurance programs for diagnostic radiology facilities. Washington, DC: United States Food and Drug Administration, 1980. (DHEW Publication-FDA 80-81 10).

CALDER, J. F. The history of radiology in Scotland, 1896-2000. Edinburgh, UK: Dunedin Academic, 2001.

CHAPPLE, C. L.; BROADHEAD, D. A.; FAULKNER, K. Reference doses for paediatrics from fluoroscopic procedures. Radiation Protection Dosimetry, v. 80, n. 1-3, p. 203-206, 1998. 
CHEVALIER, M. et al. Breast dose measurements on a large group of patients: results from a 4 year period. Radiation Protection Dosimetry, v. 80, n. 1-3, p. 187-190, 1998.

COMISSÃO NACIONAL DE ENERGIA NUCLEAR- NN -3.01. Dispóe sobre as Diretrizes Básicas de Proteção Radiológica. Diário Oficial da União, Brasília, 14 nov. 2005.

COMMISSION OF THE EUROPEAN COMMUNITIES. European Guidelines for Quality Assurance in Mammography Screening. 3nd edn. Luxembourg: CEC. 2001.EUR

COSTA, Ediná Alves. Vigilância sanitária: proteção e defesa da saúde. São Paulo: Hucitec-Sobravime, 2004.

Vigilância sanitária: proteção e defesa da saúde. In: ROUQUARIOL, M. Z.; ALMEIDA FILHO, N. (Org.). Epidemiologia e saúde. São Paulo: Medsi, 2003. p. 357-387.

.; ROZENFELD. S. D. Constituição da Vigilância Sanitária no Brasil. In: ROZENFELD, Suely (Org.). Fundamentos da vigilância sanitária. Rio de Janeiro. FIOCRUZ, 2000.

COVELLO, V. T.; MUNPOWER, J. Risk analysis and risk management: an historical perspective. Risk Analysis, v. 5, n. 2, p. 103-120, 1985.

CZERESNIA, D. Ciência, técnica e cultura: relações entre riscos e práticas de saúde. Cadernos de Saúde Pública, Rio de Janeiro, v. 20, n. 2, p. 447-455, 2004.

D’IPPOLITO, G.; MEDEIROS, R. B. Exames radiológicos na gestação. Radiologia brasileira, v. 38, n. 6, p. 447-450, 2005.

DREXLER, G. Diagnostic reference levels in the 1990 and 1996. recommendations of the icrp. Radiation Protection Dosimetry, v. 80, n. 1-3, p. 7-10, 1998.

.; ERISKAT, H.; SCHIBILLA, H. (Ed.). Criteria and methods for quality assurance in medical x-ray diagnosis. London: British Institute of Radiology, 1985. (BJR Supplement n. 18). 
ESPANHA. Real Decreto 1976/1999, de 23 de diciembre, por el que se establecen los criterios de calidad en radiodiagnóstico. Boletín Oficial del Estado, n. 311, 29 dez. 1999.

EUROPEAN COMISSION. European guidelines on quality criteria for diagnostic radiographic images. Luxembourg: Office for Official Publications of the European Communities, 1996a. EUR 16260

. European guidelines on quality criteria for diagnostic radiographic images in paediatrics. Luxembourg: Office for Official Publications of the European Communities, 1996b. EUR 16261. . European guidelines on quality criteria for computed tomography.

Luxembourg: Office for Official Publications of the European Communities, 1996c. EUR 16262.

European protocol on dosimetry in mammography. Luxembourg: Office for Official Publications of the European Communities, 1996d. EUR 16263.

EURATOM 29. Council Directive 96/29 Euratom of 13 may 1996, Laying Basic Safety Standars for protection of the Health of Workers and General Públic Against the Dangers from Ionizing radiation. Official Journal of the European Communities, Luxembourg, n. L 159 of 29 jun. 1996.

EURATOM 43. Council Directive 97/43 Euratom on Health Protection of Individuals against the Dangers of Ionizing Radiation in Relation to Medical Exposure. Official Journal of the European Communities, Luxembourg, L180, v. 40, 9 july 1997.

FEIG, S. A. Screenig mamography: a successful public health initiative. Rev. Panam Salud, v. 20, n. 2-3, 2006.

FELDMAN, A. A sketch of the technical history of radiology from 1896 to 1920. RadioGraphics, v. 9, n. 6, p. 113-1128, 1989.

FERNANDES, G. S.; CARVALHO, A. C. P.; AZEVEDO, A. C. P. Análise e gerenciamento de efluentes de serviços de radiologia. Radiologia Brasileira, v. 38, n. 5, p. 355-358, 2005a. 
Avaliação dos riscos ocupacionais de trabalhadores de radiologia. Radiologia Brasileira, v. 38, n. 4, p. 279-281, 2005 b.

FIGUEIREDO, Vilma. Produção social da tecnologia. São Paulo: EPU, 1989.

FISCHHOFF, B. et al. Acceptable risk. New York: Cambridge University, 1983.

FISCHHOFF, B.; BOSTRUM, A.; QUADREL, M. J. Risk perception and communication. In: DELGADO-RODRÍGUEZ, Miguel (Ed.). Oxford Textbook of Public Health. 4. ed. Oxford: Oxford University, 2005.

FREITAS, C. M. Riscos e processos decisórios: implicaçóes para a vigilância sanitária. In: ROSENFELD, Suely (Org.). Fundamentos da vigilância sanitária. Rio de Janeiro: FIOCRUZ, 2000.

.; GOMEZ, C. M. Análise de riscos tecnológicos na perspectiva das ciências sociais. História, Ciências, Saúde, Manguinhos, v. 3, n. 3, p. 500-504, 1997.

GELMAN, A.; NOLAN, D. Teaching statistic a bag of tricks. London: OXFORD, 2004.

GLASSER, O. Wilhelm Conrad Röntgen. San Francisco: Norman Publishing, 1993.

GLYN, A. H. Defining Risk. Financial Analysts Journal, v. 60, n. 6, p. 19-25, 2004.

GODDARD, P. et al. Error in radiology. The British Journal of Radiology, v. 74, p. 949-951, 2001.

GRABER, M. Diagnostic errors in medicine: a case of neglect. Journal on Quality and Patient Safety, v. 31, p. 113-119, 2005.

GRAY, J. E. et al. Quality control in diagnostic imaging. Maryland: Aspen Publishers, 1983.

HAMPEL, J. Different concepts of risk: a challenge for risk commnication.

International Journal of Microbiology, v. 296, p. 5-10, 2006. Supplement 1.

HENDEEW, R.; ROSSI, R. P. Quality assurance or conventional tomographic Xray units. Washington, DC: United States Food and Drug Administration, 1980a.

(DHEW Publication-FDA 80-8096). 
. Quality assurance for fluoroscopic X-ray units and associated equipment.

Washington, DC: United States Food and Drug Administration, 1980b. (DHEW

Publication-FDA 80-8095).

HOOD, C.; ROTHSTEIN, H.; BALDWIN, R. The government of risk:

understanding risk regulation regimes. New York: Oxford University, 2004.

INTERNATIONAL ATOMIC ENERGY AGENCY. Applying Radiation Safety

Standards in Diagnostic Radiology and Interventional Procedures using $X$ rays. VIENA, 2006. SRS 39.

. International Basic Safety Standards for Protection Against Ionizing Radiation and for the Safety of Radiation Sources. VIENA, 1996. BSS.

. Optimization of the radiological protection of patients undergoing radiography,

fluoroscopy and computed tomography. VIENA, 2004. TECDOC 1423.

INTERNATIONAL COMMISSION ON RADIOLOGICAL PROTECTION.

Recommendations of the International Commission on Radiological Protection.. Oxford: Pergamon, 1959. (ICRP Publication 1).

. Recommendations of the International Commission on Radiological Protection.

Oxford: Pergamon, 1966. (ICRP Publication 9).

. Recommendations of the International Commission on Radiological Protection.

Oxford: Pergamon, 1977. (ICRP Publication 26).

. Recommendation of the International Commission on Radiological Protection.

Oxford: Pergamon, 1991. (ICRP Publication 60).

. Recommendation of the International Commission on Radiological Protection.

Oxford: Pergamon, 1996. (ICRP Publication 73).

. Recommendation of the International Commission on Radiological Protection.

Draft. 2005.

INTERNATIONAL RISK GOVERNANCE COUNCIL. White Paper on Nanotechnology. Geneva, 2006.

KAHNEMAN, D.; SLOVIC, P.; TVERSKY, A. Judgment under uncertaintly:

heuristics and biases. New York: Cambridge University, 1982. 
KARILA, K. T. Quality control of mammographic equipment: a 5-year follow-up. Br. J. Radiol, v. 61, p. 1155-1167, 1988.

KELLERER, A. M. Radiation risk: historical perspective and current issues. Journal of Radiological Protection, v. 22, (A1-A10), 2002.

KOH, D.; JEYARATNAM, J. Occupational health. In: DETELS, R.; McEWEN, J.; TANAKA, H. Oxford textbook of public health. 4. ed. Oxford: Oxford University, 2005.

KOTSUBO, M. T. K.; MARCHIORI, M.; AZEVEDO, A. C. P. Estudo dosimétrico de radiografias de tórax com o emprego de técnicas de alta quilovoltagem. Radiologia Brasileira, v. 36, n. 3, p. 163-167, 2003.

LEWELLEN, T. K.; GRAHAM, M. M. A low-contrast phantom for daily quality control. J. Nucl. Med., v. 22, n. 3, p. 279-282, mar. 1981.

LIMA, A. A.; CARVALHO, A. C. P.; AZEVEDO, A. C. P. Avaliação dos padrões de dose em radiologia pediátrica. Radiologia Brasileira, v. 37, n. 4, p. 279-282, 2004.

LINDELL, B. The history of radiation protection. Radiation Protection Dosimetry, v. 68 , n. $1-2$, p. $83-95,1996$ a.

. The risk philosophy of radiation protection. Radiation Protection Dosimetry, v. 68, n. 3-4, p. 157-163. 1996 b.

LIPPMANN, M.; COHEN, B. S.; SCHLESINGER, R. B. Enviromental health science. Oxford: Oxford University, 2003.

LOCHARD, J.; SCHIEBER, C. The evolution of radiological protection risk management: an overview. Journal of Radiological Protection, v. 20, n. 2, p. 101-110, 2000 .

LUCCHESE, G. Globalização e regulação sanitária: os rumos da vigilância sanitária no Brasil. Tese (Doutorado em Saúde Pública) - Escola Nacional de Saúde Pública, Fundação Oswaldo Cruz, Rio de Janeiro, 2001

MACCIA, C. R.; CASTELLANO, S. Quality control in mammography: an initiative in France. British Journal of Radiology, v. 67, p. 371-383, 1994. 
MAGALHÃES, L. A. G.; AZEVEDO, A. C. P.; CARVALHO, A. C. P. Avaliaçấo da velocidade de processamento de processadoras automáticas utilizando o método "step test". Radiologia Brasileira, v. 37, n. 3, p. 185-186, 2004.

A. importância do controle de qualidade de processadoras automáticas. Radiologia Brasileira, v. 35, n. 6, p. 357-363, 2002.

MARTIN, C. J.; SUTTON, D. G. Practical radiation protection in health care. London: Oxford, 2002.

MARTÍNEZ-NOGUERA, A. et al. César Comas and Agusti Prió: Pioneers and Martyrs of Spanish Radiology. Radiographycs, v. 16, p. 1215-1220, 1996.

MARTINS, R. A. A descoberta dos raios-X: o primeiro comunicado de Roentgen. Revista Brasileira de Ensino de Física, v. 20, n. 4, p. 373-91, 1998.

. Investigando o invisível: as pesquisas sobre raios-X logo após a sua descoberta por Röntgen. Revista da Sociedade Brasileira de História da Ciência, n. 17, p. 81-102, 1997.

MEDEIROS, R. B.; ALVES, F. F. R.; RUBERTY, E. M. Influência da luminância do negatoscópio na detectabilidade de fibras e microcalcificaçôes, determinada por meio de objetos simuladores. Radiologia Brasileira, v. 36, n. 1, p. 21-25, 2003.

MÉXICO. SSa Salud Ambiental. Norma Oficial Mexicana NOM-158-ssa1-1996, Salud Ambiental. Especificaciones Técnicas para Equipos de Diagnóstico Médico con Raios X. 1996.

MILLER, K. L.; STOLTZFUS, W. R.; LATSHAW, R. F. An added quality-control measurement for fluoroscopic x-ray systems. Radiology, v. 140, p. 518-519, aug 1981.

MOORES, B. M.; CANNOLLY, P. A.; COLE, P. R. Audit programmes in a Diagnostic Radiology Facility. Radiation Protection Dosimetry, v. 80, n. 1-3, p. 253-259, 1998.

MOULD, R. F. A century of $x$-rays and radioactivity in medicine. Philadelphia: Institute of Physics Publishing, 1995. 
The discovery of radium in 1898 by Maria Sklodowska-Curie and Pierre

Curie with commentary on their life and times. The British Journal of Radiology, v. 71, p. 1229-54, 1998.

. The early history of $\mathrm{x}$-ray diagnosis with emphasis on the contributions of physics 1895-1915. Phys. Med. Biol., v. 40, p. 1741-1787, 1995.

NATIONAL COUNCIL ON RADIATION PROTECTION AND

MEASUREMENT. Quality assurance for diagnostic imaging. Washington DC:

Library of Congress, 1988.

NATIONAL RESEARCH COUNCIL. Physics a new era: an overview. Washington DC: National Academy, 2001.

. Risk assessment in the government: managing the process. Washington DC:

National Academy, 1983.

NITSKE, W. R. The life of Willhem Conrad Rontgen, discoverer of the $x$-ray. Tucson: University of Arizona, 1971.

NORWEGIAN SOCIETY OF MEDICAL RADIATION PHYSICS. Quality assurance control for X-ray diagnostic equipment. Osteraas: State Institute of Radiation Hygiene, 1980.

OESTMANN, J. W. The Role and Impact of Reference Doses in Diagnostic Radiology: Problems and Perpectives. Radiation Protection Dosimetry, v. 80, n. 1-3, p. 21-22, 1998.

OLIVEIRA, M. L.; KHOURY, H. Influência do procedimento radiográfico na dose de entrada na pele de pacientes em raios-X pediátrico. Radiologia Brasileira, v. 36, n. 2, p. 105-109, 2003.

OLIVEIRA, S. R.; AZEVEDO, A. C. P.; CARVALHO, A. C. P. Elaboração de um programa de monitoraçáo ocupacional em radiologia para o hospital universitário Clementino Fraga Filho. Radiologia Brasileira, v. 36, n. 1, p. 27-34, 2003.

OMENN, G. S.; FAUSTMAN, E. M. Risk assessment and risk manegement. In: DETELS, R.; McEWEN, J.; TANAKA, H. 4. ed. Oxford Textbook of Public Health. Oxford: Oxford University, 2005. 
ORGANIZAÇÃO MUNDIAL DE SAÚDE. Diagnostic imaging: what is it? when and how to use it where resources are limited?. Geneva, 2001.

. Introduction of radiation medicine into the undergraduate medical curriculum. Geneva, 1958a. (Technical Report Series, n. 155).

. Medical radiation physics. Geneva, 1968. (Technical Report Series, n. 390).

. The medical uses of ionizing radiation and radioisotopes. Geneva, 1972.

(Technical Report Series, n. 492).

. Post-graduate training in the public health aspects of nuclear energy. Geneva, 1958b. (Technical Report Series, n. 154).

. Public health and the medical use of ionizing radiation. Geneva, 1965.

(Technical Report Series, n. 306).

. Quality assurance in radiology. Geneva, 1982.

ORGANIZAÇÃO PANAMERICANA DE SAÚDE. Evaluación de la calidad de los servicios de radiodiagnóstico en cinco países latinoamericanos. Washington DC, 2001.

- Organización, desarrollo, garantía de calidad y radioprotección en los servicios de radiología: imaginología y radioterapia. Washington DC, 1997.

OUDKERK, M.; ROSENBUSCH, G.; AMMANN, E. Roentgen in historical perspective of medicine. In: . (Org.). Radiology in Medical Diagnostics:

Evolution of X-Ray applications 1895-1995. Berlin: Blackwell Science, 1995.

PERIAGO, M. R. Radiological Physics Within The Framework of PAHO Technical Cooperation Programs. Rev. Panam Salud, v. 20, n. 2-3, 2006.

PERLMUTTER, N. et al. The Quality criteria for diagnostic radiographic images in paeditrics. Radiation Protection Dosimetry, v. 80, n. 1-3, p. 45-48, 1998.

POMBAR, M. et al. Quality control in mammography: analysis of the results from a 4 year period. Radiation Protection Dosimetry, v. 80, n. 1-3, p. 81-84, 1998.

REGULLA, D. F; EDER, H. Patient exposure in medical x-ray imaging in Europe. Radiation Protection Dosimetry, v. 114, n. 1-3, p. 11-25, 2005.

RENCORET, G. S. Auditoría médica: demandas y responsabilidad por negligencias medicas. Revista Chilena de Radiología, v. 9, n. 3, p. 167-160, 2003. 
ROBINSON, P. J. A. Radiology's achilles' hell: error and variation in the interpretation of the Röntgen image. The British Journal of Radiology, v. 70, p. 1085-1098, 1997.

ROMERIO, F. Wich paradigm form managing the risk of ionizing radiation. Risk Analysis, v. 22, n. 1, p. 59-66, 2002.

ROSENBUSCH, G.; OUDKERK, M.; AMMANN, E. Radiology in medical diagnostics: evolution of X-Ray applications 1895-1995. Berlin: Blackwell Science. 1995.

ROSSI , R. P. et al. X-ray equipment performance: a 3.5 years case history. Am. J. Roentgenol., v. 136, p. 1199-1205, jun 1981.

SAMET, Jonathan, Environmental and occupational health sciences in public health. In: DETELS, Roger et al. (Ed.). Oxford Textbook of Public Health. 4. ed. Oxford: Oxford University, 2005.

SAXEBOL, G. et al. Nordic guidance levels for patient doses in diagnostic radioly. Radiation Protection Dosimetry, v. 80, n. 1-3, p. 99-101, 1998.

SCHULTZ, J. X-ray effects on drosophila pseudo-obscura. Genetics, v. 18, p. $284-291$, may 1933.

SILVA, Lígia M. Vieira da. Conceitos, abordagens e estratégias para a avaliação em saúde. In: HARTZ, Zulmira M. de A., SILVA, Lígia M. Vieira da. (Org.). Avaliação em saúde: dos modelos teóricos à prática na avaliação de programas e sistemas de saúde. Rio de Janeiro: FIOCRUZ; Salvador: EDUFBA, 2005. p. 15-39.

SILVA, M. O.; CARVALHO, A. C. P.; AZEVEDO, A. C. P. Levantamento das condiçôes de funcionamento dos serviços de radiologia de hospitais públicos e universitários do Rio de Janeiro. Radiologia Brasileira, v. 37, n. 4, p. 271-278, 2004.

SLOVIC, P. (Ed.). The perception of risk. London: Earthscan Publication, 2000.

SMITH, A. D. C.; SMITH, I. A. C. Objective assessment of phantom image quality in mammography: a feasibility study. The British Journal of Radiology, v. 71, p. 48-58, 1998.

SMITH, E. L. X-Ray and abnormalities: increased abnormality of segments in drosophila due to x-raying of gametes. PNAS., v. 21, p. 399-403, jun. 1935. 
SNIUREVICIUTE, M.; ADLIENE, D. Problems with film processing in medical $\mathrm{x}$-ray imaging in Lithuania. Radiation Protection Dosimetry, v. 114, p. 260-263, 2005.

STARR, C. The precautionary principle versus risk analysis. Risk Analysis, v. 23, n. $1,2003$.

STEINER, R. M.; KRAMER, S. A history of radiology and radiation oncology at thomas jefferson university. American Journal of Roentgenology, v. 167, p. 561-570, 1996.

STEVENS, A. T. Quality management for radiographic imaging. New York: Medical Publishing Division, 2001.

TAYRA, F.; RIBEIRO, H. Vigilância e saúde ambiental: o papel dos indicadores de sustentabilidades: danos, riscos e incertezas científicas. REVISA, v. 1, n. 2, p. 108-116, 2005.

THOMAS, A. M. K.; BANERJEE, A. K.; BUSCH, U. Classic papers in modern diagnostic radiology. Germany: Springer, 2005.

THOMPSON, K. M.; DEISLER, P. F.; SCHWING, R. C. Interdisciplinary vision: the first 25 years of the Society for Risk Analysis (SRA), 1980-2005. Risk Analysis, v. 25 , n. 6,2005 .

TRIOLA, M. F. Introdução à estatística. Rio de Janeiro: LTC, 2005.

TUBIANA, M. et al. Dose-effect relationships and estimation of the carcinogenic effects of low doses of ionizing radiation. Académie des Sciences. Paris : Académie Nationale de Médecine, 2005.

UNSCEAR. Report of the United Nations Scientific Committee on the Effects of Atomic Radiation. UN., 1958.

UNSCEAR. Report of the United Nations Scientific Committee on the Effects of Atomic Radiation. UN., 2000.

WACH, K.; RIEDE, R. Acceptance and constancy testing according to the röntgenverordnung (X Ray Ordinance) of the Federal Republic of Germany. Radiation Prot Dosimetry, v. 49, p. 63-66, sep. 1993. 
WALL, B. F.; SHRIMPTON, P. C. The historical development of reference doses in diagnostic radiology. Radiation Protection Dosimetry, v. 80, n. 1-3, p. 15-20, 1998.

WILLIAMS, S. M.; CONNELY, D. J.; WADSWORTH, S. Radiological review of accident and emergency radiographs: a 1-year audit. Clinical Radiology, v. 55, p. 861-865, 2000.

YOUNG, K. C.; RAMSDALE, M. L.; BIGNELL, F. Review of dosimetric methods for mammography in the uk breast screening programme. Radiation Protection Dosimetry, v. 80, n. 1-3, p. 183-186, 1998. 
Este livro foi publicado no formato 180 x $230 \mathrm{~mm}$ utilizando a fonte Adobe Garamond Pro Impresso no Setor de Reprografia da EDUFBA Capa impressa na ESB Serviços Gráficos Papel Alta Alvura $75 \mathrm{~g} / \mathrm{m}^{2}$ para o miolo e Cartấo Supremo $250 \mathrm{~g} / \mathrm{m}^{2}$ para a capa.

Tiragem de 400 exemplares

Salvador, 2009 

A Medicina transformou-se após ter acesso a uma das ferramentas mais poderosas do diagnóstico médico e dos estudos sobre o interior do corpo humano: o radiodiagnóstico. Poucas descobertas causaram tamanho impacto na Medicina. Por mais de um século, o radiodiagnóstico vem sendo de fundamental importância para a atenção à saúde humana. Contudo, essa nova tecnologia não trouxe consigo apenas benefícios. Tão rápidos quanto a sua utilização foram os danos causados em pesquisadores, médicos, pacientes e outros indivíduos expostos a esse tipo de radiação. Os danos possíveis não estão relacionados, apenas, aos efeitos nocivos das radiações ionizantes, mas também aos possíveis erros em diagnóstico.

Visando a contribuir para o desenvolvimento da área de controle de riscos em radiodiagnóstico, nos campos de conhecimento da Saúde Coletiva e Vigilância Sanitária, tão importantes para a saúde individual e coletiva, publica-se, neste livro, a análise do controle de riscos em radiodiagnóstico e seus condicionantes, considerando o marco regulatório vigente e a identificação dos diversos atores implicados nessas práticas.

Esse estudo foi desenvolvido na tese Conceito e controle de riscos à saúde: uma abordagem de vigilância sanitária, apresentada no Instituto de Saúde Coletiva da Universidade Federal da Bahia, no final de 2007.

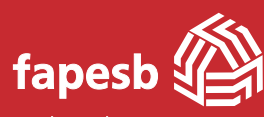

